Detecção de comunidades em redes complexas utilizando estratégia multinível 



\title{
Detecção de comunidades em redes complexas utilizando estratégia multinível
}

\author{
Leonardo Jesus Almeida
}

Orientador: Prof Dr Alneu de Andrade Lopes

Dissertação apresentada ao Instituto de Ciências Matemáticas e de Computação - ICMC-USP como parte dos requisitos para obtenção do título de Mestre em Ciências de Computação e Matemática Computacional.

USP - São Carlos

Agosto/2009 



\section{Dedicatória}

Aos meus pais,

Antônio Carlos e Renilda. 



\section{Agradecimentos}

A dissertação que agora se apresenta resultou de um trajeto atribulado ao longo do qual fui recebendo o maior apoio e estimulo de muitos. Estas breves palavras não serão capazes de representar a minha imensa gratidão para com todos aqueles que me apoiaram e contribuíram para a produção desse trabalho.

O meu maior agradecimento é dirigido a Deus, pela concessão da vida, de forças e serenidade impulsionando quando o desgaste assolava.

Agradeço de forma carinhosa, aos meus pais pelo contínuo apoio em todos estes anos, ensinando-me, principalmente, a importância da construção e coerência dos meus próprios valores.

Às minhas irmãs, pela atuação no período de construção deste trabalho: a paciência e a crença na capacidade de realização a mim atribuída foram, sem dúvidas, os elementos propulsores desta dissertação.

Em especial, o agradecimento ao professor e meu orientador Alneu de Andrade Lopes pelo acompanhamento, desde a primeira proposta de projeto até a revisão final da dissertação, sempre me aconselhando e direcionando durante o desenvolvimento do trabalho.

Aos demais docentes, às secretárias da pós-graduação e funcionários do Instituto de Ciências Matemáticas e de Computação, que direta ou indiretamente contribuíram para realização desse trabalho.

Aos meus colegas do LABIC: André Gustavo, André Rossi, Bruno Nogueira, Carlos Andres, Edson, Márcio, Merley, Rafael, Robson e Ronaldo pelo excelente ambiente de trabalho e convivência.

Aos amigos em geral, que de diversas maneiras contribuíram com apoio e incentivo.

Agradeço ao Conselho Nacional de Desenvolvimento Cientifico e Tecnológico (CNPq) pelo auxílio financeiro. 



\section{Resumo}

O grande volume de dados armazenados em meio digital dificulta a análise e extração de informações por um ser humano sem que seja utilizada alguma ferramenta computacional inteligente. A área de Aprendizado de Máquina (AM) estuda e desenvolve algoritmos para o processamento e obtenção automática de conhecimento em dados digitais. Tradicionalmente, os algoritmos de AM modelam os dados analisados com base na abordagem proposicional; entretanto, recentemente com a disponibilidade de conjuntos de dados relacionais novas abordagens têm sido estudadas, como a modelagem utilizando redes complexas. Redes complexas é uma área de pesquisa recente e ativa que têm atraído a atenção de pesquisadores e tem sido aplicada em diversos domínios. Mais especificamente, o estudo de detecção de comunidades em redes complexas é o tema principal deste trabalho. Detectar comunidades consiste em buscar grupos de vértices densamente conectados entre si em uma rede. Detectar a melhor divisão em comunidades de uma rede é um problema NP-completo, o que requer que o desenvolvimento de soluções viáveis baseiem-se em heurísticas como, por exemplo, medidas de qualidade. Newman propôs a medida de modularidade Q que tem se mostrado eficiente na análise de comunidades em redes. Este trabalho apresenta o Algoritmo Multinível de Otimização de Modularidade (AMOM) que é baseado a na otimização da medida de modularidade e integrado na estratégia multinível. A estratégia multinível é composta de três fases: (i) sucessivas compactações da rede inicial com base em contrações de arestas e fusões de vértices, (ii) particionamento da rede reduzida utilizando Algoritmo de Otimização de Modularidade (AOM) modificado, e (iii) sucessivas descompactações das redes intermediárias até que se retorne a rede inicial. O principal atrativo da estratégia é viabilizar a utilização de algoritmos custosos no particionamento do grafo compactado, uma vez que neste grafo a quantidade de vértices e arestas é uma fração reduzida em relação ao grafo inicial. O trabalho também propõe dois novos métodos para refinamento dos particionamentos durante a fase de uncoasening. A fim de avaliar a escalabilidade e eficiência da metodologia proposta foram realizados experimentos empíricos em redes consideradas benchmark. Os resultados demonstram um significativo ganho de desempenho, mantendo bons resultados qualitativos. 



\section{Abstract}

Human based analysis of large amount of data is a hard task when no intelligent computer aid is provided. In this context, Machine Learning (ML) algorithms are aimed at automatically processing and obtaining knowledge from data. In general, ML algorithms use a propositional representation of data such as an attribute-value table. However, this model is not suitable for relational information modeling, which can be better accomplished using graphs or networks. In this context, complex networks have been call attention of scientific community recently and many applications in different domains have been developed. In special, one of complex networks research trends is the community detection field which is the main focus of this work. Community detection is the problem of finding dense and disjoint connected groups of vertices in a network. The problem is a well know NP-complete task which requires heuristics approaches, like quality measures, to be addressed. Newman introduced a specific quality measure called modularity that proved to be useful for analysis communities in networks. This work presents a new algorithm, called Multilevel Modularity Optimization Algorithm, based on modularity measure optimization integrated in a multilevel graph partitioning strategy. The multilevel graph partitioning scheme consists of three phases: (i) reduction of the size (coarsen) of original graph by collapsing vertices and edges, (ii) partitioning the coarsened graph, and (iii) uncoarsen it to construct a partition for the original graph. The rationale behind this strategy is to apply a computationally expensive method in a coarsened graph, i.e., with a significantly reduced number of vertices and edges. In addition, it is proposed two new methods that uses modularity and clustering coefficient for partition refinement. Empirical evaluation on benchmarks networks using this approach demonstrate a significant speed up gain compared to the original modularity-based algorithm, keeping a good quality clusters partitioning. 

Esta dissertação foi preparada com o formatador de textos $\mathrm{L}_{\mathrm{E}} \mathrm{X}$. Foi utilizado um estilo (style) desenvolvido por Ronaldo Cristiano Prati. O sistema de citações de referências bibliográficas utiliza o padrão Apalike do sistema BibTEX.

Algumas palavras utilizadas neste trabalho não foram traduzidas da língua inglesa para a portuguesa por serem amplamente conhecidas e difundidas na comunidade acadêmica. 



\section{Sumário}

Resumo .............................. ix

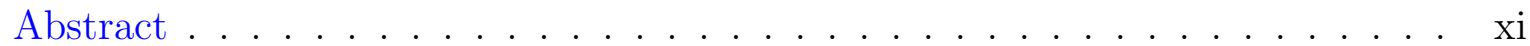

Sumário . . . . . . . . . . . . . . . . . . . xvi

Lista de Figuras . . . . . . . . . . . . . . . . . . . . . . . . . xviii

Lista de Tabelas . . . . . . . . . . . . . . . . . . . . . xix

Lista de Abreviaturas $\quad$ xxi

1 Introdução 1

1.1 Motivação . . . . . . . . . . . . . . . . . . . . . . . . 3

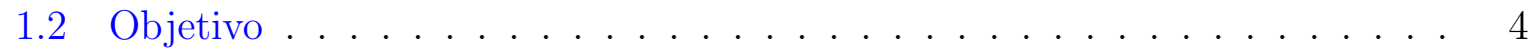

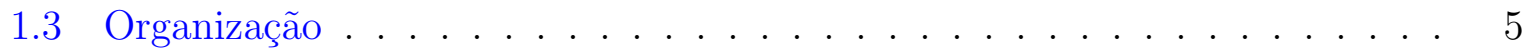

2 Redes complexas $\quad 7$

2.1 Grafos . . . . . . . . . . . . . . . . . . . . . 7

2.2 Redes complexas . . . . . . . . . . . . . . . . . . . . 9 9

2.2.1 Medidas para caracterização . . . . . . . . . . . . . . . . 10

2.2 .2 Modelos . . . . . . . . . . . . . . . . . . . 14

2.3 Detecção de Comunidades . . . . . . . . . . . . . . . . . . . . . 17

2.4 Algoritmo de Otimização de Modularidade (AOM) . . . . . . . . . . . . 19

2.5 Considerações Finais . . . . . . . . . . . . . . . . . . . . . . 21

3 Particionamento em grafos $\quad 23$

3.1 Técnicas de particionamento em grafos . . . . . . . . . . . . . . . . 23

3.1 .1 Funções objetivo . . . . . . . . . . . . . . . . . . . . . 24

3.1.2 Algoritmos de Particionamento de Grafos . . . . . . . . . . . . . . . 26

3.2 Particionamento multinível em grafos . . . . . . . . . . . . . . . . . . . 29

3.2.1 Fase de Coarsening . . . . . . . . . . . . . . . . . . . . . . . 29

3.2.2 Fase de particionamento . . . . . . . . . . . . . . . . 32

3.2.3 Fase de Uncoarsening . . . . . . . . . . . . . . . . . . . . 33

3.2 .4 Implementações da estratégia multinível . . . . . . . . . . . . . . . 35

3.3 Validação . . . . . . . . . . . . . . . . . . . . . 36

3.4 Considerações Finais . . . . . . . . . . . . . . . . . . . . . . . . . . 39 
4 O Algoritmo Multinível de Otimização de Modularidade para detecção de comunidades em redes complexas $\quad 41$

4.1 Considerações iniciais . . . . . . . . . . . . . . . . . . . . . . . . . 42

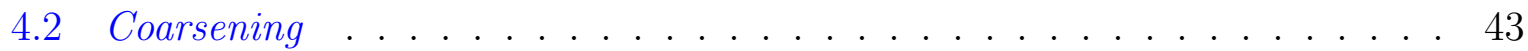

4.3 Particionamento . . . . . . . . . . . . . . . . . . . 44

4.4 Uncoarsening . . . . . . . . . . . . . . . . . . 46

4.5 Considerações finais . . . . . . . . . . . . . . . . . . . . . . . 48

5 Experimentos $\quad 51$

5.1 Conjunto de dados . . . . . . . . . . . . . . . . . . . . . . . . 51

5.2 Avaliação de escalabilidade . . . . . . . . . . . . . . . . . . 53

5.3 Avaliação qualitativa . . . . . . . . . . . . . . . . . . . 54

5.4 Avaliação em conjunto de dados de imagens . . . . . . . . . . . . . . . 61

5.5 Considerações Finais . . . . . . . . . . . . . . . . . . . 65

6 Conclusão $\quad 67$

6.1 Contribuições . . . . . . . . . . . . . . . . . . . . . 68

6.2 Limitações . . . . . . . . . . . . . . . . . . . . . . . . . . . . . . . . . 69

6.3 Trabalhos Futuros . . . . . . . . . . . . . . . . . . . 69

$\begin{array}{ll}\text { Referências } & 76\end{array}$ 


\section{Lista de Figuras}

1.1 Exemplos de clusters de diferentes tamanhos e formas Karypis et al. (1999). 2

1.2 Exemplo de dendrograma gerado por algoritmos hierárquicos. . . . . . . . 3

2.1 Figura representativa da rede formada por domínios na Internet obtida em janeiro de 2005 pelo The Opte Project. . . . . . . . . . . . . . . . . . 11

2.2 (a) Grafo aleatório de Erdös e Rényi (b) Distribuição de conexões para a rede formada por 1000 vértices e uma probabilidade $p=0,2 \ldots$. . . . . 14

2.3 Visualização do modelo de rede Watts e Strogatz de acordo com a variação de valores de probabilidade Watts (1999a). . . . . . . . . . . . . 15

2.4 (a) Rede livre de escala gerada pelo modelo de Barabási e Albert (b) Distribuição de conexões para a rede formada por 1000 vértices . . . . . . . . 16

2.5 Rede de amizade entre os integrantes clube de Karatê de Zachary. Os quadrados indicam integrantes mais amigos do instrutor, enquanto que os círculos indicam os mais amigos do administrador Newman e Girvan (2004).

2.6 Dendograma gerado pela algoritmo de otimização de Modularidade na rede de Zachary. Os círculos e os quadrados representam a divisão real entre os integrantes do grupo Newman (2004c). . . . . . . . . . . . . . 21

3.1 Exemplos particionamentos diferentes em um mesmo grafo. . . . . . . . . . 25

3.2 Exemplo de divisão da rede representando a interação entre funcionários de uma empresa. A divisão foi feita em três departamentos, que são compostos por 5 a 7 funcionários Schaeffer (2007) . . . . . . . . . . . . . .

3.3 Esquema de Particionamento multinível em Grafos. Figura adaptada de Karypis e Kumar (1998) . . . . . . . . . . . . . . . . . . . . . . . . 30

3.4 Exemplo de coarsening utilizando a o conceito de matching. . . . . . . . . 31

3.5 Exemplo de grafos reduzidos gerado na fase de coarsening. Em 3.5(a) o matching é feito utilizando o método Random Matching (RM). Já em 3.5(b) é utilizado o Heavy-edge Matching (HEM). . . . . . . . . . . . . . .

3.6 Exemplo de cálculo de graus internos e externos no algoritmo de refinamento Karypis e Kumar (1995a). Figura adaptada de Karypis e Kumar (1998) . . . . . . . . . . . . . . . . . . 35 
3.7 Exemplo de particionamento obtido pelo algoritmo Chameleon Karypis et al. (1999).

4.1 Variação da Modularidade Q na execução do algoritmo AOM na rede de Karate de Zachary. O ponto com maior modularidade ocorre quando a rede é dividida em duas comunidades. . . . . . . . . . . . . . . . . . . . . . . 45

4.2 Exemplo do critério de escolha de partição pelo método baseado no coeficiente de agrupamento. . . . . . . . . . . . . . . . . . 48

5.1 Visualização da rede netScience . . . . . . . . . . . . . . . . . . 52

5.2 Gráfico da variação do tempo de execução em função da quantidade de vértices e $\operatorname{arestas} \ldots \ldots \ldots \ldots$. . . . . . . . . . . . . . . . 54

5.3 Gráfico da variação do tempo de execução em função do método escolhido na fase de coarsening . . . . . . . . . . . . . . . . . . . 55

5.4 Gráfico da variação do tempo de execução em função do Critério de Parada

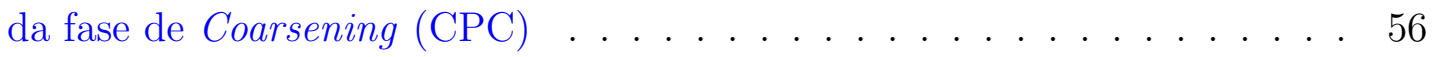

5.5 Gráfico da variação do tempo de execução em função do Critério de Parada da fase de Coarsening (CPC) . . . . . . . . . . . . . . . 56 56

5.6 Gráfico da média e desvio padrão da modularidade em função do Critério de Parada da fase de Coarsening (CPC) . . . . . . . . . . . . . . . 57

5.7 Visualização das comunidades geradas pelo AMOM para as redes netscience e $c b r$-ilp-ir. . . . . . . . . . . . . . . . . . 59

5.8 Comparativo entre as matrizes de adjacências do grafo t60k . . . . . . . 60

5.9 Conjunto de dados de imagens bi-dimensionais Karypis et al. (1999) . . . . 61

5.10 Comparativo entre as separações de pontos na Imagem 1 geradas pelos algoritmos AOM, AMOM e Chameleon. . . . . . . . . . . . 63

5.11 Comparativo entre as separações de pontos na Imagem 2 geradas pelos algoritmos AOM, AMOM, AMOM* e Chameleon. . . . . . . . . . 63

5.12 Comparativo entre as separações de pontos na Imagem 3 geradas pelos algoritmos AOM, AMOM e Chameleon. . . . . . . . . . . . . . . 64

5.13 Comparativo entre as separações de pontos na Imagem 4 geradas pelos algoritmos AOM, AMOM e Chameleon. . . . . . . . . . . . . . . 64 


\section{Lista de Tabelas}

1.1 Exemplo de representação de dados em uma tabela atributo-valor . . . . . 3

3.1 Valores das medidas de RAssoc, RCorte e NCorte para o grafo ilustrado na Figura 3.1. . . . . . . . . . . . . . . . . . . . . . 25

3.2 Exemplo de representação entre dois particionamentos distintos. As linhas representam os grupos do particionamento $\mathrm{X}$ e as colunas representam os

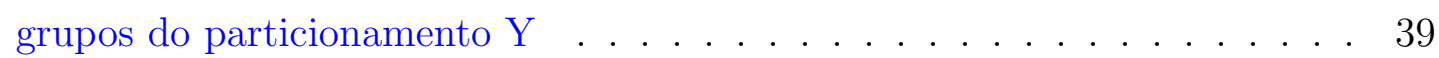

5.1 Tabela descritiva das redes utilizadas nas avaliações. . . . . . . . . . . . . . 51

5.2 Exemplo da visualização de matriz de adjacência para análise de particio-

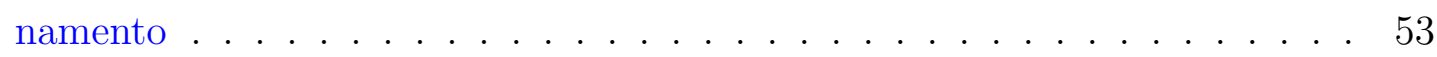

5.3 Tabela comparativa entre os valores de modularidade obtidos pelo AOM e

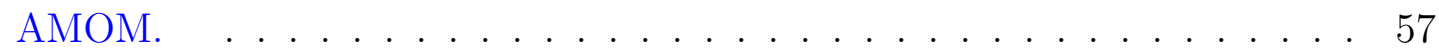

5.4 Tabela comparativa entre valores dos índices de validação dos particionamentos gerados pelo AMOM em comparação com o AOM. . . . . . . . . . 58

5.5 Tabela comparativa entre os valores de corte obtido pelos algoritmos no particionamento dos grafos em 16, 32 e 64 grupos. . . . . . . . . . . . 60

5.6 Tabela descritiva das redes 7-nn geradas para o conjunto de dados de imagens 62

5.7 Tabela comparativa entre os valores de corte e modularidade para o particionamento das redes $7-n n \ldots \ldots . \ldots . \ldots 65$ 



\section{Lista de Abreviaturas}

AM Aprendizado de Máquina

AMOM Algoritmo Multinível de Otimização de Modularidade

AOM Algoritmo de Otimização de Modularidade

CBR-ILP-IR Base de textos sobre Case Based Reasoning, Inductive Logic

Programming, Information Retrieval e Sonification

CPC Critério de Parada da fase de Coarsening

CPR Critério de Parada de Refinamento

FRC Fator de Redução na fase de Coarsening

HEM Heavy-edge Matching

KL Kernighan-Lin

LEM Light Edge Matching

MHEM Modified Heavy-edge Matching

PMSV Peso Máximo do Super-Vértice

PEx Projection Explorer

RM Random Matching

ROCA Refinamento por Otimização do Coeficiente de Agrupamento

ROM Refinamento por Otimização de Modularidade 



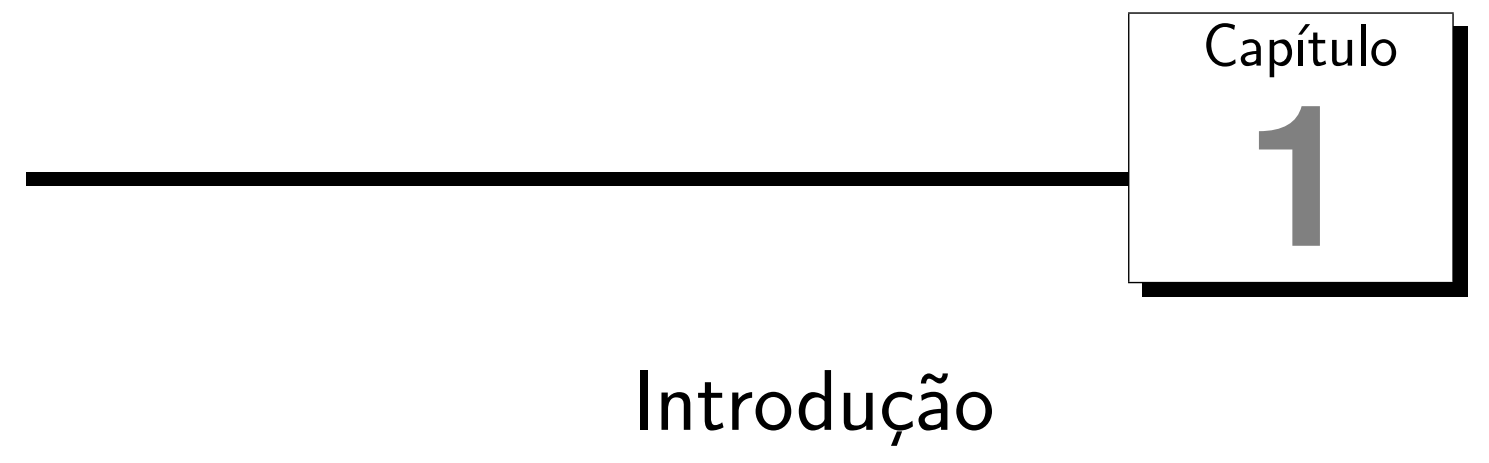

A quantidade de dados armazenados em meio digital vem crescendo consideravelmente, e estimava-se que esse volume anual ultrapassasse a barreira dos hexabytes em 2003, o que supera em muito as informações armazenadas em meios impressos Lyman e Varian (2003). Diante dessa realidade, torna-se muito difícil para um ser humano analisar, estudar, entender e extrair informações desses dados sem a utilização de ferramentas computacionais inteligentes.

Em Inteligência Artificial, a área de pesquisa que estuda algoritmos e técnicas relacionadas a obtenção automática de conhecimento em dados é denominada de Aprendizado de Máquina (AM) Mitchell (1997). Essa área utiliza-se de paradigmas estatístico, baseados em casos, simbólico, conexionista e genético para construção de algoritmos capazes de aprender e inferir padrões em dados. Contudo, é importante ressaltar que, embora os computadores possam analisar grandes volume de dados, sua capacidade de aprendizado é muito inferior a dos seres humanos.

Em aprendizado de máquina, os algoritmos são utilizados de acordo com as características do problema estudado e dos dados disponíveis para estudo, e podem ser divididos em três grupos: Aprendizado Supervisionado, Aprendizado Semi-Supervisionado e Aprendizado Não-Supervisionado. No Aprendizado Supervisionado, é fornecido ao algoritmo um conjunto de dados de treinamento, em que existe a informação de classe, ou rótulo, a fim de que seja induzido um modelo ou hipótese sobre as relações entre os dados. Se a classe possui valores discretos, o problema é conhecido como de classificação. Caso possua valores contínuos, é conhecido como regressão. Em alguns problemas, a informação de classe não está disponível em todos os exemplos do conjunto de treinamento, e para esses casos, são utilizados algoritmos de Aprendizado Semi-Supervisionado.

O Aprendizado Não-Supervisionado é utilizado quando o conjunto de dados utilizado não é rotulado. Para esse tipo de problema, o algoritmo tenta descobrir padrões a partir de algum critério de similaridade entre os dados, de maneira que possam ser formados grupos, ou "clusters", em que os exemplos sejam muito similares entre si internamente. 
Esse processo, conhecido pelo termo em inglês clustering, tem aplicações em áreas como bioinformática, agrupamento de documentos, segmentação de imagens, análise de redes sociais, entre outras. Neste trabalho, referenciaremos o termo clustering pelo termo equivalente em português, agrupamento. Ressalta-se que é neste grupo de Aprendizado de Máquina Não-Supervisionado que está inserida a investigação realizada neste trabalho.

$\mathrm{Na}$ tarefa de agrupamento, diversos fatores podem ser considerados a fim de obter os agrupamentos, tais como a medida de similaridade, a avaliação da qualidade do resultado e a representação dos dados, que influenciam diretamente no desempenho dos algoritmos.

Um algoritmo de agrupamento clássico é o K-Médias (K-means) MacQueen (1967). O $K$-Médias é um algoritmo iterativo que tenta minimizar a função de erro quadrático dada pela variação entre os dados e o centro de cada um dos $k$ grupos. O algoritmo é muito eficiente quando os grupos estão isolados, e tende a buscar clusters com formas específicas Jain et al. (2000). Entretanto, enfrenta problemas para detectar clusters de tamanhos ou formas diferentes, como os apresentados na Figura 1.1.

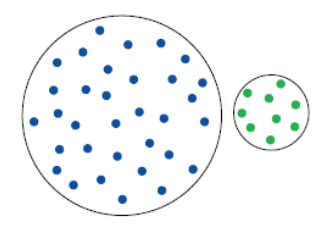

(a)

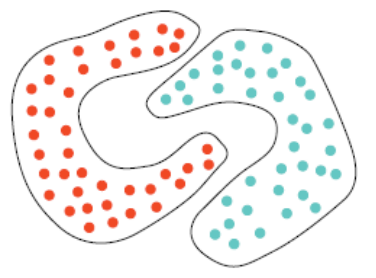

(b)

Figura 1.1: Exemplos de clusters de diferentes tamanhos e formas Karypis et al. (1999).

Um outra abordagem bastante utilizada é dividir gradativamente os dados em $k$ grupos, conhecido como agrupamento hierárquico. A maneira com que as partições são construídas classifica os algoritmos como aglomerativo ou divisivo. Algoritmos aglomerativos hierárquicos consideram inicialmente que cada objeto é um grupo diferente, e então realizam sucessivas junções até obter um único grupo, ou até que seja alcançado um ponto de parada. Já os algoritmos divisivos iniciam considerando que todos os dados foram um único grupo, e então realizam sucessivas divisões até que cada dado torne-se um grupo distinto, ou que seja atendido um critério de parada. Pela característica do processo sucessivo de divisões ou junções, o resultado gerado por um algoritmo de agrupamento hierárquico pode ser visualizado como uma árvore ou um dendrograma, como o ilustrado na Figura 1.2. Na literatura, existem ainda outras abordagens para agrupamento de dados, tais como Redes Auto-Organizáveis, Algoritmos Espectrais, Máquina de Vetor de Suporte (Support Vector Machine) e Algoritmos Bioinspirados Jain et al. (1999); Mirkin (2005); Xu e Wunsch (2005).

A tarefa de agrupamento também é utilizada para identificar padrões em dados relacionais representados como grafos, nos quais suas partes possam ser representadas por vértices e as relações entre essas partes por arestas. Assim, nesses domínios, as técnicas de agrupamento assemelham-se ao problema de particionamento de grafos, no qual o objetivo é encontrar subconjuntos de vértices que possuam mais características em comum.

Com a evolução dos sistemas computacionais, tornou-se possível a análise de grafos 


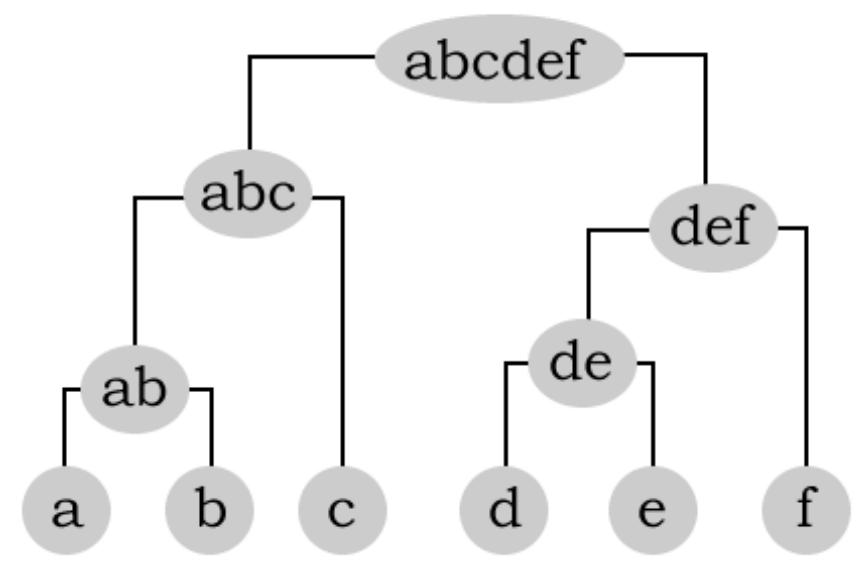

Figura 1.2: Exemplo de dendrograma gerado por algoritmos hierárquicos.

com um grande numero de vértices e com estrutura e propriedades não triviais, dando origem a uma nova área chamada de Redes Complexas Watts (1999a); Barabási e Albert (1999); Newman (2003). Diversas redes de relações existentes tais como a Internet, redes sociais entre indivíduos e redes biológicas, foram modeladas como redes complexas, e diversas pesquisas foram feitas contribuindo para consolidação dessa área de pesquisa.

Uma investigação interessante em redes complexas é a detecção de comunidades. Uma comunidade é definida como um conjunto de vértices que são fortemente conectados entre si e fracamente conectados com os demais Newman e Girvan (2004). Desta forma, o conceito de deteç̧ão comunidades aproxima-se dos conceitos de particionamento de grafos e da tarefa de agrupamento.

\subsection{Motivação}

Tradicionalmente, as técnicas de aprendizado de máquina são baseadas na lógica proposicional, que utilizam tabelas atributo-valor para representação dos dados De Raedt (2008). Nessa abordagem, os dados são representados com uma tabela $(n \times m)$, na qual cada linha refere-se a uma instância, e cada coluna contém um peso ou valor associado a um atributo. Na Tabela 1.1 é apresentada um formato geral da representação utilizando tabela atributo-valor. Cada exemplo $v_{i}$ é representado por um vetor $\left(x_{i, 1}, x_{i, 2}, \ldots, x_{i, j}, \ldots, x_{i, m}\right)$ onde $x_{i, j}$ é o valor do atributo $a t_{j}$ para o exemplo $v_{i}$.

No AM Supervisionado é utilizando mais um atributo além dos $m$ que descrevem os objetos. Esse atributo é a informação da classe a qual cada objeto pertence. No AM Não-Supervisionado, esse atributo não está presente.

Tabela 1.1: Exemplo de representação de dados em uma tabela atributo-valor

\begin{tabular}{c|c|c|c|c}
\hline \hline & $a t_{1}$ & $a t_{2}$ & $a t_{j}$ & $a t_{m}$ \\
\hline$v_{1}$ & $x_{1,1}$ & $x_{1,2}$ & $x_{1, j}$ & $x_{1, m}$ \\
$v_{2}$ & $x_{2,1}$ & $x_{2,2}$ & $x_{2, j}$ & $x_{2, m}$ \\
$v_{3}$ & $x_{3,1}$ & $x_{3,2}$ & $x_{3, j}$ & $x_{3, m}$ \\
$v_{i}$ & $x_{i, 1}$ & $x_{i, 2}$ & $x_{i, j}$ & $x_{i, m}$ \\
$v_{n}$ & $x_{n, 1}$ & $x_{n, 2}$ & $x_{n, j}$ & $x_{n m}$ \\
\hline \hline
\end{tabular}


Um outra opção para representação dos dados é a utilização de grafos, e a disponibilidade de grandes coleções de dados com características relacionais oferece novas oportunidades para minerar e extrair padrões em grafos Džeroski (2003); De Raedt (2008). Assim como as técnicas de agrupamento, o particionamento de grafos tem aplicações interessantes em diversas áreas de conhecimento. No campo de análise de redes sociais e informacionais, o particionamento de grafos serve de ferramenta para análise, modelagem, predição e evolução dessas redes, sendo aplicado aos ramos de negócios, análise de mercado, marketing, redes de infra-estrutura, relacionamentos, comunicações e outras tarefas. Na área de Bioinformática, o particionamento de grafos é tipicamente utilizado no agrupamento de expressões gênica e de interação entre proteínas Eisen et al. (1998). Em Mineração de Dados, pode ser aplicado para realizar agrupamento de documentos textuais, modelar a relação documentos-tópicos, co-autoria de trabalhos científicos, entre outras aplicações.

Na literatura é encontrada uma grande quantidade de algoritmos para realização das tarefas de agrupamento, ou particionamento de grafos, porém muitas apresentam aplicações específicas ou restrições no tipo de dado e no tipo de solução. Alguns algoritmos fornecem soluções muito boas, porém possuem um complexidade de tempo muito alta, tornando sua utilização proibitiva para um volume grande de dados. O Algoritmo de Otimização de Modularidade (AOM) Newman (2004c), por exemplo, possui complexidade de tempo da ordem de $O\left(n^{2}\right)$ para grafos esparsos. Desta forma, ainda é possível explorar e investigar novas técnicas e algoritmos para essa área.

Uma alternativa para particionamento de grafos com grande número de vértices sem que haja significativa perda de qualidade nas soluções é utilizar a estratégia de particionamento multinível Karypis e Kumar (1995a, 1998); Hendrickson e Leland (1993). A abordagem multinível tem como principal característica realizar sucessivas etapas de compactação a fim de encontrar um grafo com uma quantidade reduzida de vértices e arestas, mas ainda semelhante ao grafo original. Tendo uma boa aproximação do grafo original, é realizado o particionamento utilizando algoritmos disponíveis na literatura. Em seguida, o particionamento encontrado é expandido sucessivamente sobre os grafos intermediários até alcançar o grafo original.

\subsection{Objetivo}

Os problemas de particionamento de grafos e detecção de comunidade são NP-completos, e portanto, não é conhecido algoritmo que encontre a solução ótima em tempo polinomial. Em casos em que a quantidade de vértices e arestas é pequena, é possível utilizar algoritmos custosos que avaliam muitas, senão todas, as soluções até encontrar a melhor. Sendo assim, para muitos dos casos reais, nos quais a dimensionalidade é elevada, torna-se necessário utilizar heurísticas para encontrar uma solução aproximada.

O principal objetivo deste trabalho foi desenvolver um novo algoritmo baseado no AOM Newman (2004c). A meta foi analisar e desenvolver o algoritmo de maneira a otimizar sua utilização em redes com elevada quantidade de vértices e arestas, mantendo a qualidade de modularidade que lhe é característica. Com este estudo, o trabalho pretende 
contribuir com um nova opção rápida e de qualidade para detecção de comunidades em redes complexas.

A fim de alcançar as metas pretendidas, este trabalho utiliza a estratégia de particionamento multinível em grafos Hendrickson e Leland (1993). Essa estratégia tem sido amplamente aplicada em diversos domínios em que o particionamento de grafos é utilizado, e tem obtido resultados significativos Karypis e Kumar (1995a); Chevalier e Pellegrini (2006); Dhillon et al. (2007). Em geral, a estratégia multinível é utilizada em problemas de particionamento em que a quantidade de agrupamentos desejada é informada a princípio. Outra característica típica da utilização é o requisito de que os agrupamento sejam balanceados.

A diferença deste trabalho em relação aos anteriores que também utilizam a estratégia multinível está no uso da otimização da medida de modularidade durante a fase de refinamento. Essa integração requer que sejam feitos ajustes nos métodos existentes a fim de garantir a eficiência e a escalabilidade do método. Um dos ajustes necessários é modificar o AOM para detectar comunidades em redes com peso nas arestas. Outro ajuste importante é o desenvolvimento de um método de otimização apropriado para refinar o particionamento inicial obtido pelo AOM.

Mais especificamente os principais pontos considerados são:

- Analisar os métodos de compactação da estratégia multinível;

- Definir critérios para o encerramento da compactação e início do particionamento de fato;

- Adaptar o algoritmo AOM para ser utilizado na fase de particionamento considerando a rede com pesos nas arestas;

- Avaliar o aumento de performance e a qualidade dos resultados encontrados;

- Utilizar medidas apropriadas para refinamento do particionamento de maneira a maximizar a medida de modularidade.

\subsection{Organização}

No próximo Capítulo são apresentados os conceitos de redes complexas e detecção de comunidades em redes complexas. No capítulo 3 são abordados os tópicos relativos ao particionamento em grafos e os conceitos de particionamento multinível. Já no Capítulo 4, descreve-se o algoritmo proposto neste trabalho para particionamento multinível em grafos utilizando algoritmo de modularidade. No Capítulo 5 são apresentados os resultados das avaliações experimentas realizadas. Por fim, no Capítulo 6, são apresentadas as conclusões alcançadas por este trabalhos e possíveis trabalhos futuros relacionados. 



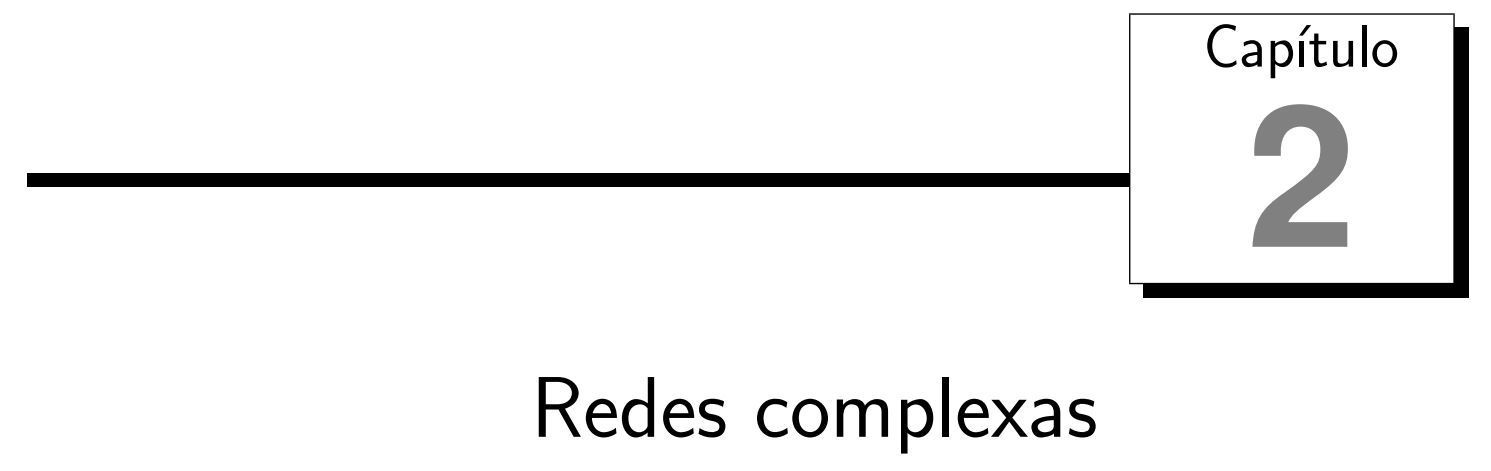

Diversos sistemas são compostos por uma quantidade de elementos os quais possuem relações entre si, e a modelagem desses sistemas como redes pode ser realizada de forma natural. Por exemplo, a Internet é composta por diversos roteadores que estão conectados entre si utilizando links Albert et al. (2000); a Web é composta por bilhões de documentos que se referenciam por meio de hyperlinks Albert et al. (1999); as rotas aéreas e as rodovias são conexões entre cidades. Alguns desses sistemas reais podem dar origem a redes com bilhões de vértices. A análise dessas redes tornou-se possível apenas recentemente com o aumento do poder de processamento e armazenamento dos sistemas computacionais dando origem a área de pesquisa de redes complexas.

Neste capítulo é apresentada uma visão geral acerca de redes complexas contendo alguns conceitos como: evolução histórica, principais modelos, medidas de caracterização e algoritmos de identificação de comunidades. Em particular, este trabalho está diretamente relacionado com o estudo de algoritmos de detecção de comunidades em Redes Complexas.

\subsection{Grafos}

A teoria dos grafos tem seu marco inicial no trabalho de Leonhard Euler para resolver o problema das Sete Pontes de Königsberg, no século XVIII. Euler modelou o problema como um grafo, representando os caminhos como arestas e as intersecções como vértices, e provou que não era possível atravessar todas as pontes sem repetir alguma. Em outras palavras, um grafo com mais de dois vértices com um número ímpar de ligações não possui um caminho contínuo que passe por todas as ligações sem que haja repetição. Segundo Bollobas (1998); Diestel (2005), Euler teria criado o primeiro grafo da história.

Em teoria dos grafos, um grafo simples é definido por um conjunto finito de vértices e por um conjunto finito de arestas (ligações ou conexões), que representam as relações 
entre os vértices. A representação é dada por

$$
G=(V, E)
$$

na qual $V$ é o conjunto de vértices e $E$ o conjunto de arestas conectando pares de vértices. Uma aresta $e$ pode ser definida como um par de vértices

$$
e=\{(u, v) \mid u \in V, v \in V\}
$$

A quantidade de vértices presentes na rede é dada por

$$
n=|V|,
$$

e a quantidade de arestas por,

$$
m=|E|
$$

Nos grafos, diversas propriedades podem ser associadas aos vértices e às arestas, tais como peso, sentido das ligações e tipos de vértices. Na modelagem de uma rede de roteadores de internet, por exemplo, poderia ser interessante armazenar a informação de largura de banda de uma conexão. Para esse caso, cada roteador é representado como um vértice, e a conexão entre eles é representada como uma aresta. A largura de banda de cada conexão é representada como peso das arestas.

As arestas de um grafo podem ou não ser direcionadas. Grafos com conexões direcionadas são chamadas de dígrafos. Um grafo representando citações de trabalhos científicos é uma exemplo de dígrafo, onde cada trabalho é representado por um vértice e as arestas direcionadas representam o sentido da citação. Existem também grafos com mais de um tipo de vértice. O grafo representando a relação documentos-tópicos possui dois tipos de vértices e as ligações ocorrem apenas entre tipos diferentes, ou seja, não existem ligações to tipo tópico-tópico ou documento-documento. Essas redes são chamadas de bipartidas.

A quantidade de arestas incidentes em um determinado vértice é definida pela medida grau do vértice $\left(\operatorname{deg}_{v}\right)$ definida pela Equação 2.5.

$$
\operatorname{deg}_{v}=\mid\{(i, j) \in E \mid i=v \text { ou } j=v\} \mid
$$

Assim, tem-se que a soma dos graus de todos os vértices é igual ao dobro da quantidade de aresta, $\sum_{v \in V} \operatorname{deg}(v)=2 m$. Na literatura é comum encontrar a representação da medida de grau do vértice utilizando a letra $k$. Entretanto, neste trabalho, optou-se por uma outra representação pois a letra $k$ está sendo utilizada para representar o número de partições de um grafo.

Seja $G=(V, E)$ um grafo qualquer, $G^{\prime}=\left(V^{\prime}, E^{\prime}\right)$ é dito sub-grafo de $G$ se $V^{\prime} \subset V$ e $E^{\prime} \subset E$, ou seja, um subgrafo é um grafo no qual o conjunto de vértices e arestas estão contidos em outro grafo. Um particionamento de um grafo, representado por um vetor $P$, é o conjunto de subgrafos distintos que unidos formam o grafo. Os subgrafos que formam o particionamento são chamados de partições, e o valor de $P_{i}$ refere-se a partição a qual o vértice $i$ pertence. As arestas que ligam vértices em diferentes partições são chamadas de 
arestas de corte. O corte de uma partição, $E C(P)$, é igual a soma dos pesos das arestas de corte que ligam vértices de $P$ a outras partições.

Computacionalmente, é possível armazenar os dados de um grafo utilizando a representação de matriz, listas de adjacências, entre outras. Em uma matriz de adjacência, o valor de uma célula $a_{i j}$ representa a ligação entre os vértices $i$ e $j$. Em grafos nos quais as arestas não tem peso, $a_{i j}=1$ quando a existe uma aresta entre os vértices $i$ e $j$, ou $a_{i j}=0$ no caso contrário. Em grafos nos quais as arestas possuem peso, este valor é armazenado em uma matriz de pesos. Quando o grafo possui muitos vértices e poucas ligações, a matriz de adjacência tende a ser esparsa, ou seja, muitas células $a_{i j}$ têm valor 0 , o que resulta em uma grande alocação de memória desnecessária. Uma alternativa para esse tipo de caso é utilizar listas de adjacências. As listas permitem uma economia de espaço, pois armazenam apenas as ligações existentes entre os pares de vértices. Por outro lado, o custo de acesso às arestas é maior devido a necessidade de buscá-las em uma estrutura de lista.

Recentemente uma nova área de pesquisa surgiu com o objetivo de analisar propriedades estatísticas de grafos com milhares e até milhões de vértices afastando-se um pouco dos trabalhos anteriores que estudam grafos pequenos e simples. Essa nova área é conhecida como Redes Complexas e é descrita a seguir.

\subsection{Redes complexas}

A teoria de redes complexas originou-se da aplicação de medidas oriundas da teoria dos grafos e de conceitos provenientes da mecânica estatística, física não-linear e sistemas complexos Newman (2003). As redes complexas possuem um caráter multidisciplinar e cobrem aplicações em diversas áreas do conhecimento, utilizando a computação como ferramenta para modelagem, tratamento e análise de dados. Algumas categorias de redes são comentadas a seguir.

- Sociais: redes que representam relações entre pessoas. Nessas redes as pessoas são representadas pelos vértices e a relações entre elas são as ligações.

- Tecnológicas: redes construídas pelo homem e desenvolvidas para distribuir algum bem ou recurso, tais como redes de distribuição de eletricidade, água e telefonia.

- Biológicas: são redes construídas para modelar sistemas biológicos. Um exemplo é a rede associada a sistema da levedura de cerveja, na qual os vértices representam as proteínas e as ligações as respectivas interações físicas entre elas.

- De informação: obtidas a partir de bases de conhecimento formal, tais como as citações de artigos científicos e a World Wide Web.

Em 1967, Stanley Milgram realizou um experimento no qual descobriu que a "distância média" entre duas pessoas quaisquer nos Estados é de aproximadamente seis Milgram (1967). O estudo foi realizado a partir do envio de centenas de cartas a pessoas aleatórias nos estados do Kansas e Nebraska. Essas pessoas deveriam enviar uma outra correspondência para um dos dois destinatários estabelecidos, uma mulher em Massachusetts ou 
um homem em Boston. Caso conhecessem o destinatário, as correspondências deveriam ser enviadas a eles diretamente, caso contrário deveriam enviar para alguém que possivelmente conhecesse os destinatários, e acrescentar seus nomes nas cartas. Aproximadamente 27\% das cartas chegaram ao destino, e Milgram pode determinar, em média, a separação entre as pessoas nos Estados Unidos. O valor de 5,5 foi arredondado para seis. A distância média pequena entre as pessoas, observadas no experimentos de Milgram, é conhecida como efeito de mundo pequeno (small world), comentado adiante na Seção 2.2.2. A falta de recursos computacionais e dados reais na época impediram um desenvolvimento mais acentuado dos estudos envolvendo redes com grande número de vértices. Isto se tornou possível apenas ao final dos anos 90, devido a disponibilidade de dados e pelo avanço na capacidade de processamento dos computadores.

Assim como os grafos, as redes complexas são descritas por um conjunto de vértices e por um conjunto de arestas (ligações ou conexões), que representam as relações entre os vértices. Uma rede é representada por

$$
R=(V, E)
$$

Na Figura 2.1 é mostrado o mapa da internet obtido em 15 de janeiro de 2005 pelo The Opte Project ${ }^{1}$. A rede construída pelo grupo de pesquisa possui mais de 50 milhões de arestas. Na figura, as cores dos vértices representam os domínios aos quais eles pertencem: (i) azul - net, ca, us; (ii) verde - com, org; (iii) vermelho - mil, gov; (iv) amarelo - jp, cn, tw, au; (v) rosa de, uk, it, pl, fr; (vi) azul claro - br, kr, nl; (vii) branco - desconhecidos .

\subsubsection{Medidas para caracterização}

As redes complexas podem apresentar diversas topologias e características de acordo com o domínio estudado, e utilizando algumas medidas, as redes podem ser analisadas, caracterizadas e modeladas Costa et al. (2007). Uma medida simples para caracterizar uma rede é a determinação do número médio de ligações entre os vértices. Essa medida, é conhecida como o grau médio. Neste trabalho foram adotados os símbolos $<>$ para representar a média de uma grandeza, como é normalmente utilizado na literatura da área.

$$
\langle\operatorname{deg}\rangle=\frac{1}{n} \sum_{i=1}^{n} \operatorname{deg}_{i}
$$

$\operatorname{deg}_{i}$ é o grau de um vértice $i$ definido na Equação 2.5. A análise do grau e de sua distribuição permite determinar se a construção da rede obedece à alguma lei de formação ou tem caráter aleatório.

\section{Força}

Em uma rede em que as conexões possuam peso, ou seja valores associados às ligações, um outra medida é utilizada. Essa medida é conhecida como força (strength) do vértice,

\footnotetext{
${ }^{1}$ http://opte.org/
} 


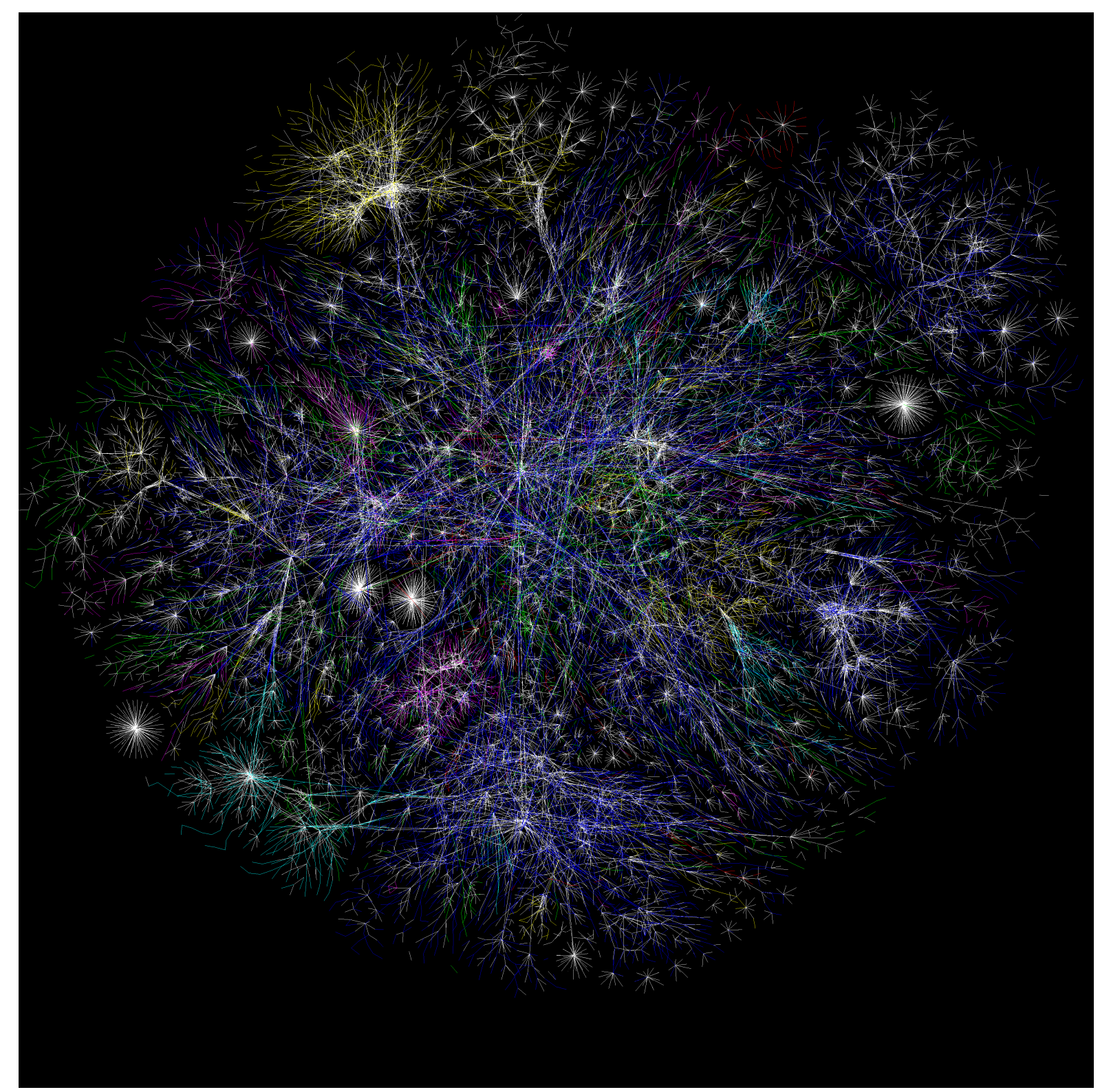

Figura 2.1: Figura representativa da rede formada por domínios na Internet obtida em janeiro de 2005 pelo The Opte Project.

conforme Equação 2.8

$$
s_{i}=\sum_{j=1}^{n} w_{i j}
$$

em que $w_{i j}$ representa o peso da ligação entre os vértices $i$ e $j$ representado em uma matriz de pesos. A força média $\langle s\rangle$ da rede é expressa pela Equação 2.9.

$$
\langle s\rangle=\frac{1}{n} \sum_{i=1}^{n} s_{i}
$$

\section{Distribuição de graus}

Seja $p_{x}$ a probabilidade de um vértice qualquer em uma rede $R$ possuir grau igual a $\mathrm{x}$, o histograma gerado para todos os vértices da rede é chamado de distribuição de graus. Em redes nas quais a probabilidade de conexão entre vértices tem um valor único definido, a distribuição é binomial ou de Poisson. Entretanto, em muitas redes reais como 
as de citação de artigos, a internet e de interação de proteínas, a distribuição de graus não segue o mesmo comportamento da distribuição binomial. Nessas redes, a distribuição de conexões tende a seguir uma lei de potência. Na próxima Seção são abordadas as características da distribuição de graus de alguns modelos de redes complexas.

\section{Coeficiente de agrupamento}

O coeficiente de agrupamento (clustering coefficient), ou coeficiente de aglomeração, expressa a presença de ciclos mínimos em uma rede, ou seja, ciclos com apenas três vertices formando "triângulos". Em outras palavras, se um vértice $v$ está conectado a um outro $u$, e $u$ está conectado a $t$, é provável que $t$ também esteja conectado a $v$. Em uma rede real, de amizades por exemplo, esse efeito representaria a probabilidade de dois amigos quaisquer terem um outro amigo em comum. Seja $v$ um vértice qualquer que possui $d e g_{v}$ vizinhos, se esses $\operatorname{deg}_{v}$ formassem um clique, ou seja, um subgrafo completo, o número de arestas entre eles seria $\operatorname{deg}_{v}\left(\operatorname{deg}_{v}-1\right) / 2$. Sendo $e_{i}$ o número de arestas que realmente existem entre os $d e g_{v}$ vizinhos, o coeficiente de agrupamento $c c_{v}$ é dado pela Equação 2.10.

$$
c c_{v}=\frac{2 e_{i}}{\operatorname{deg}_{v}\left(\operatorname{deg}_{v}-1\right)}
$$

Um alto coeficiente de agrupamento indica que um vértice $v$ e seus respectivos vizinhos possuem coesão, e o vértice $v$, chamado de vértice central, pode ser um bom representante do agrupamento. O coeficiente de agrupamento médio $\langle c c\rangle$ entre todos os vértices é dado pela Equação 2.11

$$
\langle c c\rangle=\frac{1}{n} \sum_{i=1}^{n} c c_{i}
$$

\section{Caminhos mínimos}

Um caminho é um conjunto de arestas que liga dois vértices quaisquer em um grafo, o comprimento do caminho é dado pelo número de arestas que são percorridas nele. Desta forma, define-se o caminho mínimo $d_{v, u}$, ou caminho geodésico, entre dois vértices $u$ e $v$ como o conjunto de arestas que ligam os dois vértices com o menor custo total. Esse custo pode ser obtido pela soma dos pesos das arestas presente no caminho entre os vértices. Em uma rede que não tem pesos, esse caminho é dada diretamente pela quantidade de arestas.

Os menores caminhos $d_{i j}$ em uma rede podem ser representados utilizando uma matriz de distâncias $D$, cujas células armazenam a distância entre os vértices. Em redes com mais de um componente, não existe caminho entre dois vértices $u$ e $v$ que estejam em componentes diferentes, o que implica em um valor de $d_{u v}=\infty$. O maior valor da matriz em uma rede conexa, $d_{\max }=\max _{v, u} d_{v, u}$, é denominado diâmetro da rede, e a distância média $\left\langle s p_{i}\right\rangle$ de um vértice $i$ qualquer para todos os outros é dada pela Equação 2.12.

$$
s p_{i}=\frac{1}{n-1} \sum_{v \neq u} d_{v, u}
$$


Outra medida utilizada parar expressar distância entre vértices em redes é a média dos caminhos mínimos definida pela Equação 2.13 .

$$
\ell=\frac{1}{n(n-1)} \sum_{v \neq u} d_{v, u}
$$

Em redes com componentes desconectados, a medida de $\ell$ diverge, já que um ou mais caminhos com valor $\infty$ interferem no somatório. Latora e Machiori propuseram uma medida para evitar esse problema, chamada eficiência global Latora e Marchiori (2001) conforme Equação 2.14 .

$$
E=\frac{1}{n(n-1)} \sum_{v \neq u} \frac{1}{d_{v, u}}
$$

\section{Grau de intermediação}

O grau de intermediação (betweenness centrality) Freeman (1977, 1978); Brandes (2001) de um vértice $v$ é dado pela quantidade de caminhos mínimos, entre qualquer par de vértices da rede, que passam por ele. A medida é expressa pela Equação 2.15,

$$
B_{u}=\sum_{i j} \frac{\sigma(i, u, j)}{\sigma(i, j)}
$$

onde $\sigma(i, u, j)$ é o número de menores caminhos entre $i$ e $j$ que passam por u, e $\sigma(i, j)$ é total de caminhos mínimos entre $i$ e $j$. A média do grau de intermediação $\langle B\rangle$ para rede é dada pela Equação 2.16 .

$$
\langle B\rangle=\frac{1}{n} \sum_{v \in V} B_{v}
$$

A partir dessa medida, é possível calcular a dominância do ponto central, Equação 2.17

$$
c_{D}=\frac{1}{n-1} \sum_{v \in V}\left(B_{\max }-B_{v}\right)
$$

$B_{\max }$ é o maior valor de $B$ na rede.

\section{Grau de proximidade}

O grau de proximidade (closeness centrality) de um vértice $v$ é a média dos caminhos mínimos desse vértice para qualquer outro vértice da rede Freeman (1977); Latora e Marchiori (2001); Newman (2008). Vértices centrais, que possuem menor distância em média para os demais, possuem grau de proximidade mais baixos. Alguns autores utilizam medidas de distância inversa, de maneira que, os vértices centrais tenham grau mais altos Latora e Marchiori (2001); Dangalchev (2006). Pela definição de Latora e Marchiori, o grau de proximidade $C v$ é dado pela Equação 2.18.

$$
C(v)=\sum_{v \neq v} \frac{1}{d_{v, u}}
$$

Na literatura podem ser encontradas outras medidas de caracterização e mais detalhes 
acerca dessas medidas podem ser encontrados nas referências Barabási (2002); Newman (2003); Dorogovtsev e Mendes (2003).

\subsubsection{Modelos}

\section{Grafos aleatórios}

Até metade do século XX, um dos objetivos em teoria dos grafos era propor novos modelos e catalogar as suas propriedades. Na década de 60, dois matemáticos húngaros, Paul Erdös e Alfréd Rényi revolucionaram a teoria dos grafos.

Erdös e Rényi propuseram a construção de um grafo em que as ligações entre os vértices fossem aleatórias Erdös e Rényi (1959); Erdös e Rényi. (1960); Erdös e Rényi (1961). Em um grafo aleatório não existem critérios que privilegiem uma ligação em relação a outras, assim, o modelo é caracterizado apenas pelos parâmetros $n$ e $p$, que representam o número de vértices e a probabilidade de ligação entre vértices, respectivamente. Para um valor $n$ grande e uma conectividade média fixada, a distribuição de probabilidades para os graus dos vértices é bem aproximada por uma distribuição de Poisson de valor médio $\langle d e g\rangle$, e a média dos caminhos mínimos tendem a valores pequenos dados por $\ell \sim \ln n / \ln \langle$ deg $\rangle$ Newman (2003). Um exemplo de rede aleatória é ilustrado na Figura 2.2(a) juntamente com a sua distribuição de graus, Figura 2.2(b). Como pode ser visto, a curva de distribuição assemelha-se a de uma distribuição de Poisson.

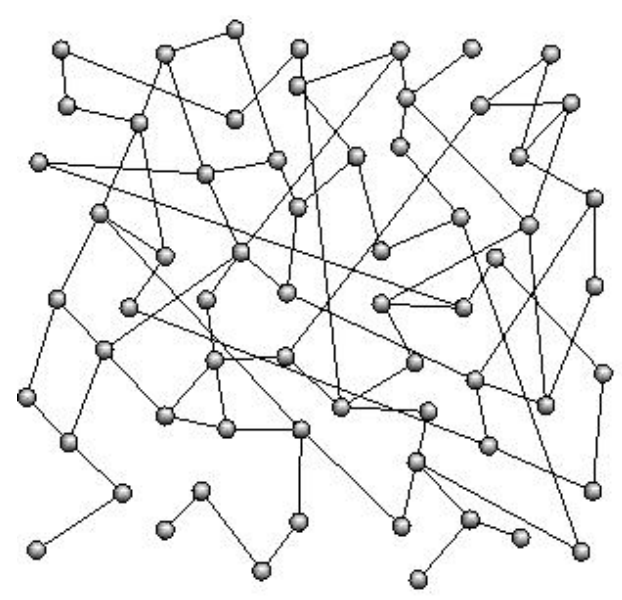

(a) Rede

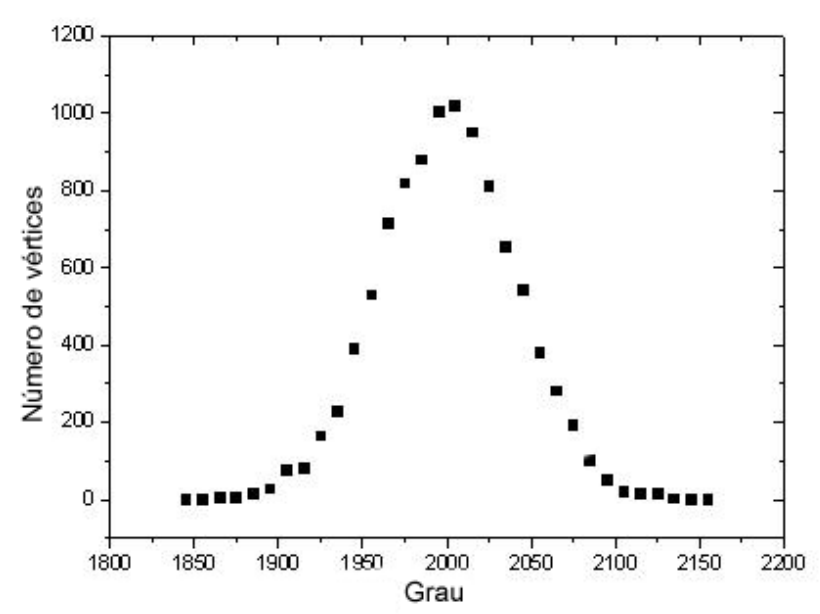

(b) Distribuição dos graus

Figura 2.2: (a) Grafo aleatório de Erdös e Rényi (b) Distribuição de conexões para a rede formada por 1000 vértices e uma probabilidade $p=0,2$ Costa et al. (2007).

\section{Redes mundo pequeno}

Em 1999, Duncan Watts e Steven Strogatz observaram que, em algumas redes reais, foram encontrados muito mais caminhos fechados com apenas três vértices do que o observado em modelos de redes aleatórias com o mesmo número de vértices e arestas Watts $(1999 a, b)$. Dessa forma, percebeu-se que para modelar muitas dessas redes reais é necessário então um modelo mais sofisticado que reproduzisse o efeito de mundo pequeno observado por Milgram e que contemplasse o novo padrão descoberto. 
O efeito mundo pequeno (small world) ocorre devido à distância de separação entre vértices crescer em um regime logarítmico ou sublogarítmico em relação ao tamanho da rede. A maioria das redes complexas apresentam o efeito de mundo pequeno. A internet possui $\ell \approx 10$, a World Wide Web $\ell \approx 11$, as moléculas nas células $\ell \approx 3$ e as espécies em cadeias alimentares $\ell \approx 2$ Albert e Barabási (2002); Barabasi (2003); Newman (2003).

Watts e Strogatz Watts (1999b) propuseram um modelo simples que apresenta características complementares às redes aleatórias. O modelo agrega a característica de baixos valores de distância entre dois vértices, presente nos grafos aleatório, e grande quantidade de ciclos curtos presentes na maioria das redes regulares, o que caracteriza o efeito de vizinhança. O processo de construção da rede parte de um grafo regular com $n$ vértices ligados formando um anel. São feitas também ligações entre os primeiros vizinhos, ou seja, cada vértice do grafo possui deg vizinhos diretos. A partir de então são removidas as ligações dos vértices com uma probabilidade $p$. Para $p=0$, o grafo representa a rede regular original, enquanto para $p=1$ obtém-se um grafo aleatório. Para valores pequenos, $p \sim 0,01$, é produzida uma rede na qual o coeficiente de agrupamento ainda é elevado, mas que ao mesmo tempo é uma rede mundo pequeno. Na Figura 2.3 são apresentados exemplos dos grafos citados anteriormente criados pelos autores.

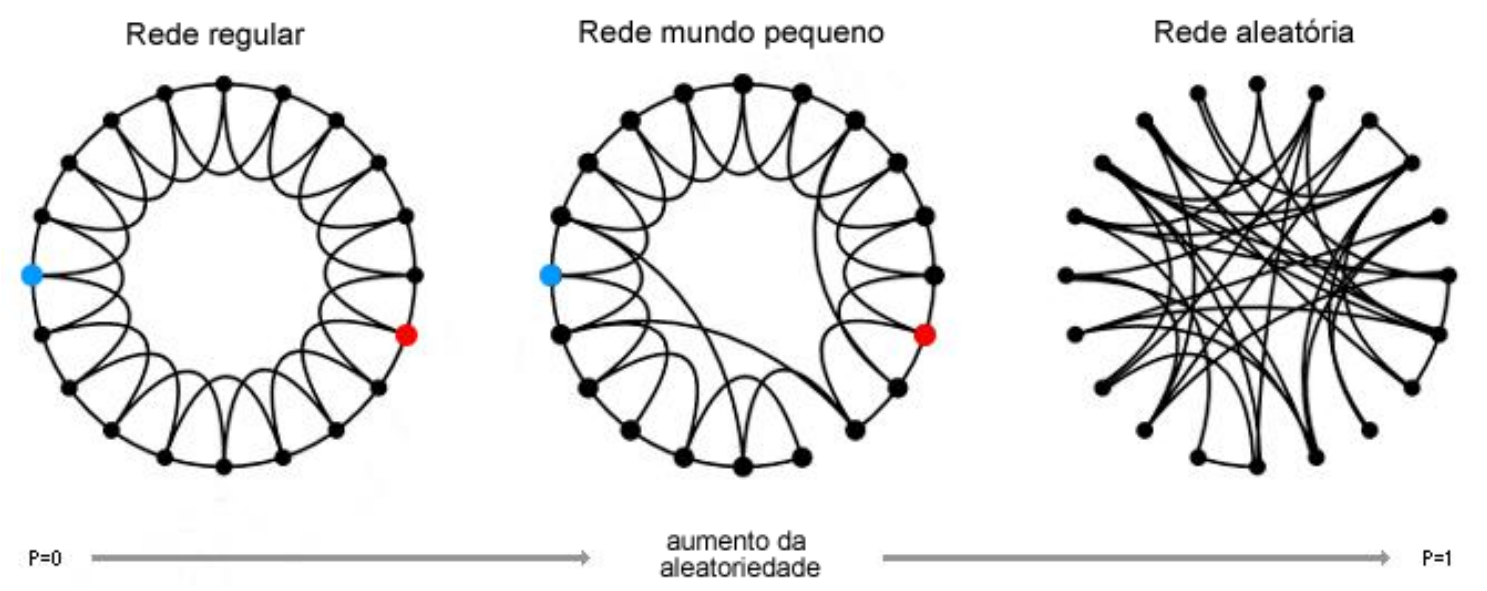

Figura 2.3: Visualização do modelo de rede Watts e Strogatz de acordo com a variação de valores de probabilidade Watts (1999a).

Redes livres de escalas

Como apresentado anteriormente, a distribuição de probabilidade dos graus dos vértices nas redes aleatórias assemelha-se bastante a distribuição de Poisson. Isto significa que quase todos os vértices da rede têm grau próximo ao valor do grau médio $\langle d e g\rangle$ da rede. Contudo, há redes reais nas quais alguns poucos vértices possuem o grau muito superior a média, enquanto os demais vértices têm grau muito inferior a média. Os vértices com alta conectividade são conhecidos como hubs.

Em 1999, um grupo da Universidade de Notre Dame estudou a estrutura da World Wide Web e constatou que além do efeito de mundo pequeno, a rede possuía vários hubs. Considerando as páginas como vértices, e o link entre elas como arestas, os pesquisadores 
descobriram que a distribuição de graus dos vértices não se aproximava do modelo de grafos aleatórios. Eles constaram que a distribuição de graus analisada seguia uma lei de potência, $P(d e g) \sim d e g^{-\gamma}$. Isto significa que, ao contrário do que acontece nas redes aleatórias e nas redes mundo pequeno, o grau dos vértices não tem um valor típico representativo, como o grau médio. As redes com essa propriedade são chamadas de redes livres de escala (scale-free).

Barabási e Albert sugeriram um mecanismo dinâmico simples para o aparecimento de redes de escala livre com vértices altamente conectados Barabási et al. (1999); Barabási e Albert (1999); Barabási et al. (2000). O modelo baseou-se na construção das redes ao longo do tempo e na ligação preferencial a vértices com grau elevado. Foi observado que mesmo tendo o processo de construção características aleatórias, a configuração das redes obedeciam a um certo critério. À medida que a rede crescia e que novos vértices eram acrescentados, esses se ligavam preferencialmente aos vértices com maior grau. Esse modelo de crescimento é denominado de ligação preferencial e segue o princípio de favorecer as ligações a vértices com maior conectividade.

O cenário de ligação preferencial é comum em muitas redes grandes, como na web. Os novos sites, por exemplo, tendem a criar links para sites populares e conhecidos. Na Figura 2.4(a) é mostrada uma rede formada seguindo o modelo de Barabási e Albert, e a distribuição de conexões para 1000 vértices. A distribuição de graus equivalente a rede é mostrada na Figura 2.4(b).

Uma aplicação real do modelo com essa lei de potência é a rede de citações de artigos desenvolvida por Price de S. Price (1965). O modelo de Price, que possui várias similaridades com o modelo de Barabási e Albert, expressa que a probabilidade de um novo artigo $i$ citar um artigo anterior $j$ é proporcional a $d e g_{j}^{i n}+1$, onde $d e g_{j}^{i n}$ representa a quantidade de vezes que o artigo $j$ já foi citado.

Outros modelos de redes livre de escala têm sido propostos visando flexibilizar o $\gamma$ que no modelo de Barabási e Albert é igual a três quando $n \rightarrow \infty$ Dorogovtsev e Mendes (2003), e manter um coeficiente de aglomeração similar a de redes reais.

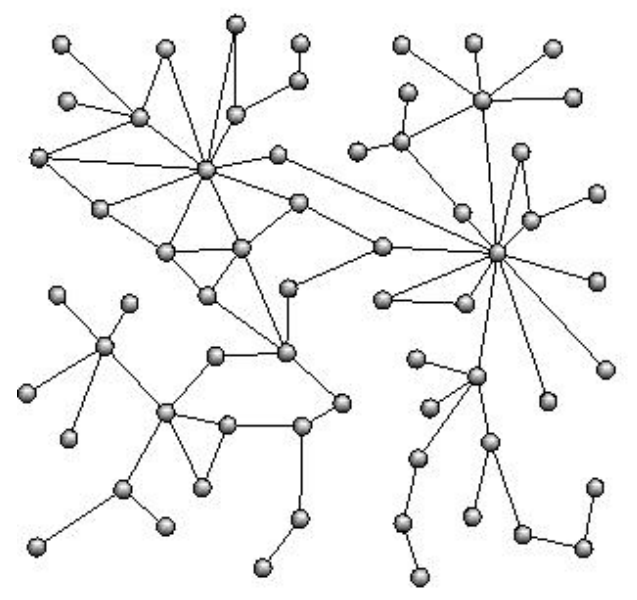

(a) Rede

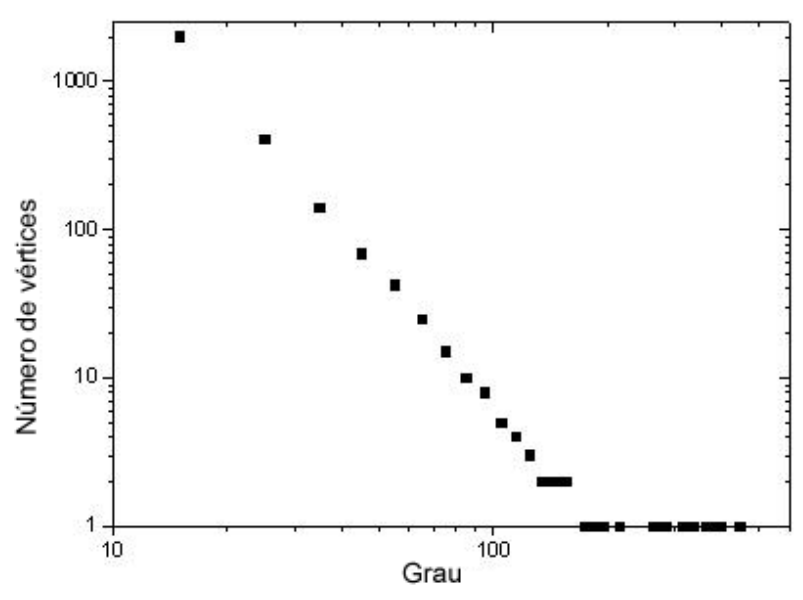

(b) Distribuição dos graus

Figura 2.4: (a) Rede livre de escala gerada pelo modelo de Barabási e Albert (b) Distribuição de conexões para a rede formada por 1000 vérticesCosta et al. (2007) 


\subsection{Detecção de Comunidades}

Uma propriedade bastante comum em redes complexas é a presença de estruturas modulares chamadas de comunidades. As comunidades são sub-grafos que são densamente conectados internamente, porém com poucas conexões externas, e o seu estudo tem diversas aplicações práticas. Os métodos de detecção de comunidades em redes complexas podem se basear na adição ou remoção de arestas da rede, sendo classificados como métodos "aglomerativos" ou "divisivos", respectivamente, seguindo o mesmo conceito da classificação dos métodos de particionamento hierárquico descritos com mais detalhes na Seção 3.1.2.

Girvan e Newman propuseram um algoritmo hierárquico divisivo baseado na remoção de arestas com alto valor de grau de intermediação Girvan e Newman (2002). A estratégia utilizada baseia-se na idéia de que as arestas com alto grau de intermediação possivelmente servem de "ponte" entre comunidades diferentes. De forma geral, o algoritmo de detecção de comunidades baseado no grau de intermediação segue os passos seguintes:

1. Calcular o grau de intermediação para todos as arestas da rede;

2. Remover a aresta com o maior valor de grau de intermediação;

3. Recalcular o grau de intermediação para as arestas remanescentes;

4. Retornar ao passo 2.

Uma característica importante do algoritmo baseado no grau de intermediação é a necessidade de recalcular a medida a cada passo, quando uma aresta é removida. Isso se deve ao fato de que ao remover uma aresta $i$, os caminhos mínimos que passavam $i$ precisarão ser atualizados para utilizar um outra aresta $j$, se possível. Como o algoritmo busca remover sempre a aresta com maior grau de intermediação, a medida tem de ser recalculada a cada passo.

Um método utilizado para calcular os valores do grau de intermediação para todas as arestas é identificar os caminhos mínimos entre os pares de vértices da rede. Esse método é conhecido como shortest-path betweenness. A complexidade de tempo para realizar o cálculo da medida parece ser de $O\left(m n^{2}\right)$, uma vez que para encontrar o caminho mínimo entre dois vértices quaisquer utilizando a busca em largura tem custo da ordem de $O(m)$, e em uma rede conectada existem $n^{2}$ pares de vértices distintos. Newman (2004b) propuseram uma adaptação do método a qual permite calcular o grau de intermediação para todas as arestas com a complexidade de tempo de $O(m n)$. Desta forma, no pior caso em que todas as arestas sejam removidas, o algoritmo tem complexidade de tempo da ordem de $O\left(m^{2} n\right)$.

A fim de qualificar um divisão de comunidades em uma rede, Newman e Girvan Newman e Girvan (2004) propuseram uma medida de modularidade $Q$. Na medida é considerada a proporção de arestas dentro da comunidade e a proporção entre as comunidades, e é calculada pela equação

$$
Q=\sum_{i}\left(e_{i i}-a_{i}^{2}\right)
$$


O primeiro termo da equação refere-se ao percentual de arestas nas comunidades. Considere que são encontradas $k$ comunidades, e que seja construída uma matriz $k \times k$ para representar a relação entre as comunidades. As células da matriz são definidas pela Equação 2.20

$$
e_{p q}= \begin{cases}\frac{1}{m} \sum_{i, j \in k_{p}}^{k_{p}} a_{i, j} & p=q \\ \frac{1}{2 m} \sum_{i \in k_{p}, j \in k_{q}}^{k_{p}, k_{q}} a_{i, j} & p \neq q\end{cases}
$$

Ou seja, $e_{p p}$ representa o percentual de aresta contidas na comunidade $p$ em relação ao total de arestas $m$. Já $e_{p q}$ representa metade do percentual da arestas que ligam as comunidades $p$ e $q$. Como a matriz é simétrica, $e_{p q}=e_{q p}$, o percentual de ligações entre as comunidades $p$ e $q$ é dado pela soma $e_{p q}+e_{q p}$. O segundo termo, $a_{i}^{2}$, que representa o percentual de ligações entre uma comunidade $i$ e as demais, é definido pela Equação 2.21

$$
a_{i}=\sum_{j} e_{i j}
$$

Em um grafo aleatório Watts (1999a,b) com valor de grau médio definido, tem-se que $e_{i j}=a_{i} a_{j}$. Sendo assim, a medida de modularidade para um grafo aleatório seria $Q=0$. Ou seja, uma divisão de uma rede em comunidades que resulte no valor de modularidade $Q=0$ indica que tal divisão é tão boa quanto a existente em um grafo aleatório. Valores de $Q$ diferentes de 0 indicam a presença de uma estrutura de comunidades no grafo. Conforme o valor da medida tende a 1 a estrutura de comunidade torna-se melhor do que a obtida em um grafo aleatório, embora na prática, valores $Q \geq 0,3$ já indiquem uma boa qualidade na divisão Newman e Girvan (2004).

Na Figura 2.5 é apresentada a divisão em duas comunidades na rede do clube de Karatê estudado por Zachary Girvan e Newman (2002). Essa é uma rede real com 35 vértices que representam integrantes de um clube que foi dividido em dois grupos por questões organizacionais. Na Figura, os vértices ilustrado por um círculo representam os integrantes que fazem parte do grupo liderado pelo administrador - vértice 34 - e os quadrado representam os integrantes do grupo liderado pelo instrutor - vértice 1.

A matriz Laplaciana para um grafo simples é definida pela Equação 2.22

$$
L_{i j}= \begin{cases}\operatorname{deg}_{i}, & \text { se } i=j \\ -1, & \text { se } i \neq j \text { e existe a aresta }(i, j) \\ 0, & \text { outros casos }\end{cases}
$$

As propriedades das matrizes Laplacianas são estudadas em diversos trabalhos na literatura, alguns dos quais serão abordados também na Seção 3.1.2. Na deteç̧ão de comunidades é analisado o autovetor $v_{i}=(1, . ., j, \ldots, m)$ correspondente ao menor autovalor $\lambda_{i}$ não-nulo da matriz $L$. O autovetor $v_{i}$ é chamado de vetor Fiedler, no qual cada dimensão é associado a um vértice da rede. Seja $v_{i}(j)$ e $v_{i}(l)$ os valores das dimensões $j$ e $l$ associadas aos vértice $j$ e $l$ respectivamente. Se $v_{i}(j)$ e $v_{i}(l)$ tiverem o mesmo sinal, ou seja $v_{i}(j) * v_{i}(l)>0$, os vértices são inseridos na mesma comunidade, caso contrário são colocados em comunidades diferentes.

Em Newman et al. (2006), Newman e colegas apresentaram um método baseado na 
análise de autovalores e autovetores da matriz de modularidade $B$, definida pela Equação 2.23

$$
B_{i j}=a_{i j}-\frac{d e g_{i} d e g_{j}}{2 m}
$$

em que $A$ representa a matriz de adjacência da rede. A matriz de modularidade tem função semelhante a matriz Laplaciana na detecção de comunidades. No método apresentado pelo autor, é obtido maior autovalor positivo da matriz de modularidade, e analisado o autovetor associado a ele. A separação na rede é feita com base na análise, no autovetor, do sinal corresponde a cada vértice. Vértices com sinais diferentes são colocando em grupos separados, originando dois novos agrupamentos. Caso nenhum autovalor positivo seja encontrado, o autovetor associado indicará que todos os vértices deverão estar no mesmo agrupamento, ou seja, não há mais divisões, e o algoritmo é finalizado.

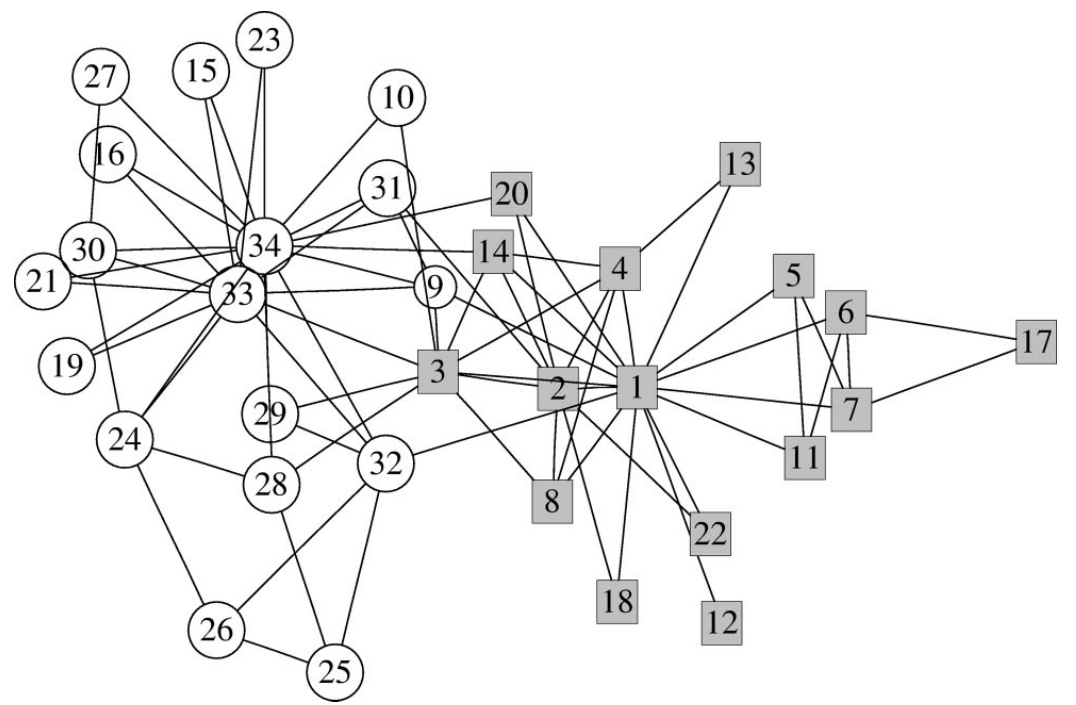

Figura 2.5: Rede de amizade entre os integrantes clube de Karatê de Zachary. Os quadrados indicam integrantes mais amigos do instrutor, enquanto que os círculos indicam os mais amigos do administrador Newman e Girvan (2004).

\subsection{Algoritmo de Otimização de Modularidade (AOM)}

Em 2004, Newman apresentou um algoritmo aglomerativo hierárquico para detecção de comunidades em redes complexas. O algoritmo baseia-se na medida de modularidade $Q$ e utiliza uma função de otimização desta medida para determinar a quantidade de comunidades. Os resultados obtidos pelo algoritmo demonstram a eficiência da medida modularidade como heurística para divisão de comunidades.

O algoritmo inicia considerando que cada vértice da rede representa um comunidade distinta. Seguindo um processo bottom-up, o algoritmo seleciona duas comunidades cuja união provocará o maior incremento na medida de modularidade. Esse passo é repetido enquanto o ganho é positivo, ou até que um ponto de parada seja alcançado. A medida de ganho de modularidade é definida pela equação

$$
\Delta Q=2\left(e_{i j}-a_{i} a_{j}\right)
$$




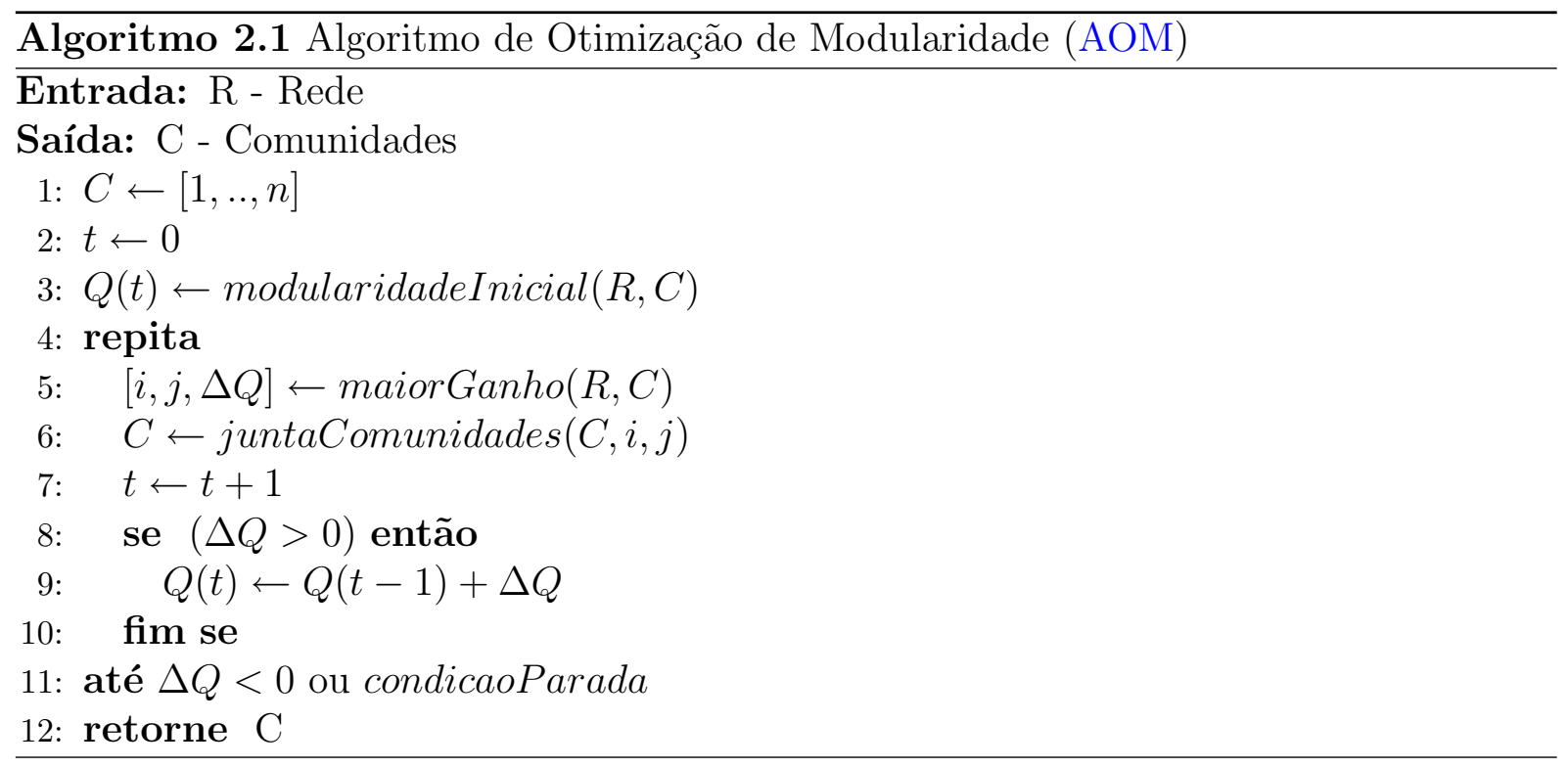

No algoritmo apresentando, o vetor $Q(t)$ armazena o valor da modularidade durante cada etapa da execução do algoritmo. Inicialmente é calculada o valor da modularidade inicial $Q(0)$ considerando cada vértice como uma comunidade, linha 3. A cada passo, o par de comunidades $(i, j)$ cuja união promova o maior ganho de modularidade $\Delta Q$ é selecionado, linha 5. Na linha 6 , é feita a junção das comunidades $i$ e $j$, formando uma nova comunidade. $\mathrm{O}$ valor de modularidade é então atualizado com o ganho gerado pela união de $i$ e $j$. O algoritmo encerra-se quando uma das condições da linha 9 é atendida, ou seja, o ganho encontrado não é positivo ou uma condição de parada foi atingida.

Nota-se que no pior caso, serão executados $n-1$ passos do algoritmo até o seu encerramento, sendo $n$ o número de vértices da rede, Equação 2.3. Neste caso, o algoritmo terminaria colocando todos os vértices em uma só comunidade. A escolha do par de comunidades com maior ganho de modularidade, que é feita a cada passo, leva em consideração as uniões feitas nos passos anteriores. Ou seja, a cada passo também é necessário atualizar os valores $e_{i j}$ referentes as comunidades $i$ e $j$ que foram agrupadas em uma só comunidade. No pior caso seria necessário calcular o ganho considerando cada uma das $m$ arestas presentes na rede. Assim, o custo total para calcular os ganhos e selecionar o maior, realizar a junção de um par de comunidades e atualizar os valores de $e_{i j}$ seria, no pior caso, da ordem de $O(n+m)$. Desta forma, o a complexidade de tempo do algoritmo no pior caso é da ordem de $O((n+m) n)$, ou $O\left(n^{2}\right)$, quando é necessário fazer $n-1$ junções.

O resultado das junções geradas pelo algoritmo pode ser visualizado como um dendograma. Na Figura 2.6 é apresentado o dendograma gerado pelo algoritmo ao ser executado na rede do clube de Karatê estudado por Zachary Girvan e Newman (2002). Essa é uma rede real com 35 vértices que representam integrantes de um clube que foi dividido em dois grupos por questões organizacionais. Na figura, os vértices ilustrado por um círculo representam os integrantes que fazem parte do grupo liderado pelo administrador, vértice 34, e os quadrado representam os integrantes do grupo liderado pelo instrutor, vértice 1. 


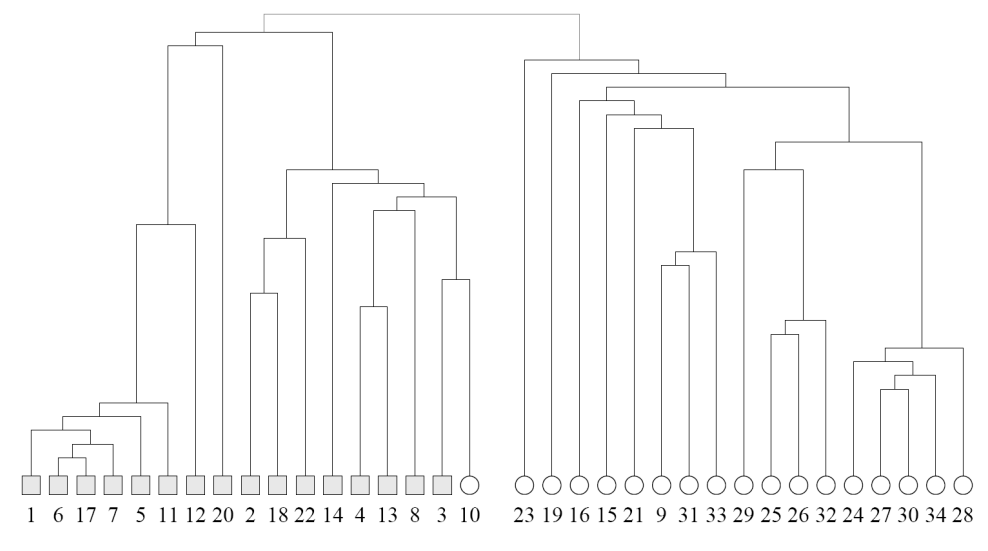

Figura 2.6: Dendograma gerado pela algoritmo de otimização de Modularidade na rede de Zachary. Os círculos e os quadrados representam a divisão real entre os integrantes do grupo Newman (2004c).

\subsection{Considerações Finais}

A teoria de redes complexas é uma das áreas que surgiu recentemente com o intuito de estudar grande volume de dados modelados como redes. Alguns dos principais conceitos dessa teoria, tais como medidas de caracterização e modelos, foram discutidos neste capítulo.

Uma propriedade interessante em diversas redes complexas é a existência de grupo de nós densamente conectados, conhecidos como comunidades. O estudo de algoritmo para deteç̧ão desses grupos tem despertado interesse da comunidade científica e trabalhos interessantes têm sido produzidos. Neste capítulo foi descrito o algoritmo de otimização da medida de modularidade $Q$, o qual é um dos focos de estudo deste trabalho.

No Capítulo 3 são apresentados alguns conceitos referentes ao problema de particionamento em grafos, tarefa diretamente relacionada com a detecção de comunidades. São comentadas as funções objetivos mais utilizadas, alguns dos principais tipos de algoritmos e medidas de avaliação encontrados na literatura. Em particular, na próxima seção é discutida a estratégia de particionamento multinível, a qual é um dos temas principais deste trabalho. 



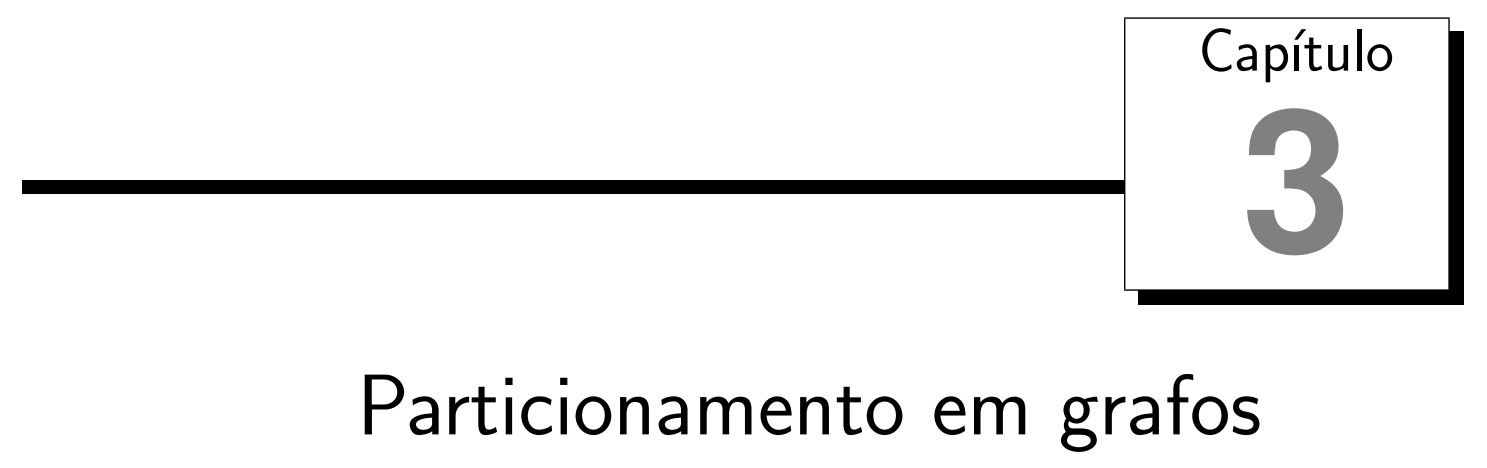

A teoria dos grafos tem sido aplicada para modelagem matemática de diversos sistemas reais. Um problema oriundo dessa teoria é o particionamento de grafos em sub-grafos cujos vértices sejam densamente conectados entre si e que possuam poucas conexões com outros sub-grafos. Neste capítulo são abordados os conceitos referentes ao particionamento de grafos tais como: padrões de notação, tipos e representação computacional de grafos. É apresentada também uma breve revisão das técnicas de particionamento encontradas na literatura diretamente relacionadas com foco deste trabalho, comentando suas características e aplicações. Por fim, são apresentadas algumas medidas objetivas utilizadas na avaliação da qualidade dos resultados encontrados pelos algoritmos e na comparação entre eles.

\subsection{Técnicas de particionamento em grafos}

O problema de particionamento em grafos em $k$ diferentes grupos pode ser definido formalmente a seguir. Dado um grafo $G$, encontrar sub-grafos $G_{1}, G_{2} \ldots G_{k}$ tais que $G_{i} \cap G_{j}$ $=\emptyset$ para $i \neq j$, e que a quantidade de arestas entre $G_{i}$ e $G_{j}$ seja minimizada. Em problemas de balanceamento de carga entre processadores, por exemplo, o particionamento de grafos representa o problema de enviar tarefas que utilizem recursos semelhantes para o mesmo processador a fim de que seja reduzido o tráfego na rede.

Para os casos em que a quantidade de vértices é pequena, torna-se viável analisar todas as possíveis soluções e escolher a melhor. Entretanto, conforme a dimensionalidade do problema aumenta, esse procedimento para solução torna-se inviável.

Nesse cenário de alta dimensionalidade surgem heurísticas para encontrar particionamentos com qualidade em grafos. Algoritmos heurísticos são baseados em percepções e intuições a respeito das características do problema e de sua estrutura capazes de realizar aproximações em tempo de execução satisfatório a fim de encontrar uma boa solução, quando não ótima, na maioria dos casos. Desta forma, não é garantido que algoritmos 
heurísticos encontrem a melhor solução sempre.

A fim de encontrar a melhor solução, os algoritmos buscam otimizar uma função objetivo que seja adequada ao problema tratado. A seguir, são apresentadas as principais funções objetivo utilizadas pelos algoritmos de particionamento de grafos.

\subsubsection{Funções objetivo}

O objetivo dos algoritmos de particionamento em grafos é encontrar sub-grafos concisos. Considere que em um grafo $G$ sejam encontrados dois subgrafos $V_{1}, V_{2} \subset V$ de modo que $V_{1} \neq \emptyset, V_{2} \neq \emptyset, V_{1} \cap V_{2}=\emptyset$ e $V_{1} \cup V_{2}=V$. Define-se como corte a soma dos pesos das aresta que ligam vértices entre os dois subgrafos conforme a Equação 3.1

$$
\operatorname{corte}\left(V_{1}, V_{2}\right)=\sum_{i \in V_{1}, j \in V_{2}} s_{i j}
$$

É possível estender a medida de corte para uma quantidade de subgrafos maior que dois utilizando a Equação 3.2

$$
\operatorname{corte}\left(V_{1}, \ldots, V_{k}\right)=\sum_{i}^{k} \operatorname{corte}\left(V_{i}, \overline{V i}\right)
$$

na qual $\overline{V_{i}}$ refere-se a complemento do conjunto $V_{i} \subset V$. Esses subgrafos também são conhecidos como partições, e o conjunto $P_{k}(G)=\left\{V_{1}, \ldots, V_{K}\right\}$ é chamado de particionamento do grafo $G$.

Um particionamento ótimo de um grafo é aquele que reduz a quantidade de arestas entre as partições, em outra palavras, é o particionamento que possui o corte mínimo (minimum cut) Ford e Fulkerson (1956); Stoer e Wagner (1997).

Com base no teorema do máximo-fluxo, menor-corte (max-flow, min-cut) de Ford e Fulkerson (1956), um corte mínimo separando um grafo em dois sub-grafos pode ser encontrado em tempo computacional de ordem $O\left(n^{3}\right)$. Técnicas de corte em árvores chegam a possuir complexidade da ordem de $O\left(n^{4}\right)$.

Optar somente pela minimização do valor de corte implica favorecer soluções com partições desbalanceadas, nas quais algumas possuem poucos vértices, e outras muitos vértices Shi e Malik (2000). Considerando que o peso das arestas represente a similaridade entre os vértices, a minimização do corte consiste em isolar um vértice de menor grau em uma partição, e o restante dos vértices em outra, para o caso de uma bissecção.

Na Figura 3.1 são ilustrados dois dos possíveis particionamentos para um mesmo grafo. Utilizando uma estratégia de minimização de corte, seria possível encontrar um particionamento semelhante ao ilustrado em 3.1(a), em que quase todos os vértices estão no mesmo grupo, e apenas um vértice está no outro grupo. Já em 3.1(b), o particionamento ilustrado possui grupo com um balanceamento melhor, alinhado a maioria das aplicações práticas.

Uma maneira de prevenir que os métodos de particionamento produzam partições com uma quantidade muito baixa de vértices é utilizar funções objetivos que considerem o tamanho dos grupos encontrados. A seguir são apresentadas algumas das funções objetivos 


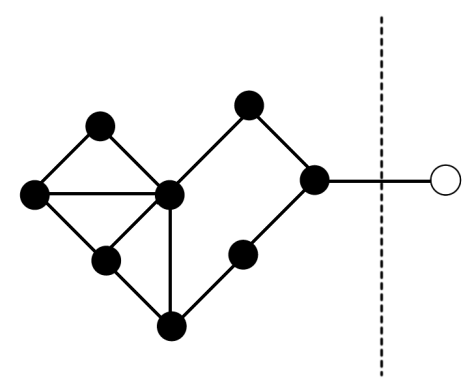

(a) $\operatorname{corte}\left(V_{1}, V_{2}\right)=1$

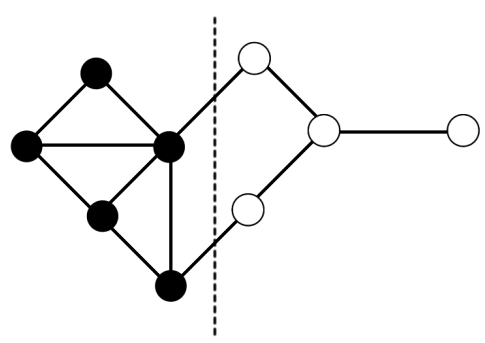

(b) $\operatorname{corte}\left(V_{1}, V_{2}\right)=2$

Figura 3.1: Exemplos particionamentos diferentes em um mesmo grafo.

mais utilizadas por algoritmos de particionamento encontrados na literatura: razão de associação, razão de corte e razão normalizada, definidas a seguir.

Razão de Associação A medida razão de associação (ratio association) Shi e Malik (2000) indica o percentual entre a parcela de arestas dentro de um grupo e a quantidade de vértice no grupo. A medida é obtida utilizando a Equação 3.3

$$
R A \operatorname{ssoc}(G)=\max _{P_{k}(G)} \sum_{c=1}^{k} \frac{\operatorname{arestas}\left(V_{c}, V_{c}\right)}{\left|V_{c}\right|}
$$

na qual $\left|V_{c}\right|$ representa a quantidade de vértices dentro do grupo $V_{c}$.

Razão de Corte A medida de razão de corte (ratio cut) Hagen e Kahng (1992) expressa o percentual entre o peso das arestas entre os grupos e o tamanho de cada grupo, e é definida pela Equação 3.4.

$$
\operatorname{RCorte}(P)=\min _{P_{k}(G)} \sum_{c=1}^{k} \frac{\operatorname{arestas}\left(V_{c}, \overline{V_{c}}\right)}{\left|V_{c}\right|}
$$

Corte Normalizado A medida de corte normalizado (normalized cut) Shi e Malik (2000) expressa o percentual entre o peso das arestas entre os grupos e o peso dentro do grupo. A função é calculada pela Equação 3.5

$$
\operatorname{NCorte}(P)=\min _{P_{k}(G)} \sum_{c=1}^{k} \frac{\operatorname{arestas}\left(V_{c}, \overline{V_{c}}\right)}{\operatorname{deg}\left(V_{c}\right)}
$$

na qual $\operatorname{deg}\left(V_{c}\right)$ representa o grau do subgrafo $V_{c}$ definido por $\operatorname{deg}\left(V_{c}\right)=\sum_{v \in V_{c}} \operatorname{deg}(v)$.

Na Tabela 3.1 são apresentados os valores da medidas RAssoc, RCorte e NCorte para os exemplos de particionamento ilustrados na Figura 3.1. Como pode ser observado, para o segundo particionamento obtém valores melhores para as três medidas.

Tabela 3.1: Valores das medidas de RAssoc, RCorte e NCorte para o grafo ilustrado na Figura 3.1.

\begin{tabular}{c|c|c|c} 
& RAssoc & RCorte & NCorte \\
\hline$P_{1}$ & 1,375 & 1,125 & 1,045 \\
$P_{2}$ & $\mathbf{2 , 1 5}$ & $\mathbf{0 , 9}$ & $\mathbf{0 , 4 7 6}$
\end{tabular}


Percebe-se que para que as funções RCorte e NCorte alcancem valores baixos, o tamanho da partição ou o grau de cada partição não podem assumir valores baixos. De fato, o mínimo de uma função do tipo $\sum_{i=1}^{k} \frac{1}{x_{i}}$ é obtido quando $x_{i} \cong x_{j}$. Nas funções RCorte e $N C$ orte representaria encontrar $\left|V_{i}\right| \cong\left|V_{j}\right|$ e $\operatorname{deg}\left(V_{i}\right) \cong \operatorname{deg}\left(V_{j}\right)$, respectivamente, o que, no problema em questão, representa encontrar partições balanceadas.

Adicionar a restrição de balanceamento ao problema de particionamento de grafos torna-o NP-difícil Garey et al. (1976); Garey e Johnson (1990); Wagner e Wagner (1993), ou seja, ainda não é conhecido nenhum algoritmo que encontre a solução ótima a menos que tente todas as soluções. Sendo assim, ao invés de buscar a melhor soluções, os algoritmos existentes buscam aproximações baseadas em heurísticas. A seguir serão discutidos alguns dos principais algoritmos encontrados na literatura.

\subsubsection{Algoritmos de Particionamento de Grafos}

A escolha do algoritmo apropriado para o particionamento de grafos depende do contexto da aplicação e envolve uma decisão entre a qualidade do resultado e o tempo de execução. Para os casos nos quais pequenos ganhos de qualidade sejam significativos, é interessante aplicar algoritmos capazes de produzir melhores resultados. Em casos nos quais o tempo de resposta é o fator determinante, os algoritmos mais rápidos são recomendados. Sendo assim, não existe um algoritmo que gere o melhor resultado para todos os problemas.

Na literatura, os algoritmos de particionamento costumam ser divididos em duas categorias: métodos globais e métodos locais Schaeffer (2007).

Os métodos globais utilizam toda a estrutura dos grafos para obter o particionamento. Essa abordagem pode se tornar inviável quando o tamanho do grafo é muito grande e possui estrutura esparsa. Uma alternativa para esse caso é utilizar o particionamento iterativo Bradley et al. (1998) que adiciona sequencialmente parte dos dados ao processo de agrupamento.

Os métodos locais são utilizados nos casos em que é possível obter uma solução inicial e utilizá-la como base para obter novas soluções melhoradas. As soluções iniciais podem ser geradas por outros métodos, construídas aleatoriamente ou construídas a partir de análise de sub-partes do grafo.

Nesta seção são comentados com mais detalhes os métodos mais relacionados ao trabalho: algoritmos hierárquicos e algoritmos espectrais.

\section{Algoritmos Hierárquicos}

Em alguns grafos, encontrar um particionamento em que as partições sejam disjuntas entre si pode não ser uma solução satisfatória. Há casos em que as partições podem pertencer a outras partições, formando uma hierarquia. Um exemplo é o grafo representando funcionários de uma empresa, ilustrado na Figura 3.2. Cada vértice no grafo representa um funcionário, e cada as arestas representam a interação profissional no dia-a-dia. Os conjuntos internos demarcados representam um particionamento mais detalhado que divide o grafo em equipes, já os mais externos representam o particionamento mais geral, 
em uma divisão em departamentos.

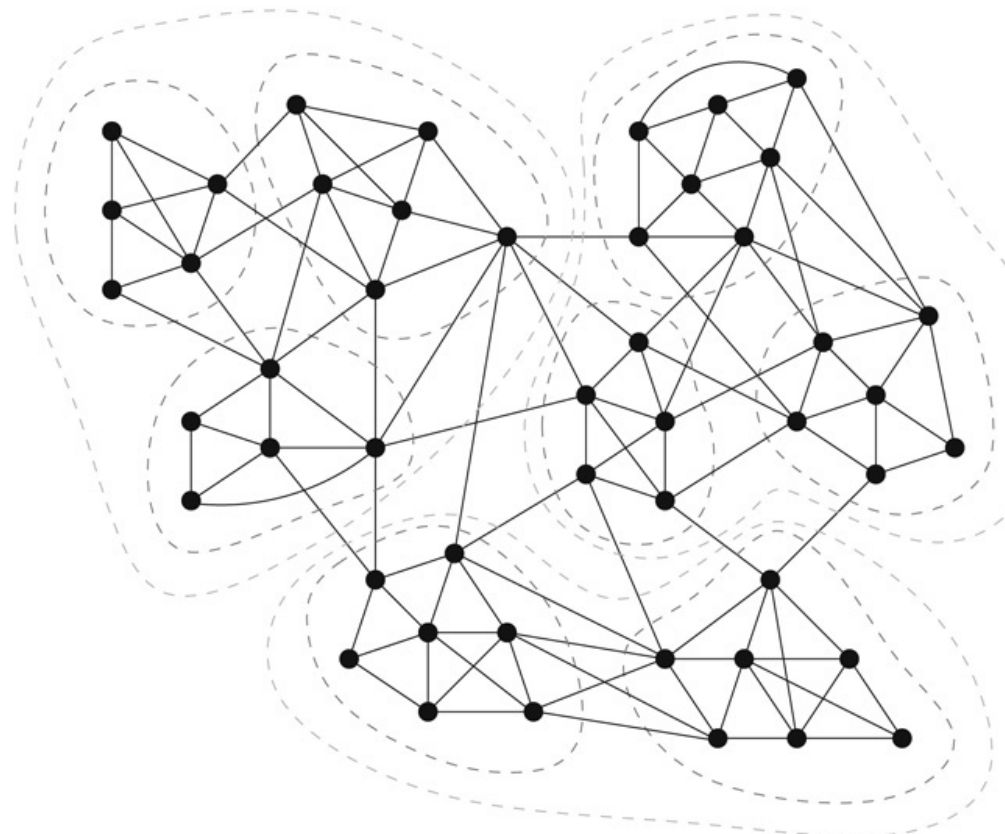

Figura 3.2: Exemplo de divisão da rede representando a interação entre funcionários de uma empresa. A divisão foi feita em três departamentos, que são compostos por 5 a 7 funcionários Schaeffer (2007).

A classe de algoritmos que gera soluções com topologia hierárquica são conhecidos como hierárquicos e são divididos em:

- divisivos: utiliza o grafo inteiro inicialmente, e realiza sucessiva divisões até alcançar a quantidade de partições desejada;

- aglomerativos: considera inicialmente cada vértice como uma partição, e realiza sucessivas uniões até alcançar a quantidade de partições desejada.

As junções ou divisões nos algoritmos hierárquicos são feitas de maneira a otimizar a função objetivo definida para o problema, e uma vantagem dos algoritmos hierárquicos é que os resultados podem ser analisados utilizando um dendrograma. Contudo, ambos os métodos possuem a desvantagem de não permitir que vértices colocados em uma partição mudem para uma outra.

Hartuv e Shamir Hartuv e Shamir (2000) desenvolveram um algoritmo divisivo que utiliza uma medida de densidade como critério de parada. O algoritmo particiona o grafo removendo as arestas pertencentes ao corte mínimo. Após remover uma aresta, é verificado se o componente conectado resultante é densamente conectado, que segundo os autores deve superior a $\frac{n}{2}$. Caso o componente seja denso, não são realizadas mais divisões nele. Caso contrário, o ciclo é reiniciado removendo mais uma aresta do corte mínimo.

Clauset e Moore Clauset e Moore (2005) propuseram um algoritmo aglomerativo, semelhante ao proposto por Newman (2004c), que realiza uma otimização gulosa da medida de modularidade com base na análise do grau de intermediação. 
Os algoritmos espectrais também são considerados como métodos globais já que utilizam todo o grafo para gerar o particionamento. A base dos algoritmos espectrais é a análise de autovetores para realizar seções nos grafos. Os autovetores utilizados no particionamento estão relacionados a matriz Laplaciana.

A matriz Laplaciana de um grafo $G$ é definida por

$$
L=D-A
$$

em que $D$ é uma matriz diagonal formada pelos graus dos vértices de $G$, e $A$ é a matriz de adjacências dos vértices em $G$. Essa definição é equivalente a que foi apresentada na Equação 2.22. Outras definições de matrizes Laplacianas encontradas na literatura Chung (1997); Filippone et al. (2008) são:

Laplaciana Normalizada $L_{N}=D^{-1 / 2} L D^{-1 / 2}$.

Laplaciana Generalizada $L_{G}=D^{-1} L$.

Laplaciana com Relaxamento $L_{\rho}=L-\rho D$.

De acordo com o contexto do problema analisado, escolhe-se qual das definições de matrizes Laplacianas é a mais apropriada. Para o particionamento de grafos, em geral é realizada a decomposição espectral da matriz utilizando a análise de seus autovetores.

A definição de autovetor pode ser dada por: seja $M$ uma matriz quadrada $n \times n$, um vetor $\vec{x}$ com $n$ dimensões é chamado de autovetor de $M$ se existir um número $\lambda \in \Re$ tal que $M \vec{x}=\lambda \vec{x}$. Em particular, os algoritmos espectrais utilizam o autovetor associado ao segundo menor autovalor para realizar o particionamento do grafo. As propriedades desse autovetor, conhecido como vetor de Fiedler, estão relacionadas com o corte em grafos.

Shi e Malik Shi e Malik (2000) desenvolveram um algoritmo espectral para ser utilizado em problemas de segmentação de imagens. O algoritmo busca minimizar a função objetivo NCorte utilizando o segundo autovetor $\overrightarrow{x_{2}}$ da matriz Laplaciana Generalizada. O particionamento é feito de acordo com os sinais das dimensões de $\overrightarrow{x_{2}}$, ou seja, os vértices $i$ cujas dimensões apresentem o mesmo sinal são colocados na mesma partição.

Hagen apresentou um estudo em particionamento também baseado na decomposição espectral utilizando o segundo maior autovalor Hagen e Kahng (1992). Além disso, os autores demonstram a efetividade de uso do algoritmo de Lanczos para calcular autovalores e autovetores de matrizes.

Ng, Jordan e Weiss Ng et al. (2001) propuseram um algoritmo que utiliza a matriz Laplaciana Normalizada. No algoritmo, é calcula uma outra matriz $U_{n \times K}$ formada pelos $K$ autovetores associados aos $K$ maiores autovalores da matriz Laplaciana. A matriz $U$ é normalizada, então é utilizado uma versão do $k$-médias para realizar a separação dos pontos.

Verma Verma e Meila (2005) realizou um estudo comparativo entre alguns algoritmos dos principais algoritmos existentes até então para particionamento de grafos, e mostrou que as diferenças de qualidade de resultados nos conjuntos analisados é pequena. 


\subsection{Particionamento multinível em grafos}

Na seção anterior foram apresentadas algumas das técnicas para particionamento de grafos existentes na literatura. Nesta seção, é apresentada uma estratégia para particionamento de grafos como grande número de vértices, conhecida com Particionamento Multinível em Grafos (Multilevel Graph Partitioning) Bui e Jones (1993); Hendrickson e Leland (1993); Karypis e Kumar (1998).

Formalmente, a estratégia multinível pode ser definida como a seguir. Considere um Grafo com Pesos $G_{0}\left(V_{0}, E_{0}\right)$, com pesos nas arestas. O algoritmo multinível realiza sucessivas reduções no grafo $G_{0}$ até encontrar um grafo $G_{x}$ que seja tão pequeno quanto desejado para realizar o particionamento. Então é realizado o particionamento de $G_{x} \mathrm{em}$ $k$ sub-grafos, e o particionamento vai sendo expandido sucessivamente aos grafos intermediários até que se retorne ao grafo original obtendo o particionamento. As três fases que compõem a estratégias são descritas a seguir.

Fase de Coarsening $\mathrm{O}$ grafo $G_{0}$ é transformado sucessivamente em grafos menores $G_{1}, G_{2}, \ldots, G_{x}$ de modo que $\left|V_{0}\right|>\left|V_{1}\right|>\left|V_{2}\right|>\ldots>\left|V_{x}\right|$.

Fase de Particionamento $\mathrm{O}$ particionamento $\left(P_{x}\right)$ do grafo $G_{x}=\left(V_{x}, E_{x}\right)$ em $k$ subgrafos é computado, separando $V_{x}$ em $k$ partes distintas.

Fase de Uncoarsening $\mathrm{O}$ particionamento $\left(P_{x}\right)$ de $G_{x}$ projetado para cada um dos grafos intermediários gerados na fase de coarsening até que se chegue ao grafo original $G_{0}$. Para cada grafo intermediário existe um particionamento intermediário: $P_{x-1}, P_{x-2}, \ldots, P_{1}, P_{0}$.

Na Figura 3.3 são ilustradas as três fases da estratégia multinível. O grafo original $G_{0}$, neste exemplo, é sucessivamente reduzido até chegar ao grafo $G_{4}$. Este último grafo, é então particionado em 6 sub-grafos. Sucessivamente, o particionamento encontrado é mapeado nos grafos intermediários $G_{3}, G_{2}$ e $G_{1}$ até chegar ao grafo original.

\subsubsection{Fase de Coarsening}

Durante a fase de coarsening, uma sequência de grafos $\left(G_{0}, G_{1}, . ., G_{i}, G_{i+1}, \ldots G_{x}\right)$ é construída a partir do grafo original $G_{0}$ de modo que $\left|V_{i}\right|<\left|V_{i-1}\right|$. Na maioria das estratégias utilizadas na fase de coarsening, um conjunto de vértices de $G_{i}$, representado por $V_{i}^{v}$, é combinado para dar origem a um único vértice $v$ no grafo reduzido $G_{i+1}$. Neste trabalho, os vértices originados de fusões de outros vértices são denominados de supervértices.

Com intuito de construir um grafo reduzido que seja uma boa representação do grafo original, o peso do vértice $v$ é dado pela soma dos pesos de cada vértice em $V_{i}^{v}$. Além disso, para também preservar a conectividade, as arestas incidentes em $v$ representam a união das arestas incidentes nos vértices de $V_{i}^{v}$. Caso mais de um vértice em $V_{i}^{v}$ seja adjacente a um vértice $u$, o peso da aresta que ligará $v$ e $u$ no grafo reduzido será dado pela soma dos pesos das arestas no grafo de origem. Essas definições garantem algumas propriedades: 


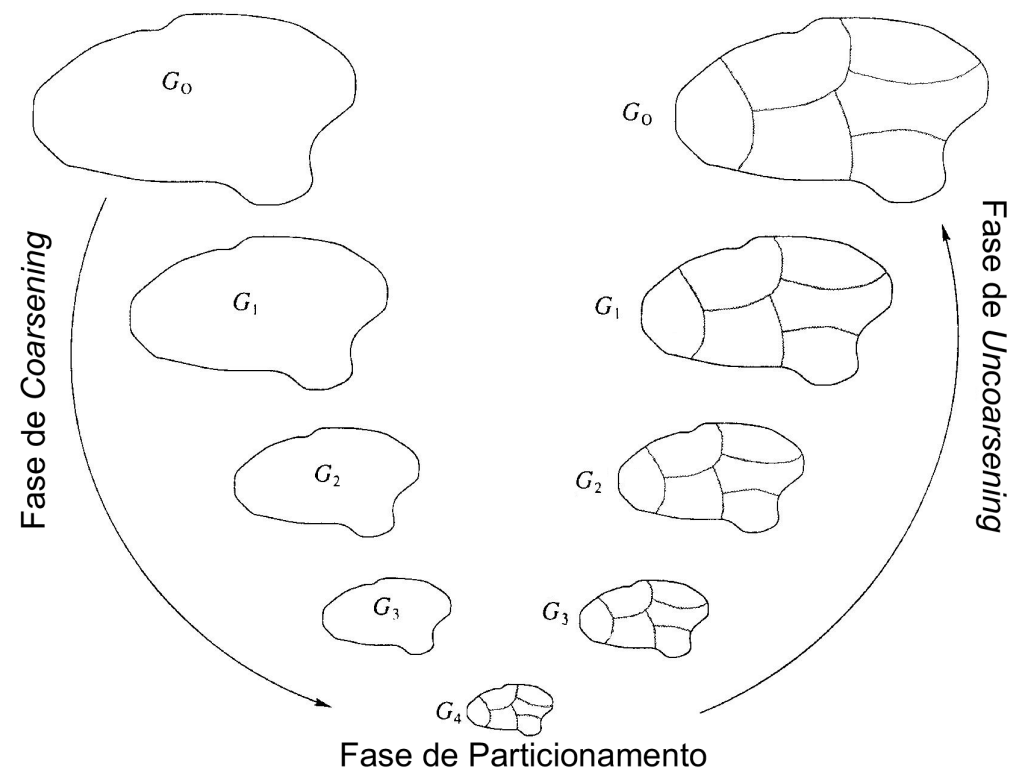

Figura 3.3: Esquema de Particionamento multinível em Grafos. Figura adaptada de Karypis e Kumar (1998).

- O corte de um particionamento no grafo reduzido é igual ao corte do mesmo particionamento no grafo original.

- Um particionamento balanceado no grafo reduzido leva a um particionamento balanceado no grafo original.

A heurística de junção de arestas é definida formalmente como matching Bui e Jones (1993); Hendrickson e Leland (1993). Um matching de um grafo é um conjunto de arestas, as quais não são incidentes aos mesmos vértices, ou seja, para cada vértice do grafo existirá somente uma aresta no conjunto matching. Assim, na fase de coarsening baseada em matchings, os pares de vértices do grafo $G_{i}$ que possuem arestas no conjunto de matching são combinados e formam um único super-vértice no grafo reduzido seguinte $G_{i+1}$. Os vértices que não pertencerem ao matching são simplesmente copiados para o grafo reduzido $G_{i+1}$.

O objetivo de combinar vértices é reduzir o tamanho do grafo $G_{i}$, e para isso, o matching deve conter o máximo de arestas possível. Um matching é dito maximal se não é possível adicionar mais arestas a ele sem que seja violada a condição de que mais de uma aresta seja incidente ao mesmo vértice. Na Figura 3.4 é ilustrado um exemplo de redução de um grafo utilizando o conceito de matching. Cada um dos três pares de vértices circulados em 3.4(a) é combinado para formar um super-vértice em 3.4(b). Cada super-vértice recebe um peso, e o seu conjunto de arestas incidentes é dado pela união das arestas incidentes nos vértice que lhe deram origem.

A fase de coarsening é repetida até que seja alcançado um grafo de tamanho desejado, que pode ser definido pela quantidade absoluta de vértices, uma razão em relação ao tamanho original, ou uma quantidade pré-estabelecida de etapas.

A seguir são descritos quatro métodos utilizados na etapa de coarsening: Random Matching (RM), Heavy-edge Matching (HEM), Modified Heavy-edge Matching (MHEM) 


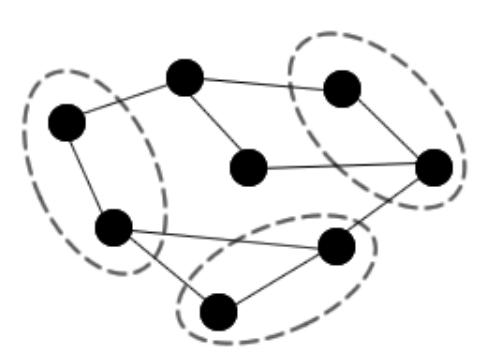

(a) $G_{i}$

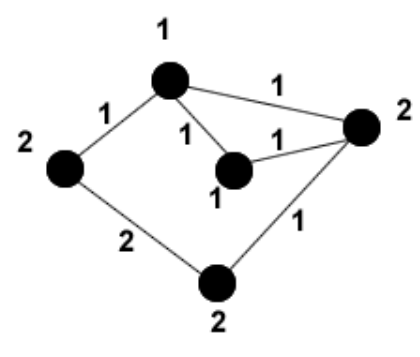

(b) $G_{i+1}$

Figura 3.4: Exemplo de coarsening utilizando a o conceito de matching.

e Light Edge Matching (LEM).

RM

Na estratégia de Random Matching (RM) é utilizado um algoritmo randômico para encontrar o conjunto maximal de vértices candidatos a compactação. Inicialmente todos os vértices no grafo são definidos não-marcados, e então são visitados aleatoriamente. As visitas continuam até que todos os vértices tenham sido visitados, ou que o fator de redução seja alcançado. Ao visitar um determinado vértice $v$ que ainda esteja não-marcado, o algoritmo busca entre seus vizinhos algum vértice $u$ que também esteja não-marcado. Se existir o vértice u que satisfaça a condição requerida, o par $(v, u)$ é selecionado para matching, e ambos são definidos como marcados. Caso contrário, o vértice v é definido como marcado, já que todos os seus vizinhos também já estão.

HEM

Na estratégia de Heavy-edge Matching (HEM), o objetivo é buscar o conjunto de vértices que reduza ao máximo o peso total das arestas no grafo reduzido gerado para próxima etapa. O HEM utiliza um método randômico semelhante ao do RM, contudo possui um critério de preferência na seleção dos vizinhos para matching. A diferença está no fato de que o HEM procura por vizinhos não-marcados cuja aresta possua o maior peso.

Considere um grafo $G_{i}=\left(V_{i}, E_{i}\right)$, o matching $M_{i}$ que é utilizado para reduzir $G_{i}$, e o grafo reduzido $G_{i+1}=\left(V_{i+1}, E_{i+1}\right)$ induzido a partir de $M_{i}$. Se $A$ é um conjunto de aresta, define-se $W(A)$ como a soma dos pesos das arestas em $A$. Pode-se observar que

$$
W\left(E_{i+1}\right)=W\left(E_{i}\right)-W\left(M_{i}\right)
$$

O peso total do grafo reduzido é diretamente relacionado ao peso do matching, logo, encontrar o matching máximo $M_{i}$ no qual as arestas possuam os maiores pesos implica em decair o peso do grafo reduzido.

No HEM ao invés de juntar um vértice aleatório $v$ com um de seus vizinhos ainda não incluídos no matching, procura-se o adjacente $u$, no qual a aresta $(v, u)$ tenha o maior peso. Embora essa heurística não garanta que o matching tenha o peso máximo possível, trabalhos anteriores mostram sua eficiência Hendrickson e Leland (1993); Karypis e Kumar 


\section{MHEM}

O Modified Heavy-edge Matching (MHEM) é uma modificação do HEM que visa gerar um grafo reduzido com grau ainda menor. Assim como o HEM, o MHEM também utiliza um método aleatório para selecionar um vértice candidato ao matching. Porém, o vizinho a ser escolhido para formar o par será aquele mais similar e que possua também mais vértices adjacentes em comum. Formalmente, considere que $v$ seja o vértice aleatório escolhido, define-se o conjunto $H$ de vértices adjacentes a $v$ que ainda não foram marcados no matching, e para cada vértice $u \in H$, é calculada a soma do peso das arestas entre $u$ e

os demais vértices $x$ quaisquer que sejam adjacentes a $u$ e $v$. É escolhido para matching de $v$, o vértice $u$ que possuir a maior soma.

\section{LEM}

O Light Edge Matching (LEM) utiliza um critério oposto ao HEM para formar o matching máximo. Ao invés de buscar minimizar os pesos das arestas no grafo reduzido, o LEM tenta maximizá-los. A maximização é obtida selecionando no matching arestas que possuam o menor peso, e que consequentemente, produzirá a menor redução no grafo reduzido gerado. O objetivo do método LEM é gerar grafos reduzidos com maior grau médio, característica que favorece alguns algoritmos de particionamento, como o de Kernighan-Lin, utilizados na fase seguinte.

Na Figura 3.5 é apresentado um exemplo comparativo entre uma eventual etapa de coarsening em um grafo. Em 3.5(a) é utilizado o método RM, que seleciona aleatoriamente os pares de vértices para formar o matching, enquanto em 3.5(b) é utilizado HEM. No grafo que será reduzido, as aresta selecionas pelos métodos estão realçadas na cor vermelha. Na parte inferior da figura, são mostrados os grafos reduzidos gerados por cada método. Pode-se observar que a redução do peso total das arestas é maior quando utilizado o método HEM.

A complexidade de tempo para os três métodos da ordem de $O(|E|)$ é assintoticamente similar para os três métodos, embora o MHEM apresente uma constante maior que os demais Hendrickson e Leland (1993); Karypis e Kumar (1998).

\subsubsection{Fase de particionamento}

A fase de particionamento da estratégia multinível é responsável por encontrar o conjunto de partições $P_{m}$ no grafo reduzido $G_{m}$. Nessa fase, é possível empregar os mais diversos algoritmos de particionamento de grafos, tais como os iterativos, hierárquico, divisivo ou aglomerativo. Alguns desses algoritmos foram comentados no capítulo anterior.

Essa fase flexibiliza a utilização de algoritmos de particionamento que possuem um custo computacional mais caro. Isto é possível porque o grafo utilizado para o particionamento possui um número reduzido de vértices e de arestas, além de ser uma aproximação de qualidade do grafo original. Ao atribuir um Super-Vértice a uma partição, por exemplo, estamos na verdade atribuindo todo o conjunto de vértices internos à partição. Desta 


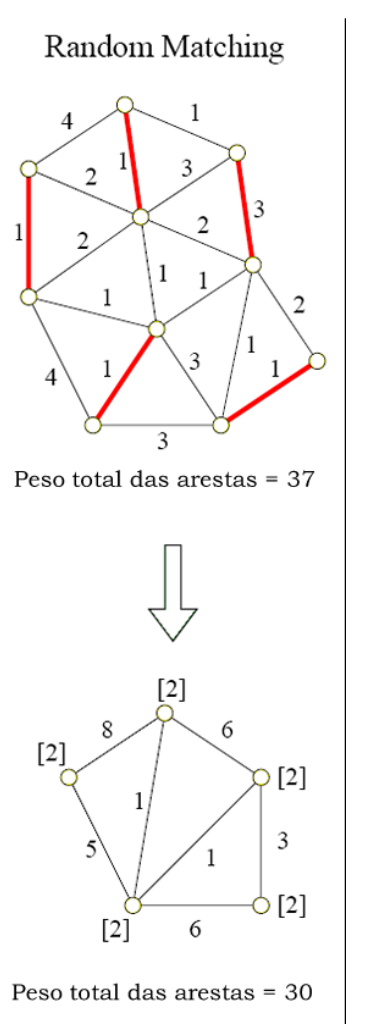

(a) RM
Heavy-edge Matching

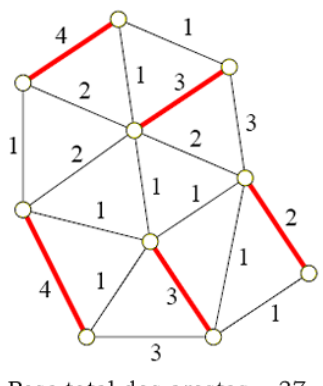

Peso total das arestas $=37$
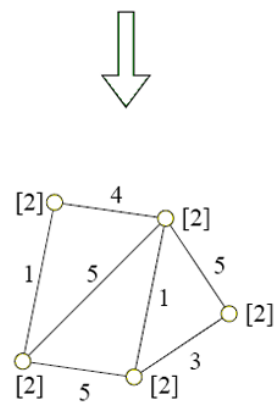

Peso total das arestas $=21$

(b) HEM

Figura 3.5: Exemplo de grafos reduzidos gerado na fase de coarsening. Em 3.5(a) o matching é feito utilizando o método RM. Já em 3.5(b) é utilizado o HEM.

forma, o custo do algoritmo de particionamento não contribui significativamente para o custo total do processo Karypis e Kumar (1995a).

\subsubsection{Fase de Uncoarsening}

A fase de uncoasening é a final do algoritmo multinível. O grafo reduzido $G_{x}$, utilizado na fase anterior de particionamento, é expandido para formar o grafo gerador $G_{x-1}$ o mesmo que foi utilizado para gerar $G_{x}$ na fase de coarsening. Uma vantagem da utilização de contração de arestas na fase de coarsening é simplificar a fase de uncoarsening. Cada super-vértice em um dos grafos reduzidos representa a união de dois vértices do grafo gerador.

$\mathrm{Na}$ fase de uncoarsening, o resultado da fase de particionamento é projetado sucessivamente a cada grafo intermediário $\left(G_{x-1}, \ldots, G_{i}, \ldots, G_{1}\right)$ até o grafo original $G_{0}$. O particionamento encontrado para o grafo reduzido $G_{x}$ é utilizado para formar o particionamento de $G_{x-1}$ da seguinte maneira: Se um super-vértice em $G_{x}$ está em uma partição $i$, então todos os vértices que lhe deram origem em $G_{x-1}$ também estarão na mesma partição. O algoritmo multinível encerra-se quando o refinamento é feito no grafo original $G_{0}$.

Em cada etapa da fase de uncoarsening, o novo particionamento pode ser ajustado para incremento de qualidade utilizando um processo de refinamento. Essa abordagem possibilita evitar que o algoritmo mantenha-se em um mínimo local, uma vez que os vértices recém adicionados ao particionamento podem trocar de partição. 
Os algoritmos de refinamento buscam melhorar a qualidade de um particionamento com base em um exemplo inicial.

Grande parte dos algoritmos para o refinamento de partições existentes na literatura é baseado no algoritmo de Kernighan-Lin (KL) Kernighan e Lin (1970). Esse algoritmo foi proposto para refinar particionamentos gerados em bisseções de grafos. No algoritmo, são realizadas sucessivas trocas de vértices entre as partições de modo a reduzir o valor de corte e manter o balanceamento.

A variação do algoritmo mais utilizada por implementações da estratégia multinível é a de Fiduccia-Mattheyses Fiduccia e Mattheyses (1988). Também utilizado para refinar o particionamento de bisseções, esse algoritmo utiliza um fila de ganhos para ordenar as trocas de vértices entre as partições. Inicialmente para cada vértice $v$ é calculado o ganho - redução no corte - da troca de sua partição $P_{i}$ para outra partição $P_{j}$. Os valores de ganhos são inseridos em duas filas de prioridade, uma para cada partição. As filas são colocadas em ordem decrescente de acordo com o valor do ganho.

A cada etapa o primeiro vértice de cada fila de prioridade é retirado, e é realizada a troca de partições entre eles. Este procedimento garante que as partições continuarão balanceadas. Os vértices selecionados são marcados como movidos a fim de impedir que sejam analisados nas próximas etapas, e para cada vértice adjacente a eles o valor de ganho é recalculado. Para cada etapa é registrado o valor de corte. Por fim, ao realizar todas as trocadas, é verificado em que etapa $i$ o corte apresentou menor valor, e todas as trocas efetuadas após a etapa $i$ são desfeitas.

O algoritmo de Fiduccia-Mattheyses necessita que sejam criadas filas de prioridade para cada possível combinação de partições no grafo. Assim, para o particionamento de um grafo em $k$ partições são necessárias $k(k-1)$ filas, o que aumenta o custo computacional da fase de uncoarsening, tornando-o viável apenas para pequenos valores de $k$ Hendrickson e Leland (1993).

Karypis e Kumar propuseram uma simplificação do algoritmo de KL utilizando grau dos vértices para refinamento de $k$ partições Karypis e Kumar (1998). Para cada vértice $v$ de um grafo $G_{i}$ define-se como vizinhança (neighborhood) $N(v)$ a união das partições adjacentes a $v$. Caso $v$ seja adjacente somente a vértices na sua própria partição, então $N(v)=\emptyset$. $N(v)$ terá o tamanho máximo no caso em que $v$ for adjacente a pelo menos um vértice em cada uma da partições existentes.

O algoritmo proposto permite que um vértice de fronteira $v$, ou seja $N(v) \neq \emptyset$, seja movido para qualquer uma de suas partições adjacentes. Para isso são calculados os valores de ganho para cada possível mudança com base no peso das arestas existentes entre o vértice e as partições. Assim, o ganho da mudança do vértice $v$ para uma partição $b \in N(v)$, denominada de grau externo, é dado pela Equação 3.8

$$
E D[v]_{b}=\sum \operatorname{peso}(v, u) \mid P_{i}[u]=b
$$

na qual $P_{i}[u]$ representa a partição que contém o vértice $u$ na fase $i$. De maneira similar, a soma do peso das aresta entre $v$ e os vértices que estão na mesma partição que ele é 


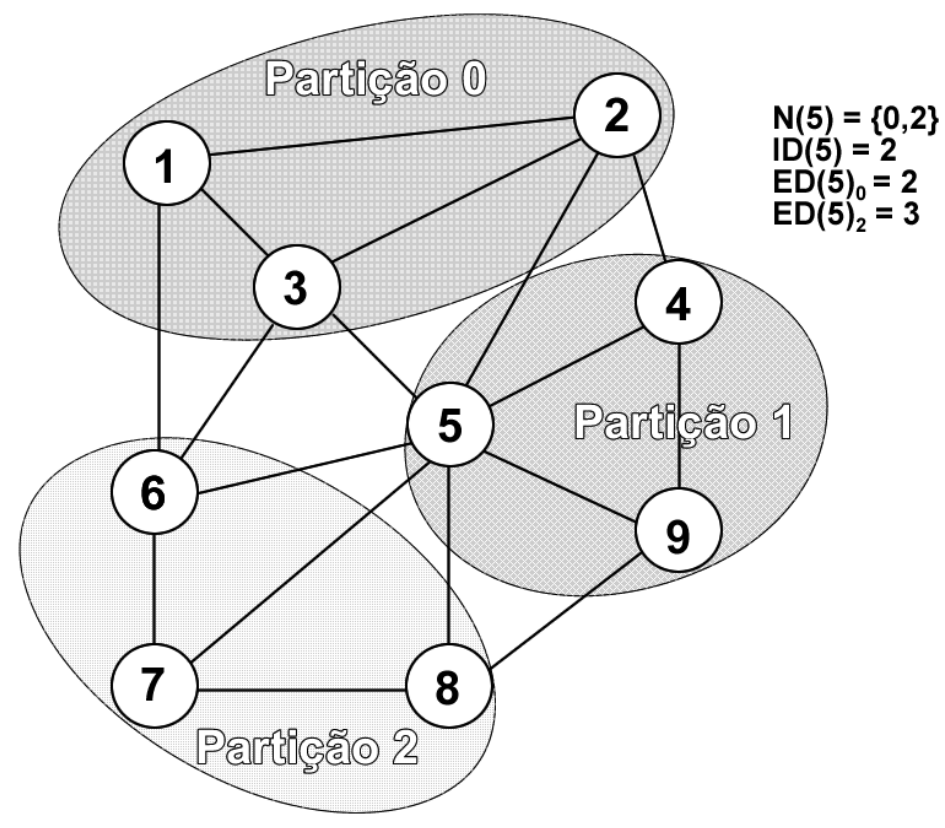

Figura 3.6: Exemplo de cálculo de graus internos e externos no algoritmo de refinamento Karypis e Kumar (1995a). Figura adaptada de Karypis e Kumar (1998).

dado por $I D[v]$, denominada de grau interno.

Na Figura 3.6 é ilustrado o procedimento de cálculo dos ganhos proposto por Karypis e Kumar (1995a). No exemplo, o vértice 5 é adjacente as partições 0 e 2 , assim $N[5]=\{0,2\}$. Dentro da sua própria partição, o vértice 5 é adjacente aos dois outros vértices, logo seu grau interno na partição é $I D[5]=2$. Os graus externos para as partições 0 e 2 são, respectivamente, $E D[5]_{0}=2$ e $E D[5]_{2}=3$.

Recentemente, Dhillon apresentou um algoritmo multinível baseado em funções kernel Dhillon et al. (2007). O algoritmo segue a estratégia multinível e utiliza, na fase de uncoarsening, o algoritmo kernel $k$-médias com funções objetivo equivalentes as funções NCorte, RCorte e KL Dhillon et al. (2004). Diferentemente dos algoritmos de KL, Fiduccia-Mattheyses e de Karypis, essa abordagem não mantém a restrição de gerar partições balanceadas.

\subsubsection{Implementações da estratégia multinível}

Os principais programas e pacotes que contém implementações da estratégia multinível encontrados na literatura são o Chaco, Chameleon, Jostle, Metis e SCOTH.

Chaco é um conjunto de algoritmos de particionamento de grafos implementados por Hendrickson e Leland Hendrickson e Leland (1994), dispondo de uma variedade de abordagens para tratar diferentes topologias nos grafos. O Cacho é disponibilizado sob a licença do Laboratório Nacional de Sandia, e pode ser obtido via Internet ${ }^{1}$. Na distribuição, é fornecido a documentação do software com um guia do usuário e os fontes implementados em linguagem $\mathrm{C}$.

Metis é um pacote de algoritmos multinível para o particionamento de grafos desenvol-

\footnotetext{
${ }^{1}$ http://www.sandia.gov/ bahendr/chaco.html
} 
vido por Karypis e Kumar Karypis e Kumar (1995a, 1998) na Universidade de Minnesota. O software encontra-se atualmente na versão 4.0, e está disponível na página dos autores ${ }^{2}$. Os algoritmos implementados no Metis constroem particionamento balanceados ou com o máximo de $5 \%$ de desbalanceamento, ou seja, as partições têm seu tamanho próximo a $|V| / k$, em que $|V|$ é a quantidade inicial de vértices, e $k$ é a quantidade de partições desejadas no grafo. Em sua composição, o Metis disponibiliza dois programas para particionamento multinível balanceado: pmetis e kmetis. O pmetis utilizado um algoritmo recursivo multinível de bissecção Karypis e Kumar (1995b) , enquanto o kmetis o $k$-particionamento multinível Karypis e Kumar (1998).

Jostle Walshaw e Cross (2007) é um pacote de algoritmos paralelizados para particionamento multinível de grafos desenvolvido na Universidade de Greenwich cuja primeira versão foi lançada em 1995. O software encontra-se na terceira versão atualmente e está disponível para fins acadêmicos.

SCOTH é um projeto desenvolvido no Laboratório de Pesquisa em Informática da Universidade de Bordeaux I (Laboratoire Bordelais de Reserche en Informatique ${ }^{3}$ ) que estuda aplicações da teoria dos grafos usando a abordagem dividir para conquistar Pellegrini e Roman (1996). O software contém diversas heurísticas para bi-particionamento de grafos, ordenação de matrizes esparsas e particionamento de hipergrafos. Atualmente na versão 5.0, o software pode ser obtido por licença de software livre GNU LGPL na internet.

\section{Chameleon}

Karypis desenvolveu em 1999 o algoritmo hierárquico Chameleon Karypis et al. (1999). O Chameleon modela os dados como um grafo esparso de $k$-vizinhos mais próximos. O procedimento de particionamento é dividido em duas fases: (i) O grafo é dividido em pequenos sub-grupos utilizando o algoritmo multinível do pacote Metis; (ii) São realizadas junções dos sub-grupos de acordo medidas de interconectividade a fim de formar os grupos reais .

Na Figura 3.7 é ilustrado o resultado do particionamento obtido pelo Chameleon para um conjunto de dados heterogêneo. Na figura, cada um dos onze grupos encontrados é representado por uma cor. É possível observar que o algoritmo detecta grupos de variadas formas e tamanhos.

\subsection{Validação}

A validação é um processo de avaliação quantitativa dos resultados obtidos por um algoritmo de agrupamento de dados Halkidi et al. (2001). Uma vez que nas tarefas de aprendizado não-supervisionado a informação de classe não está disponível inicialmente, a ratificação de consistência dos resultados requer avaliação baseada em algumas técnicas e critérios Dubes (1993); Rezaee et al. (1998). Os índices de validação encontrados na literatura são divididos em três grupos Theodoridis e Koutroumbas (1999): critérios externos, internos e relativos.

\footnotetext{
${ }^{2}$ http://glaros.dtc.umn.edu/gkhome/metis/metis/overview

${ }^{3}$ http://www.labri.fr/
} 


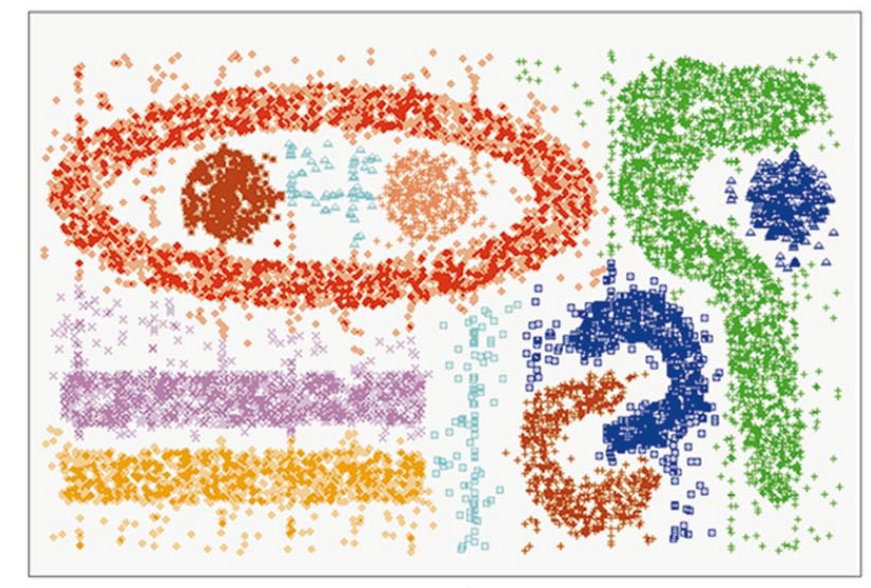

Figura 3.7: Exemplo de particionamento obtido pelo algoritmo Chameleon Karypis et al. (1999).

Critérios externos: nessa abordagem é testado se os dados do conjunto analisado são aleatoriamente estruturados ou não. A análise é baseada na Hipótese Nula $H_{0}$, comprovada por testes estatísticos.

Critérios internos: baseiam-se na matriz de similaridade para avaliar o quão ajustado o particionamento encontrado está. Nessa abordagem é necessário avaliar a quantidade real de partições, e quão altos ou baixos são os valores gerados pela análise Jain e Dubes (1988).

Critérios relativos: são utilizados para comparar os resultados obtidos por dois algoritmos diferentes, ou para calcular algum dos parâmetros de entrada utilizado pelo algoritmo, como a quantidade de agrupamentos.

Os critérios externos e internos são baseados em testes estatísticos e possuem como principal desvantagem o alto custo computacional para execução. Além disso, esses critérios tentam medir o quanto a solução encontrada aproxima-se de uma hipótese inicial especificada Halkidi et al. (2001). Por outro lado, os critérios relativos buscam validar a melhor solução que um algoritmo de agrupamento pode encontrar em determinada circunstância.

Na literatura é possível encontrar diversos índices de validação Rezaee et al. (1998); Theodoridis e Koutroumbas (1999); Halkidi et al. (2001). A seguir são comentados alguns dos mais utilizados.

Davies-Bouldin: índice interno utilizado inicialmente como critério de parada para o algoritmo de agrupamento de Jain e Dubes (1988). O índice pode ser calculado utilizando a Equação 3.9

$$
D B(k)=\frac{1}{k} \sum_{i}^{k} R_{i}, R_{i}=\max _{i=1, \ldots, k, i \neq j} R_{i j}, i=1, \ldots, k
$$

em que $R_{i j}$ é o maior valor de dissimilaridadade entre dois pares de grupos $i$ e $j$. Assim, quanto menor o valor de $D B(k)$ melhor é o particionamento encontrado. 
Contudo, caso o a quantidade de grupos seja igual a quantidade de elemento, $k=n$, o índice tem valor 0. Esse resultado significaria considerar cada elemento como um grupo isolado.

Jaccard: no índice de Jaccard Jaccard (1912) a semelhança entre as classes de um conjunto $X$ e os resultados de um agrupamento $Y$ é determinada pela quantidade de pares que possuam a mesma determinação em ambos os grupos, ou seja, se um par $(i, j) \in X_{v}$ então $(i, j)$ devem estar em um mesmo grupo de $Y$. O índice é calculado pela Equação 3.10:

$$
J(X, Y)=\frac{a}{a+b+c},
$$

em que a denota a quantidade de pares com o mesmo rótulo em $X$ que estão em um mesmo grupo em $Y, b$ determina a quantidade de pares que possuem o mesmo rótulo, mas foram colocados em grupos distintos no agrupamento, e $c$ indica os pares que possuem rótulos distintos, mas que foram colocados no mesmo grupo. Os resultados gerados pelo índice estão limitados ao intervalo $[0,1]$, assumindo o valor máximo quando $X$ e $Y$ são idênticos.

Rand: o índice de Rand Rand (1971) é semelhante ao índice de Jaccard, porém considera também os pares de vértices que possuem rótulos diferentes e que são colocados em grupos diferentes, representados pela variável $d$ na Equação 3.11

$$
R=\frac{a+d}{a+b+c+d}
$$

Rand Corrigido: o índice de Rand Corrigido, proposto por Hubert e Arabie (1985), é uma versão ajustada do índice de Rand Jain e Dubes (1988) para tratar casos de particionamentos gerados aleatoriamente. Esses casos, na versão original podem não assumir um valor constante igual a zero. O Rand Corrigido é baseado em uma generalização de uma distribuição aleatória, e é definido pela Equação 3.12

$$
\begin{aligned}
& C R=(A-B) /(C-D), \text { em que } \\
& A=\quad \sum_{i, j}\left(\begin{array}{c}
x_{i j} \\
2
\end{array}\right) \\
& B=\left[\sum_{i}\left(\begin{array}{c}
x_{i} \\
2
\end{array}\right) \sum_{i}\left(\begin{array}{c}
x_{j} \\
2
\end{array}\right) /\left(\begin{array}{l}
x \\
2
\end{array}\right)\right] \\
& C=\frac{1}{2}\left[\sum_{i}\left(\begin{array}{c}
x_{i} \\
2
\end{array}\right) \sum_{i}\left(\begin{array}{c}
x_{j} \\
2
\end{array}\right)\right] \\
& D=\left[\sum_{i}\left(\begin{array}{c}
x_{i} \\
2
\end{array}\right) \sum_{i}\left(\begin{array}{c}
x_{j} \\
2
\end{array}\right)\right] /\left(\begin{array}{l}
x \\
2
\end{array}\right)
\end{aligned}
$$

O índice de Rand Corrigido pode ser obtido utilizando uma transformação linear do índice de Rand, conforme definido na Equação 3.13

$$
C R=\frac{a-((a+b)(a+c) /(a+b+c+d))}{((a+b)(a+c) / 2)-((a+b)(a+c) /(a+b+c+d))}
$$


A fim de ilustrar a diferença de valores de avaliação gerados pelas três medidas apresentadas anteriormente, pode-se realizar uma comparação hipotética. Sejam $X=$ $[1,1,2,2,2,2,3,3,3,3]$ e $Y=[1,2,1,2,2,3,3,3,3,3]$ dois particionamentos distintos encontrados para um mesmo conjunto de dados, ou um grafo, e a Tabela 3.2 que relaciona os dois particionamentos encontrados. Utilizando os índices de Jaccard, Rand e Rand Corrigido resulta, respectivamente, nos valores $0,35,0,711$ e 0,313.

Tabela 3.2: Exemplo de representação entre dois particionamentos distintos. As linhas representam os grupos do particionamento $\mathrm{X}$ e as colunas representam os grupos do particionamento Y

\begin{tabular}{c|ccc|c}
$\mathrm{X} \mathrm{Y}$ & $Y_{1}$ & $Y_{2}$ & $Y_{3}$ & Total \\
\hline$X_{1}$ & 1 & 1 & 0 & 2 \\
$X_{2}$ & 1 & 2 & 1 & 4 \\
$X_{3}$ & 0 & 0 & 4 & 4 \\
\hline Total & 2 & 3 & 5 & 10
\end{tabular}

\subsection{Considerações Finais}

A teoria dos grafos é uma área de pesquisa ampla e com aplicações em diversos domínios. O problema de particionamento de grafos, por exemplo, têm diversas aplicações práticas: ordenação de matrizes, organização de circuitos eletrônicos, segmentação de imagens, entre outras. Nesse cenário, diversos algoritmos foram desenvolvidos ao longo do tempo a fim de produzir soluções interessantes para os domínios analisados.

Neste capítulo foi apresentada uma breve revisão bibliográfica os tópicos de particionamento de grafos mais relevantes ao presente trabalho. Foram discutidas as funções objetivos utilizadas para otimização nos algoritmos mais conhecidos foram descritas e duas classes de métodos de particionamento global: algoritmos hierárquicos e espectrais. Foram apresentados os conceitos acerca do particionamento multinível em grafos. A estratégia proposta por Hendrickson e Leland (1993) é bastante utilizada para particionamento de grafos com grande quantidade de vértices e arestas. Embora já tenham sido apresentados algoritmos com resultados interessantes, ainda há espaço para novas investigações e aplicações do método, como por exemplo o estudo recente sobre a utilização de funções de kernel na fase de refinamento Dhillon et al. (2007).

Nesse contexto, é apresentado no capítulo a seguir o método de detecção de comunidades proposto neste trabalho. Trata-se de uma implementação em conjunto do Algoritmo de Otimização de Modularidade (AOM) e da estratégia de particionamento multinível. O objetivo do estudo foi de viabilizar a utilização do AOM para a detecção de comunidade em redes com elevada quantidade de vértices e arestas mantendo o padrão de qualidade alcançado em redes menores.

No próximo capítulo também são apresentadas duas novas propostas de métodos de refinamento baseadas nas medidas de modularidade e de coeficiente de agrupamento. 



\section{Capítulo}

\section{O Algoritmo Multinível de Otimização de Modularidade para detecção de comunidades em redes complexas}

A diversidade de características nos conjuntos de dados cria dificuldades para que algoritmos de agrupamento e de particionamento de grafos sejam eficientes em todos os casos Karypis e Kumar (1998). A escolha do algoritmo apropriado para o particionamento de grafos depende do contexto da aplicação e envolve uma decisão entre a qualidade do resultado e o tempo de execução. Alguns algoritmos constroem soluções com alta qualidade, mas por outro lado possuem custo computacional elevado, o que restringe sua aplicação a casos de dimensionalidade não muito elevada. Existem também algoritmos de baixo custo computacional, mas que possuem limitações no tipo de solução gerada. Para os casos nos quais pequenos ganhos de qualidade sejam significativos, é interessante aplicar algoritmos capazes de produzir melhores resultados. Em casos nos quais o tempo de resposta é o fator determinante, os algoritmos mais rápidos são recomendados. Sendo assim, não existe um único algoritmo capaz de prover a melhor solução para todos os problemas.

Encontrar a solução ideal para o problema de particionamento em grafos é uma tarefa de custo computacional elevado e proibitiva para problemas com grande quantidade de vértices. Para esses casos, a alternativa é buscar por soluções aproximadas utilizando algum critério, ou heurística. Uma estratégia bastante conhecida é o particionamento multinível Hendrickson e Leland (1993) apresentada no Capítulo 3.2. Como discutido anteriormente, essa técnica é uma alternativa que viabiliza a utilização de algoritmos com alto custo computacional para o particionamento de grafos com elevada quantidade de vértices e arestas.

Nos últimos dez anos, uma nova área de pesquisa surgiu para análise de grafos com milhares ou milhões de vértices, conhecidos como redes complexas Watts (1999a); Barabási 
e Albert (1999); Newman (2003). Entre as características estudadas sobre as redes complexas, destaca-se a presença de grupos de vértices densamente conectados, chamados de comunidades. As investigações acerca de medidas e métodos a fim de encontrar comunidades têm despertado interesse de pesquisadores e trabalhos interessantes foram produzidos, como a medida de modularidade $Q$ Newman (2004a) e os algoritmos de otimização da modularidade Newman (2004c).

Neste trabalho é proposto o Algoritmo Multinível de Otimização de Modularidade (AMOM). Resumidamente, o algoritmo utiliza na fase de particionamento uma modificação do algoritmo AOM descrito na Seção 2.4 para obter um particionamento inicial de qualidade. Posteriormente, na fase de uncoarsening, as medidas de modularidade ou de coeficiente de agrupamento são utilizadas como critério de refinamento das soluções até se obter o resultado final sobre a rede original.

\subsection{Considerações iniciais}

O AMOM procura conciliar as vantagens do algoritmo de otimização da modularidade com capacidade da estratégia multinível de viabilizar o particionamento de grafos com grande quantidade de vértices. O algoritmo, seguindo a estratégia multinível, é composto de três fases:

(i) Coarsening: nessa fase a rede inicial é reduzida sucessivamente a redes menores até que seja obtida uma rede com tamanho aceitável e que preserve ao máximo as características da rede inicial.

(ii) Particionamento: obtendo uma representação reduzida e representativa da rede inicial, é realizado o particionamento em comunidades utilizando a heuristíca de otimização da modularidade modificado para tratar arestas com pesos.

(iii) Uncoarsening: o particionamento encontrado na fase anterior é reproduzido nos grafos intermediários gerados na fase de coarsening, e em cada fase é feito o refinamento da solução. Duas estratégias, baseadas na medida de modularidade (Refinamento por Otimização de Modularidade (ROM)) e no coeficiente de agrupamento (Refinamento por Otimização do Coeficiente de Agrupamento (ROCA)) são propostas neste capítulo.

No Algoritmo 4.1 é apresentada uma descrição em alto nível da seqüência de métodos utilizados pela estratégia multinível. O trecho entre as linhas 2 e 5 do algoritmo está relacionado com a fase de coarsening, e consiste basicamente de uma repetição de compactações do grafo original até alcançar um grafo com tamanho desejado. O critério de parada dessa fase é definido utilizando um parâmetro de configuração, comentado na próxima seção. Na linha 6 é feita a chamada da função de particionamento de fato, que é responsável por encontrar as partições sobre o grafo reduzido. Na fase de particionamento, é utilizado o AOM modificado.

Por fim, no trecho entre as linhas 7 e 11 é realizada a fase de uncoarsening. Na linhas 8, o grafo reduzido $G_{i}$ é expandido de maneira a formar o grafo que o gerou $G_{i}$. Na 
mesma linha, o particionamento da fase anterior $i$ é utilizado com solução inicial para fase $i-1$. Essa solução é passível de melhoramento utilizando algum critério de otimização. Na linha 9, o refinamento é feito utilizando um dos métodos de otimização proposto neste trabalho. O processo se encerra ao se obter o particionamento para o grafo inicial.

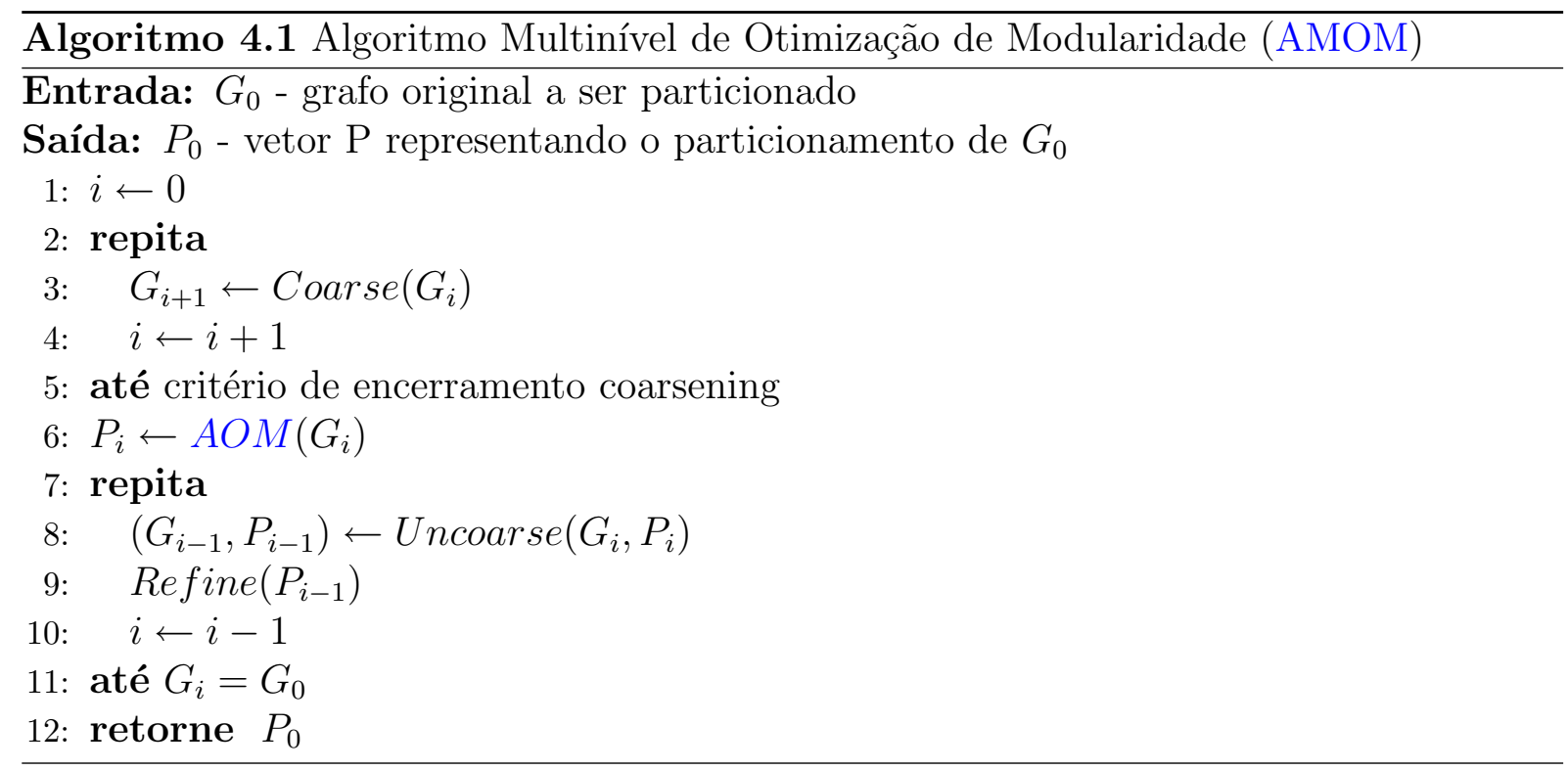

Os detalhes das fases que compõem o algoritmo são descritos com mais detalhes a seguir.

\subsection{Coarsening}

A fase de coarsening é baseada principalmente em contrações de arestas, e os conceitos relativos a essa fase são basicamente os apresentados na Seção 3.2.1. O algoritmo proposto utiliza nesta fase implementações dos métodos RM, HEM e MHEM.

Durante a fase de coarsening existem alguns parâmetros que precisam ser ajustados a fim de manter a eficiência dos métodos e produzir um grafo reduzido de boa qualidade e representativo do grafo inicial. Esses parâmetros são (i) CPC; (ii) Fator de Redução na fase de Coarsening (FRC); (iii) Peso Máximo do Super-Vértice (PMSV).

$\mathrm{O}$ CPC indica o momento em que a fase de coarsening deve ser encerrada. Esse critério pode ser definido de acordo com a quantidade absoluta de vértices ou com um percentual em relação ao grafo original.

O FRC limita o tamanho do matching em cada etapa da fase de coarsening. Quanto mais arestas forem selecionadas para o matching, maior será o FRC e por conseqüência, menor será o grafo reduzido. O valor máximo do FRC é de 50\%, quando o matching é máximo.

O PMSV define a quantidade máxima de vértices internos presentes em um supervértice. Esse parâmetro evita que seja gerado um desbalanceamento entre os pesos dos vértices e super-vértices ao longo das etapas da fase de coarsening.

No Algoritmo 4.2 é descrito em alto nível o procedimento para realização da fase de coarsening. Inicialmente, linha 1, o matching é selecionado utilizando um dos métodos implementados, RM, HEM, MHEM ou LEM. A seguir, a contração do grafo é de fato 
realizada. Na linha 3, é feita a contração de um par de vértices dando origem ao supervértice $S V$ que os representará no grafo reduzido. Em seguida é feita a verificação de vizinhos em comum dos vértices, ou seja, caso existam as arestas $(u, x)$ e $(v, x)$ no grafo $G_{i}$, a aresta representante em $G_{i+1}$ será $(S V, x)$. Nesses casos, o peso da aresta no grafo reduzido será igual a soma dos pesos do grafo gerador. Esse critério garante que o corte dos grafos reduzidos estejam condizentes com o grafo original.

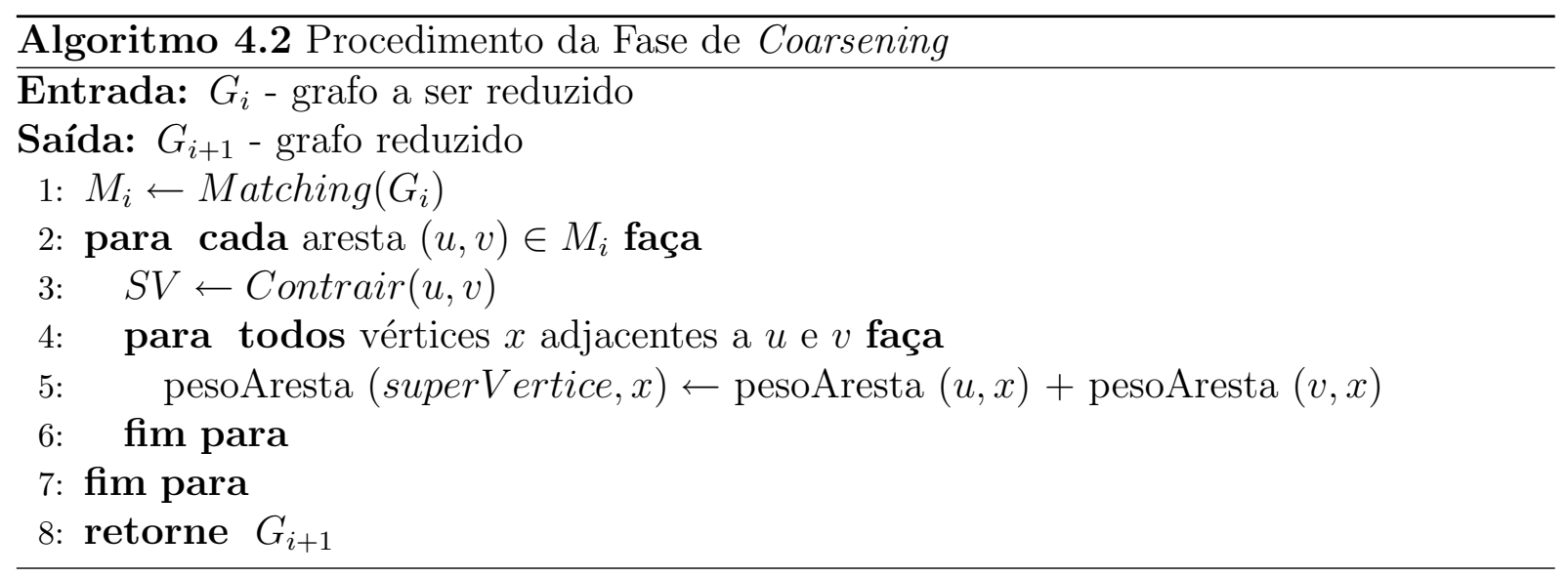

A complexidade de tempo dos métodos RM, HEM, MHEM ou LEM é da ordem de $O(m)$, ou seja, linear com a quantidade de arestas no grafo, conforme apresentado anteriormente na Seção 3.2.1. Seja $M_{i}$ o matching selecionado em um grafo $G_{i}$ da fase de coarsening, o tamanho máximo de $M_{i}$ é definido pela Equação 4.1

$$
\max \left|M_{i}\right|=\frac{\left|V_{i}\right|}{2}
$$

em que $\left|V_{i}\right|$ refere-se a quantidade de vértices do grafo $G_{i}$. Desta forma, a repetição contida entre as linhas 2 e 7 no Algoritmo 4.2 acontece no pior caso $\left|V_{i}\right| / 2$ vezes em cada etapa. Considerando que a cada etapa o matching é maximal, o fator de redução é de $50 \%$, assim a cada etapa a quantidade de vértice no grafo se reduz a metade.

Tendo um fator de redução de $50 \%$, o custo computacional do trecho de repetição do algoritmo após $t$ etapas é $\frac{\left|V_{0}\right|}{2}+\frac{\left|V_{1}\right|}{2}+\ldots+\frac{\left|V_{t}\right|}{2}=\sum_{i=1}^{t} \frac{n}{2^{i}}<n$, sendo $\left|V_{0}\right|=n$ e $\left|V_{i}\right|=2 *\left|V_{i+1}\right|$.

Adicionando o custo computacional do trecho de repetição ao custo do procedimento de matching, tem-se que o a complexidade de tempo do fase de coarsening é da ordem de $O(m+n / 2)$

\subsection{Particionamento}

Na fase de Particionamento é feita a aglomeração de fato dos vértices em grupos. Nessa fase uma gama de opções de algoritmos de particionamento de grafos pode ser utilizada já que se tem como parâmetro de entrada um grafo $G$ e deseja-se como saída um vetor $P$ representando o particionamento de $G$. Uma das vantagens da estratégia multinível é permitir que algoritmos mais custosos possam ser utilizados nessa fase, sem que seja gerado impacto significativo no desempenho geral. Isto se deve ao fato de que o grafo fornecido como entrada é uma representação reduzida do grafo original. Por exemplo, em 
alguns casos, o grafo reduzido pode ter menos de $30 \%$ da quantidade de vértices do grafo original.

Neste trabalho, o particionamento inicial é obtido utilizando uma versão modificada do algoritmo AOM descrito na Seção 2.4. A modificação proposta visa adicionar o tratamento de redes com pesos nas arestas. O cálculo da medida de modularidade Q, descrita na Equação 2.19, considera que todas as arestas possuem o mesmo peso, o que não é o caso do grafo utilizado na fase de particionamento. Assim, é necessário redefinir a medida $e_{p q}$ seguindo a Equação 4.2

$$
e_{p q}= \begin{cases}\frac{1}{p t} \sum_{i, j \in k_{p}}^{k_{p}} w_{i, j} & p=q \\ \frac{1}{2 p t} \sum_{i \in k_{p}, j \in k_{q}}^{k_{p}, k_{q}} w_{i, j} & p \neq q\end{cases}
$$

em que $w_{i j}$ representa o peso da aresta entre os vértices $i$ e $j$, e $p t=\sum_{i j}^{n} w_{i j}$ é o peso total da rede.

O AOM é um algoritmo de otimização guloso que realiza decisões locais para encontrar a solução final de particionamento. O critério utilizado para definir qual o par de comunidades será unido é o que provoca maior incremento no valor de modularidade. Assim, a cada passo a junção das duas comunidades que resultam no maior incremento na medida de modularidade é realizada, e o valor da medida atualizado. O AOM tem apresentado resultados qualitativos interessantes na área de detecção de comunidade e análise de redes sociais. Uma das característica que motivou a escolha foi a capacidade de inferir a quantidade de comunidades em uma rede, ou seja, sem precisar ter esse valor como entrada.

Na Figura 4.1 é apresentado um exemplo de execução do AOM. No gráfico é apresentada a variação do valor da modularidade $Q$ no particionamento da rede de Karate de Zachary. O valor máximo 0,38, representado pelo ponto em preto no gráfico, é obtido para a divisão da rede em duas comunidades.

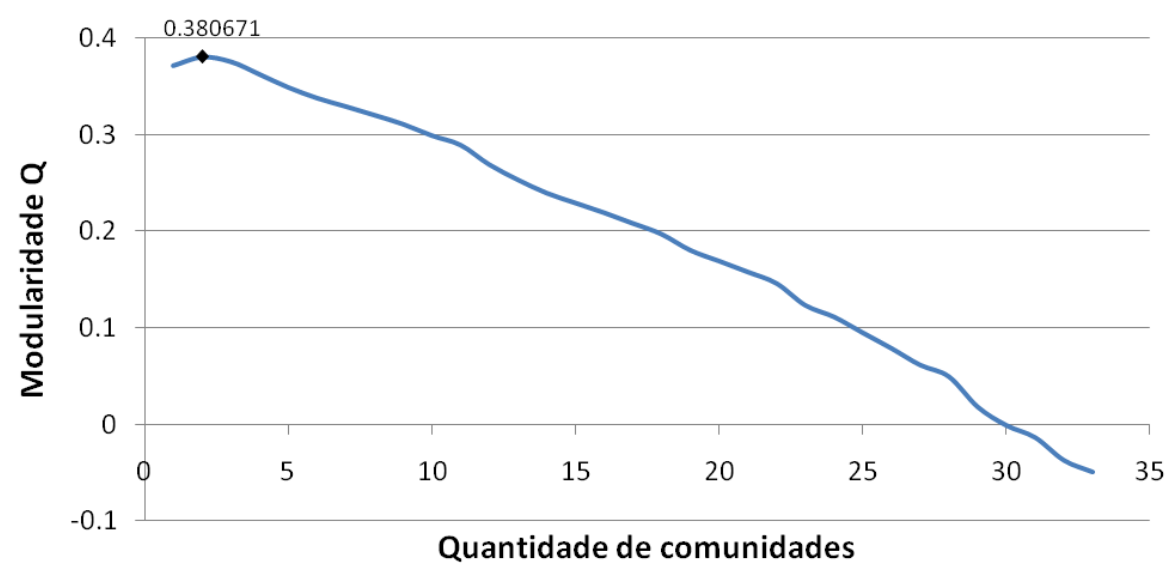

Figura 4.1: Variação da Modularidade Q na execução do algoritmo AOM na rede de Karate de Zachary. O ponto com maior modularidade ocorre quando a rede é dividida em duas comunidades.

Embora o AOM possibilite identificar o ponto de maior modularidade e utilize esse valor para definir o particionamento de uma rede, é possível obter o particionamento também nos outros pontos. Para isso, é necessário informar a quantidade de grupos 
desejada.

O particionamento obtido nessa fase serve como solução inicial para a fase seguinte, uncoarsening. Vale ressaltar que a solução encontrada nessa fase, em geral, possui uma boa qualidade. O grafo reduzido utilizado é composto predominantemente por super-vértices gerados na fase anterior. Utilizando os métodos RM ou HEM, obtém-se super-vértices formados por vértices que são mais similares e tende-se a manter no grafo as arestas ligando os vértices menos similares. Assim, a fase de particionamento está realizando o particionamento de um grafo composto de grupos de vértices similares.

\subsection{Uncoarsening}

$\mathrm{Na}$ fase de uncoarsening é feito o processo reverso ao efetuado na fase de coarsening. Os grafos reduzidos, construídos na primeira fase da estratégia, são agora expandidos até que se obtenha novamente o grafo original. A cada etapa o super-vértice $s V$ do grafo reduzido $G_{i+1}$ é separado em seus vértices de origem $u$ e $v$ no grafo $G_{i}$. As arestas que ligavam $s V$ aos demais vértices são distribuídas entre $u$ e $v$ mantendo a estrutura existente antes de redução feita na fase de coarsening. Essas condições garantem que a estrutura dos grafos é preservada, e que, ao final da fase de uncoarsening será obtido o grafo original.

A cada etapa da fase de uncoarsening o particionamento obtido na etapa anterior é projetado sobre o grafo expandido, ou seja, o particionamento $P_{i}$ é construído com base no particionamento $P_{i+1}$. O processo é repetido até que seja obtido o particionamento $P_{0}$ do grafo original. A cada etapa, os super-vértices são divididos e o grafo volta a ter os vértices que o formaram, assim é preciso definir a que partição esses vértices pertencem. Inicialmente, o vértices são colocados na mesma partição em que está o super-vértice que os representava. Assim, sendo o $s V \in G_{i+1}$ o super-vértice que representa os vértices $u, v \in G_{i}$, os vértices $u, v$ são colocados na mesma partição que $s V$, ou seja, $P_{i}(u)=$ $P_{i}(u)=P_{i+1}(s V)$.

Ao substituir os super-vértices pelos vértices que lhe deram origem incluindo-os no particionamento, é possível refinar a solução obtida realizando, por exemplo, mudanças de partição dos vértices recém rotulados.

Neste trabalho, a etapa de refinamento da fase de uncoarsening é realizada por um dos dois métodos de refinamento propostos: Refinamento por Otimização de Modularidade (ROM) e Refinamento por Otimização do Coeficiente de Agrupamento (ROCA). Os algoritmos propostos seguem o modelo utilizado por Karypis e Kumar (1998) descrito na Seção 3.2.3, entretanto, consideram como objetivo maximizar a medida modularidade Q ou o coeficiente de agrupamento, ao invés de buscar a redução do corte e aumento do balanceamento.

Em cada etapa da fase $i$ de uncoarsening é feita uma análise dos vértices $u, v \in G_{i}$ que substituíram os super-vértices $s V \in G_{i+1}$ a fim de verificar se $u$ e $v$ são vértices de fronteira, e portanto, candidatos a mudar de partição. Restringir a seleção apenas à vértices de fronteira acarreta em duas conseqüências diretas:

1. Redução na quantidade de vértices considerados para refinamento a cada fase; 
2. Garantir a convergência rápida do algoritmo de refinamento.

De fato, a verificação se um vértice é de fronteira é feita um vez durante a fase de particionamento, e na fase de uncoarsening é feita uma análise do super-vértice que os representava. Sendo $s V \in G_{i+1}$ o super-vértice representante de $u, v \in G_{i}$, então:

- Se $s v$ é um vértice interno, ou seja, todos seus vizinhos estão na mesma partição que a sua, então $u$ e $v$ também serão vértices internos;

- Se $s V$ não possui vizinhos em sua partição, então $u$ e $v$ serão considerados com vértices de fronteira;

- Para os outros casos, são analisados os vizinhos de $u$ e $v$ para verificar qual dos vértices é de fronteira.

\section{Refinamento por Otimização de Modularidade (ROM)}

No Algoritmo 4.3 é descrito em alto nível os passos seguidos pelo ROM utilizado na fase de uncoarsening da estratégia multinível. Inicialmente é calculado o ganho de modularidade de cada possível mudança de vértice de partição, linha 1. A seguir é selecionado a mudança que proporciona o maior ganho de modularidade e o vértice $v$ é movido para a partição $p$ de $P_{i}$, linhas 3 e 4 . Na linha 5 é efetuada a atualização dos ganhos para os vértices remanescente. A repetição é feita enquanto os ganhos são positivos.

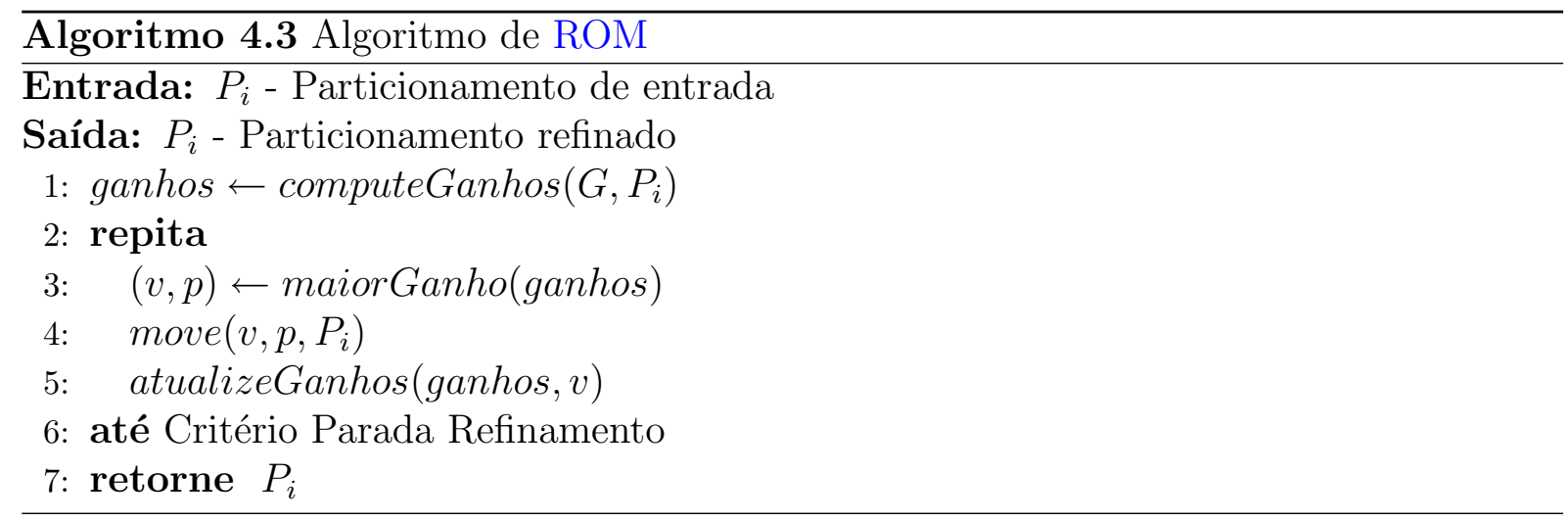

Devido a qualidade do particionamento inicial obtido na fase de particionamento, a convergência do algoritmo de refinamento é rápida. Outro fator que contribui para a eficiência do algoritmo é que apenas os vértices de fronteira são selecionados como candidatos a mudança.

\section{Refinamento por Otimização do Coeficiente de Agrupamento (ROCA)}

Similar ao ROM, o ROCA utiliza a medida de coeficiente de agrupamento, Equação 2.10, como critério de otimização durante o refinamento do particionamento. O objetivo do algoritmo é manter a maior quantidade possível de ciclos curtos de tamanho 3 dentro das partições. Considerando um vértice $u$ de fronteira, é calculado o coeficiente de agrupamento $C C_{u} P_{i}$ para cada partição que $u$ possa ser inserido e $u$ é inserido na partição que promover o maior valor de $C C_{u}$. Utilizando esse critério é possível mudar um vértice de partição mesmo que a mudança ocasione um aumento no corte. 
Na Figura 4.2 é ilustrado um exemplo de como é realizado o procedimento de refinamento do ROCA. O vértice $v$ está na fronteira entre os grupos 1 e 2 . Caso seja deslocado para o grupo 2, o corte do particionamento será reduzido a duas arestas, contudo dentro do grupo 2 não haverá nenhum ciclo mínimo contendo o vértice $v$. Movendo $v$ para o grupo 1 ocorre um aumento no corte para três arestas, mas o grupo 1 passará a conter um ciclo mínimo de $v$.

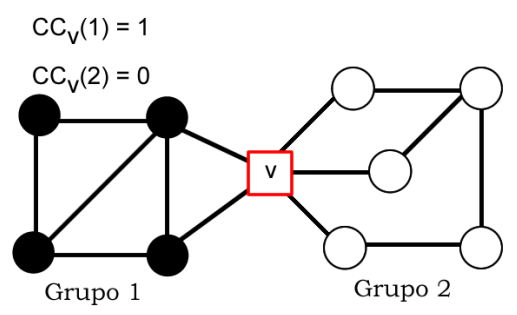

Figura 4.2: Exemplo do critério de escolha de partição pelo método baseado no coeficiente de agrupamento.

\subsection{Considerações finais}

Neste capítulo foi apresentado o algoritmo proposto para detecção de comunidades em redes complexas. No capítulo são utilizados conceitos apresentados nas seções anteriores como fundamentos para desenvolvimento do novo algoritmo. Conforme discutido anteriormente encontrar a solução ótima para o problema de particionamento é inviável quando o grafo analisado possui grande quantidade de vértices, e nesse cenário é que surgem diversas heurísticas para encontrar soluções aproximadas. A medida de modularidade é considerada adequada e relevante para deteç̧ão de comunidade, e os algoritmos que se baseiam na sua otimização têm produzido resultados com boa qualidade para diversas aplicações. Contudo, a complexidade de tempo dos algoritmos encontrados na literatura ainda condiciona o particionamento de grafos muito grandes à utilização de alguma outra estratégia, como o particionamento multinível.

O algoritmo desenvolvido é composto por três fases: na primeira, a rede inicial é sucessivamente contraída até formar uma rede pequena o suficiente para ser particionada; na segunda, a rede reduzida é particionada utilizando o algoritmo de otimização da modularidade; na terceira, o particionamento é aplicado sobre cada grafo intermediário, e a solução parcial é refinada, até que se retorne a rede original.

Neste capítulo foi apresentada também uma análise da complexidade de tempo computacional do algoritmo proposto. Foi mostrado que, assim como os demais algoritmos encontrados na literatura que utilizam a estratégia multinível, este algoritmo mantém a complexidade na ordem de $O(m)$, em que $m$ é a quantidade de arestas da rede inicial. Além disso, como a rede reduzida é gerada a fim de ser uma boa representação da rede inicial, o primeiro particionamento gerado é uma solução com boa qualidade, auxiliando que a etapa de refinamento convirja rapidamente. O Capítulo 5 apresenta os resultados 
obtidos pelo algoritmo proposto em algumas redes reais utilizadas como benchmark para os algoritmos de particionamento de grafos. É apresentada também uma comparação com alguns dos principais algoritmos encontrados na literatura. 



\section{Experimentos}

Nos Capítulos 2 e 3 foram apresentadas as revisões bibliográficas sobre redes complexas e particionamento em grafos. No Capítulo 4 foi apresentado e detalhado o Algoritmo Multinível de Otimização de Modularidade (AMOM) proposto resultado do estudo de integração do AOM com a estratégia multinível. Neste capítulo são detalhados os experimentos realizados para avaliar a performance do AMOM com base nas análises de escalabilidade e de qualidade dos resultados. Os experimentos foram realizados utilizando redes que fazem parte de conjuntos de dados conhecidos na literatura, e que são utilizados como benchmark para algoritmos de particionamento.

\subsection{Conjunto de dados}

Na Tabela 5.1 é apresentada uma descrição contendo nome, fonte, quantidade de vértices e de arestas das redes utilizadas nos experimentos realizados neste trabalho. Tratam-se de redes com as mais variadas características e utilizadas em diferentes domínios.

Tabela 5.1: Tabela descritiva das redes utilizadas nas avaliações.

\begin{tabular}{c|c|c|c}
\hline redes & fonte & $n$ & $m$ \\
\hline \hline cbr-ilp-ir & própria & 574 & 19213 \\
\hline netscience & & 1589 & 2742 \\
cond2003 & Newman & 31163 & 120029 \\
cond2005 & & 40421 & 175691 \\
\hline add20 & & 2395 & 7462 \\
add32 & & 4960 & 9462 \\
crack & & 10240 & 30380 \\
4elt & Walshaw & 15606 & 45878 \\
t60k & & 60005 & 89440 \\
finan512 & & 74752 & 261120 \\
144 & & 144649 & 1074393 \\
\hline
\end{tabular}

A rede $c b r$-ilp-ir foi construída a partir de um corpus com 574 artigos científicos das 
áreas de Raciocínio Baseado em Casos (Cased Based Reasoning), Programação Lógica Indutiva (Inductive Logic Programming) e Recuperação de Informação (Information Retrieval). Os arquivos, em formato de texto plano, foram pré-processados utilizando a ferramenta Projection Explorer (PEx) Paulovich et al. (2007) e a similaridade entre os documentos foi calculada utilizando a função de cosseno. Foi aplicado um threshold de 0,15, assim similaridades abaixo desse valor foram desconsideradas. Mais detalhes sobre a construção dessa rede de similaridade podem ser encontrados na referência Mota et al. (2008).

As redes netscience, cond2003 e cond2005 foram obtidas da página do professor Newman $^{1}$. A rede netscience Newman (2006), ilustrada na Figura 5.1. Cond2003 e cond2005 Newman (2001) são redes de coautoria entre cientistas do arquivo de artigos entre os anos de 1999 e 2003, e 1999 e 2005, respectivamente.

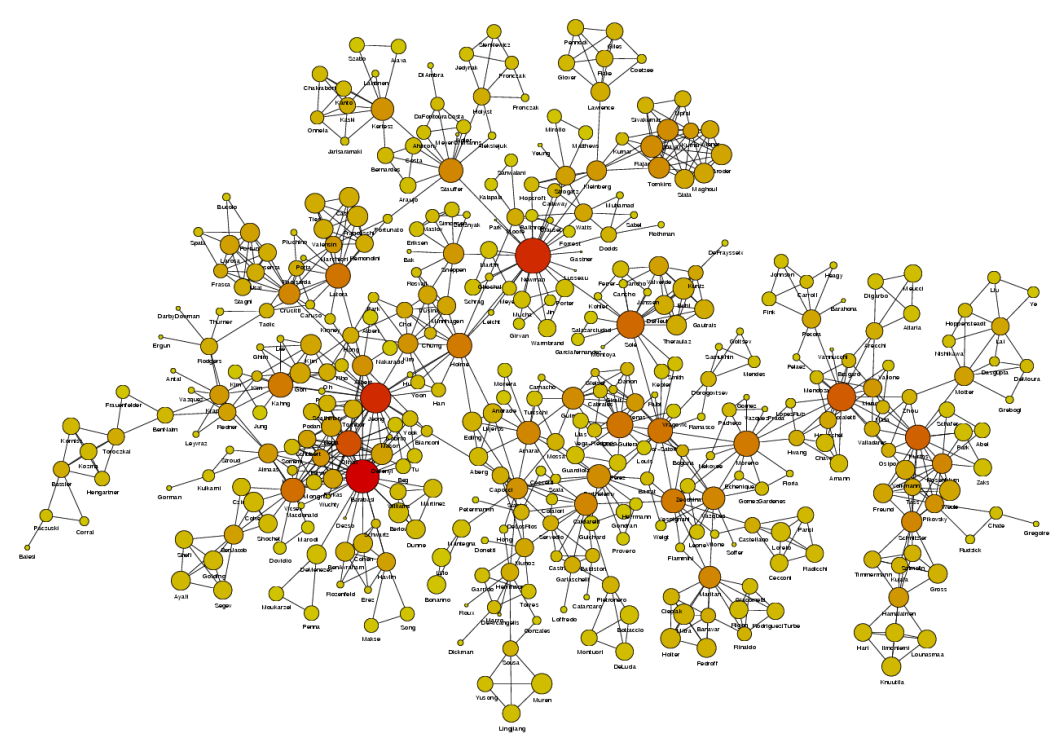

Figura 5.1: Visualização da rede netScience

Os grafos add20, add32, crack, 4elt, t60k, finan512 e 144 fazem parte do conjunto de dados utilizado como benchmark para algoritmos de particionamento disponível na página do professor Chris Walshaw da Universidade de Greenwich² . O conjunto disponibilizado possui exemplos de diversas aplicações do particionamento de grafos, bem como os algoritmos que obtiveram os melhores resultados de particionamento Soper et al. (2004).

Em grafos com a quantidade de vértices e arestas não muito grandes, é possível construir uma visualização em duas dimensões que permite observar e avaliar os resultados de um algoritmo de particionamento. Para alguns das redes estudadas, foi possível gerar tal visualização utilizando a ferramenta Prefuse Heer et al. (2005), sendo, portanto, outro critério de avaliação. Para as redes em que o número de vértices torna a visualização confusa, optou-se por gerar uma visualização das matrizes de adjacência. Essa visualização é feita organizando as linhas e colunas da matriz com base nas comunidades encontradas. Por exemplo, considere que em uma rede com 20 vértices foram encontradas 4 comunidades com 5 vértices cada. Assim, constrói-se a matriz de adjacência com 4 blocos.

\footnotetext{
${ }^{1}$ http://www-personal.umich.edu/ ${ }^{\sim}$ mejn/netdata/

${ }^{2}$ http://staffweb.cms.gre.ac.uk/ ${ }^{\sim}$ wc06/partition
} 
Tabela 5.2: Exemplo da visualização de matriz de adjacência para análise de particionamento

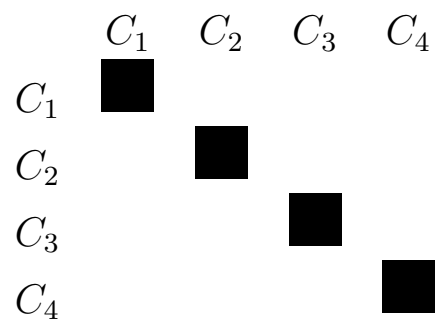

\subsection{Avaliação de escalabilidade}

A medição de tempos absolutos de execução de algoritmos, embora sirva de parâmetro para comparação, está sujeita a interferência de fatores externos como configuração de hardware, sistemas operacionais e a linguagem de programação em que foi implementado. A fim de reduzir a influência desses fatores, as medições consideradas neste trabalho foram feitas em iguais condições para os algoritmos e os valores apresentados são médias de 30 repetições realizadas. Os tempos foram medidos em milisegundos em uma máquina com processador Core 2 Duo com 3Gb de memória. As implementações foram feitas em linguagem de programação Java.

Inicialmente foi feita uma verificação do tempo de execução do AOM e do AMOM no conjunto de grafos de Walshaw. Na Figura 5.2 são apresentados os gráficos do tempo de execução em função da quantidade de vértices e de arestas. Nos gráficos é feita a comparação entre o AOM e o AMOM utilizando os métodos RM, HEM e MHEM na fase de coarsening. Nesse experimento, o AMOM foi configurado para encerrar a fase de coarsening ao atingir 30\% do tamanho do grafo inicial, e o refinamento na fase de uncoarsening foi realizado utilizando o ROM. Pode-se observar que o crescimento do tempo de execução do AOM em ambos os gráficos é mais acentuado do que os demais métodos. O tempo de execução dos métodos RM, HEM e MHEM estiveram bem próximos, exceto no último ponto no qual o RM obteve uma leve alta.

Os algoritmos baseados na estratégia multinível, em geral, possuem um parâmetro de ajuste que determina a transição da fase de coarsening para fase de particionamento. No AMOM esse parâmetro é denominado Critério de Parada da fase de Coarsening (CPC) e pode ser ajustado para um valor absoluto ou para um percentual relativo ao tamanho da rede inicial. A variação no valor do $\mathrm{CPC}$ influencia diretamente no tempo de execução do AMOM. Percentuais mais altos definem uma fase coarsening mais curta e uma fase de particionamento com um grafo pouco compactado.

Um avaliação realizada foi a do impacto do CPC nos métodos utilizados na fase de coarsening. Os gráficos na Figura 5.3 (a) e (b) apresentam a variação do tempo de execução dos métodos RM, HEM e MHEM em função dos valores relativos de CPC nas redes add32 e 4elt. Conforme esperado, os tempos de execução crescem de acordo com o aumento do percentual da rede utilizado na fase de particionamento em relação a rede inicial.

Na Figura 5.4 é apresentado um gráfico da variação dos tempos de execução de cada fase do AMOM em função do valor relativo definido para o CPC. O algoritmo foi configu- 


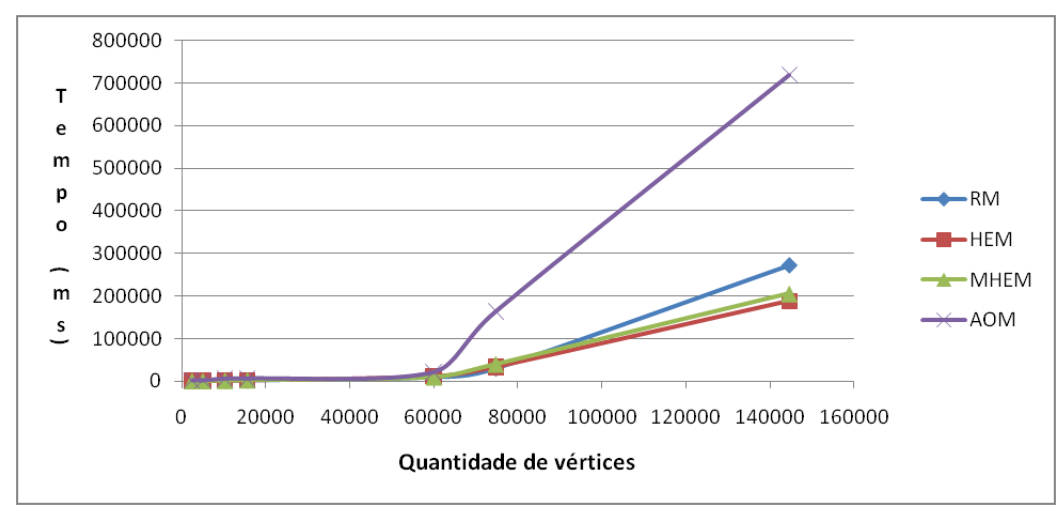

(a) Variação por quantidade de vértices

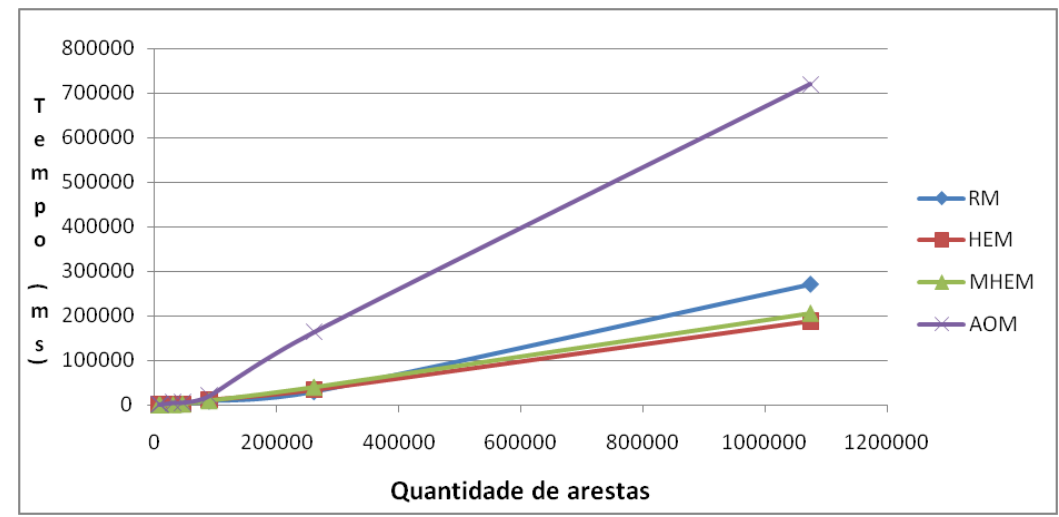

(b) Variação por quantidade de arestas

Figura 5.2: Gráfico da variação do tempo de execução em função da quantidade de vértices e arestas

rado para utilizar o método HEM na fase de coarsening e realizar a fase de uncoarsening sem refinamento. Em (a) o gráfico é referente a avaliação da rede add-20, enquanto que em (b) a rede avaliada foi a crack. Pode-se observar que à medida que o valor relativo aumenta, os tempos de execução da fases de coarsening e uncoarsening são reduzidos, em contrapartida o tempo da fase de particionamento cresce, assim como o tempo total para realização do particionamento, o qual é dado pela somatório dos tempos em cada fase.

\subsection{Avaliação qualitativa}

O objetivo dos experimentos realizados nessa seção é avaliar a qualidade dos resultados obtidos pelo AMOM. A avaliação foi feita considerando as medidas de modularidade e corte obtida pelo algoritmo nos casos analisados. Além da análise das medidas objetivas, foram realizadas também comparações com outros algoritmos.

\section{Avaliação qualitativa do Critério de Parada da fase de Coarsening (CPC)}

Como mostrado anteriormente, o CPC interfere diretamente no tempo de execução do AMOM. Definir um valor baixo para CPC de maneira a reduzir tempo de execução pode comprometer a qualidade do particionamento gerado. Assim, é necessário verificar o comportamento de ambos requisitos em função do valor de CPC.

Na Figura 5.5 são apresentados os gráficos de variação do tempo e da medida de modularidade $Q$ em função dos valores relativos de CPC. Nos gráficos, a escala do eixo 


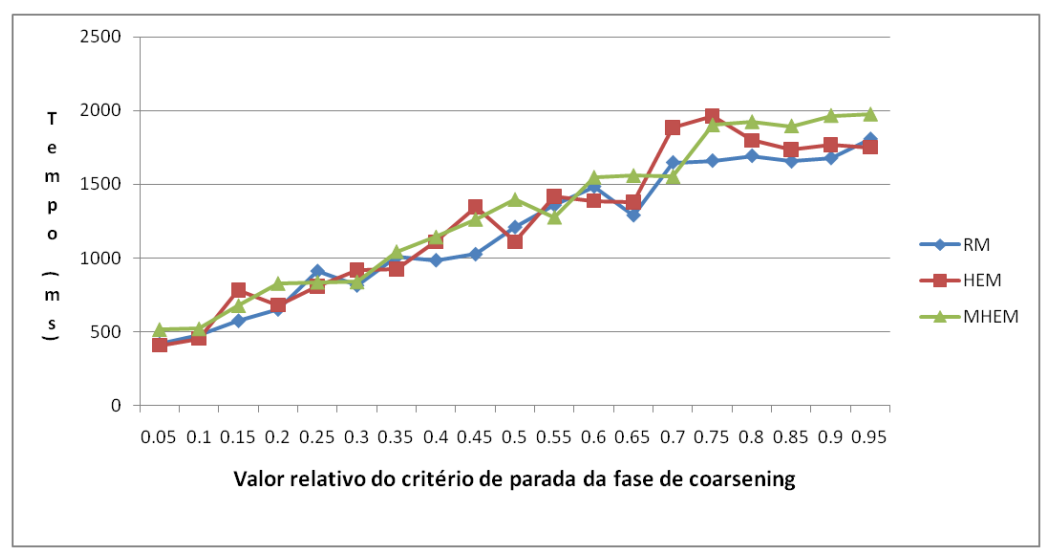

(a) Add32

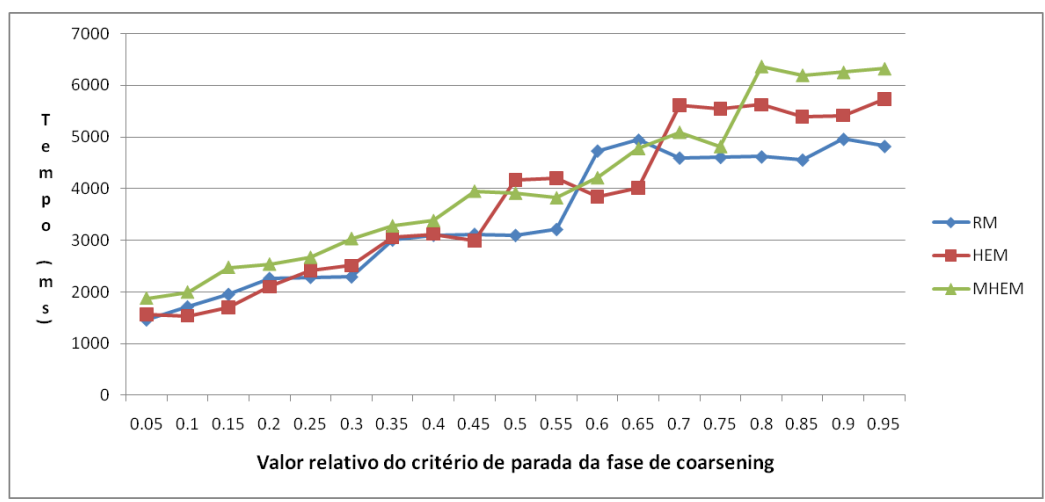

(b) 4elt

Figura 5.3: Gráfico da variação do tempo de execução em função do método escolhido na fase de coarsening

vertical esquerdo refere-se a medida de tempo, enquanto que a escala do eixo vertical direito refere-se a medida de modularidade. Pode-se observar que em ambos os gráficos, a variação da média de modularidade entre o valor do CPC a $5 \%$ e $95 \%$ é pequena, sendo de 0,06 para a rede add20 e 0,05 para a rede crack.

A variação da modularidade nas repetições da execução também se mostrou pequena. Na Figura 5.6 são apresentados os gráficos com a média e desvio padrão da medida de modularidade nas redes add20 e crack.

\section{Avaliação qualitativa dos métodos de refinamento}

No Seção 4.4 do Capítulo 4 foram apresentados dois métodos de refinamento para serem utilizados na fase de uncoarsening do AMOM. O método ROM utiliza o ganho de modularidade Q como critério para realizar mudanças de partições entre os vértices, enquanto que o ROCA visa maximizar a quantidade de ciclos curtos dentro das partições.

Com o intuito de avaliar a eficiência dos métodos foi realizado um comparativo entre a modularidade média obtida pelo AMOM utilizando o ROM, ROCA e sem utilizar o refinamento $\left(\mathrm{AMOM}^{*}\right)$. Em todas as três configurações, o AMOM utilizou o HEM na fase de coarsening e o CPC com valor relativo de $30 \%$. Na avaliação também foi incluído o valor de modularidade obtido pelo AOM.

Para as redes netscience e cond2005 o maior valor de modularidade foi obtido pelo AOM, enquanto que na rede cond2003 o maior valor pertenceu ao AMOM utilizado o mé- 


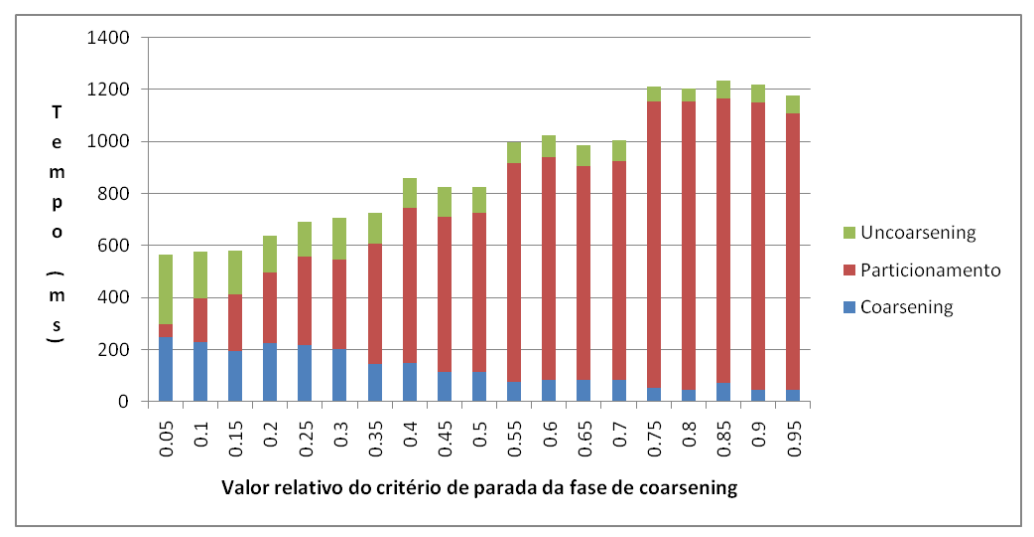

(a) $\operatorname{Add} 20$

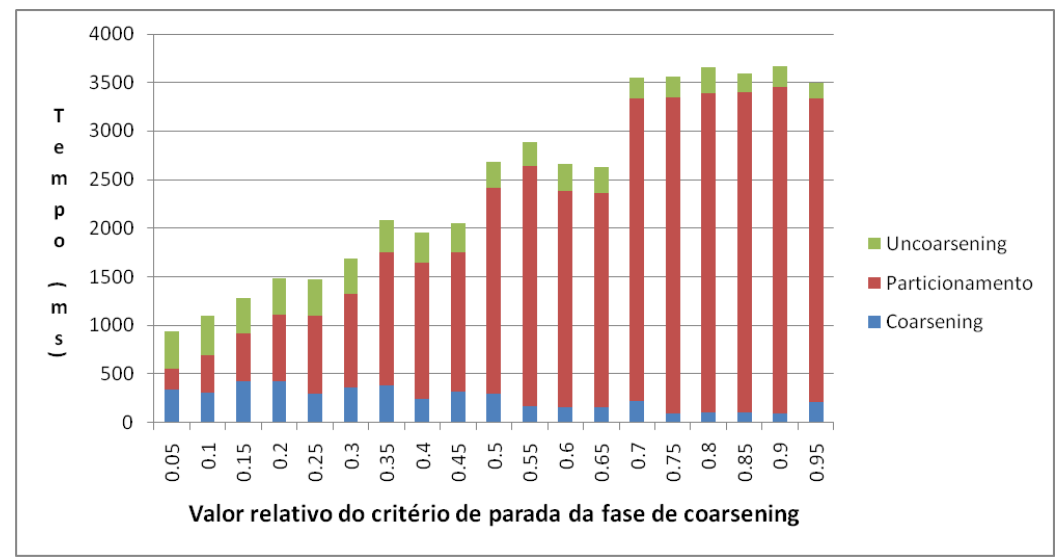

(b) Crack

Figura 5.4: Gráfico da variação do tempo de execução em função do Critério de Parada da fase de Coarsening (CPC)

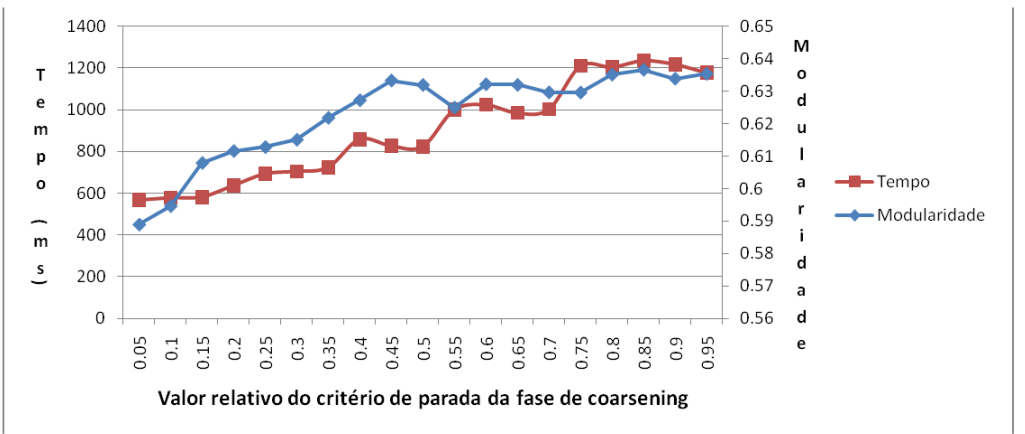

(a) Add20

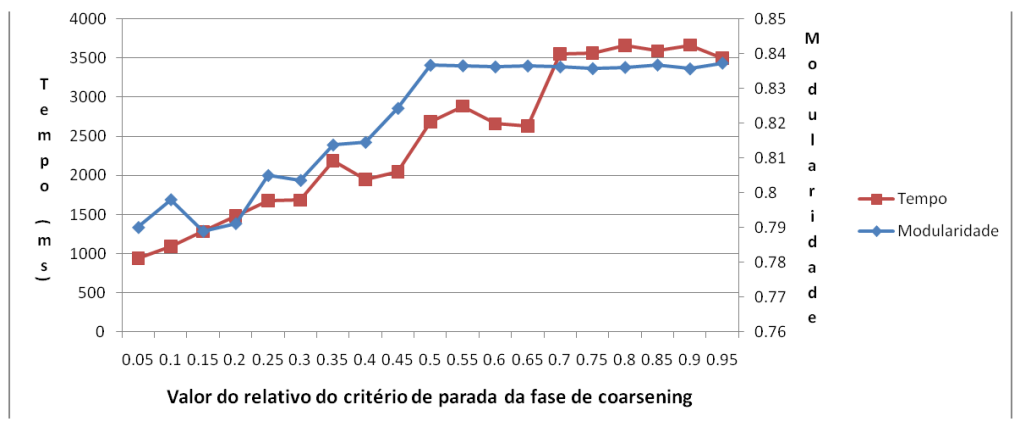

(b) Crack

Figura 5.5: Gráfico da variação do tempo de execução em função do Critério de Parada da fase de Coarsening (CPC) 


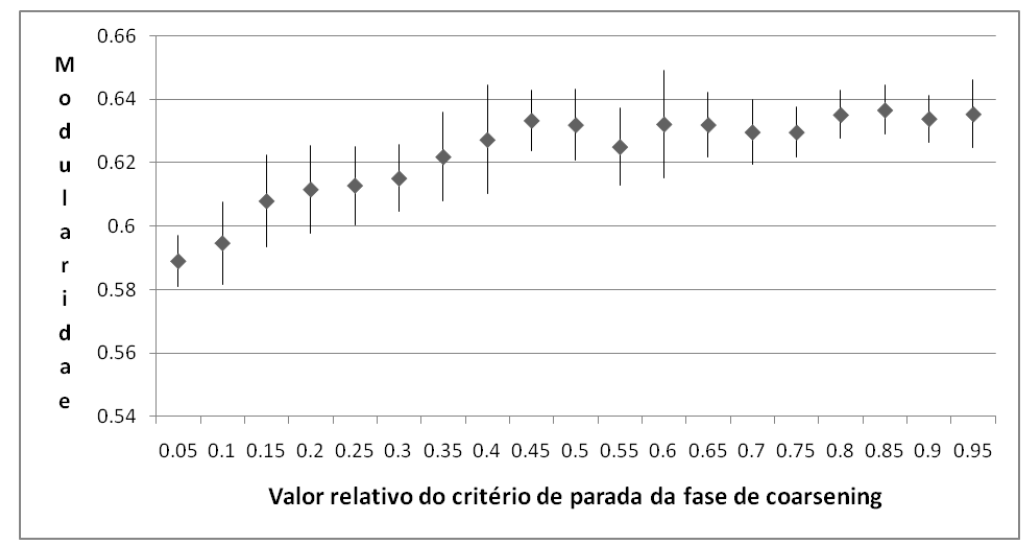

(a) Add20

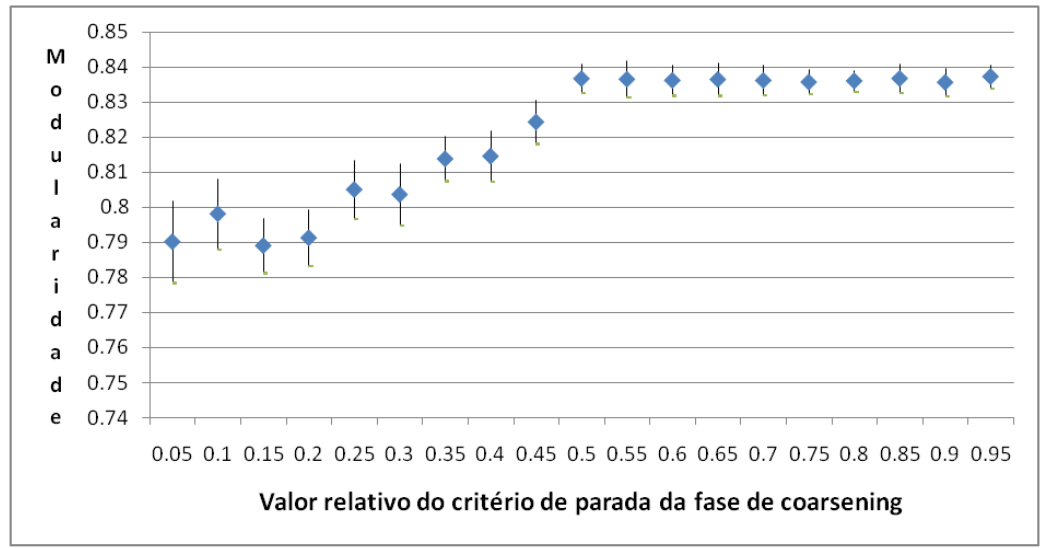

(b) Crack

Figura 5.6: Gráfico da média e desvio padrão da modularidade em função do Critério de Parada da fase de Coarsening (CPC)

Tabela 5.3: Tabela comparativa entre os valores de modularidade obtidos pelo AOM e AMOM.

\begin{tabular}{c|c|c} 
Rede & Algoritmo & $\mathrm{Q}$ \\
\hline \hline \multirow{4}{*}{ netscience } & AOM & $\mathbf{0 , 9 4 3}$ \\
& AMOM* & 0,791 \\
& AMOM (ROM) & 0,814 \\
& AMOM (ROCA) & 0,835 \\
\hline \multirow{4}{*}{ cond2003 } & AOM & 0,703 \\
& AMOM* & 0,697 \\
& AMOM ( ROM) & $\mathbf{0 , 7 1 3}$ \\
& AMOM ( ROCA) & 0,692 \\
\hline \multirow{4}{*}{ cond2005 } & AOM & $\mathbf{0 , 7 4 6}$ \\
& AMOM* & 0,673 \\
& AMOM ( ROM) & 0,678 \\
& AMOM (ROCA) & 0,664 \\
\hline
\end{tabular}

todo ROM. Pode-ser observar na tabela que para todas as redes a utilização dos métodos de refinamento refletiram em um aumento da medida de modularidade em comparação com a realização sem refinamento.

Além da comparação absoluta dos valores de modularidade, foi realizado um comparativo entre as comunidades encontradas pelo AMOM utilizando como padrão de referência o resultado obtido pelo AOM. O comparativo foi feito utilizando os índices de validação 
Jaccard, Rand e Rand Corrigido, apresentados na Seção 3.3 do Capítulo 3, e os resultados são apresentados na Tabela 5.4.

A configuração do AMOM utilizando o ROM alcançou os melhores índices validação para todas redes, exceto o índice de Rand na rede netscience cujo melhor índice foi obtido pelo ROCA. Entretanto, para todas as três redes, os índices obtidos pelo AMOM possuem valores baixos, o que indica que os grupos encontrados não se assemelham aos encontrados pelo AOM.

Tabela 5.4: Tabela comparativa entre valores dos índices de validação dos particionamentos gerados pelo AMOM em comparação com o AOM.

\begin{tabular}{c|c|c|c|c} 
Rede & Algoritmo & Jaccard & Rand & Rand Corrigido \\
\hline \hline \multirow{3}{*}{ netscience } & AMOM* & 0,106 & 0,847 & 0,161 \\
& AMOM (ROM) & $\mathbf{0 , 1 6 7}$ & 0,903 & $\mathbf{0 , 2 6 0}$ \\
& AMOM (ROCA) & 0,161 & $\mathbf{0 , 9 0 4}$ & 0,252 \\
\hline \multirow{3}{*}{ cond2003 } & AMOM* & 0,14 & 0,810 & 0,167 \\
& AMOM ( ROM) & $\mathbf{0 , 1 6 3}$ & $\mathbf{0 , 8 2 2}$ & $\mathbf{0 , 1 9 3}$ \\
& AMOM ( ROCA) & 0,1544 & 0,813 & 0,176 \\
\hline \multirow{3}{*}{ cond2005 } & AMOM* & 0,230 & 0,798 & 0,296 \\
& AMOM ( ROM) & $\mathbf{0 , 2 6 5}$ & $\mathbf{0 , 8 2 9}$ & $\mathbf{0 , 3 2 7}$ \\
& AMOM ( ROCA) & 0,253 & 0,817 & 0,315 \\
\hline
\end{tabular}

Na Figura 5.7 são apresentadas, com intuito de ilustração, as comunidades encontradas pelo AMOM utilizando os métodos HEM e ROM nas redes netscience e cbr-ilp-ir. Nas figuras as cores do vértices indicam as diferentes comunidades encontradas pelo algoritmo, e a separação espacial dos vértices foi gerada utilizando a ferramenta de visualização Prefuse Heer et al. (2005). A rede netscience é menos densa que a crb-ilp-ir, de modo que na primeira fica mais claro identificar as 7 comunidades encontradas pelo AMOM. Já para a rede $c b r$-ilp-ir o algoritmo encontrou 3 comunidades. Pode-se observar que as comunidades encontradas coincidem que a disposição espacial gerada pela visualização do Prefuse, ou seja, os grupos estão bem definidos, e possuem pouca sobreposição entre si.

\section{Comparativo com outros algoritmos multinível}

Os grafos disponibilizados por Walshaw são utilizados como benchmark pelos algoritmos de particionamento de grafos. A comparação dos algoritmos é feita com base no valor de corte obtido por eles para particionamentos dos grafos em determinadas quantidades de grupos. Outro critério utilizado é o fator de balanceamento das partições. Os resultados são separados para comparação de acordo com o percentual de balanceamento, ou seja, algoritmo que geram resultados com até $1 \%$ de desbalanceamento são comparados entre si no mesmo grupo, enquanto os que geram até 3\% são comparados em outro grupo. Esse critério é um requisito importante em aplicações como balanceamento de carga entre processadores, tráfego em redes e circuitos.

Na tabela 5.5 é apresenta uma comparação entre os valores de corte obtido pelo AMOM em comparação com outros algoritmos que seguem a estratégia multinível. A comparação inclui o valor de corte do algoritmo que obteve melhor resultado, obtido na página de Walshaw, para cada rede analisada, resultado que é destacado na primeira linha de cada 


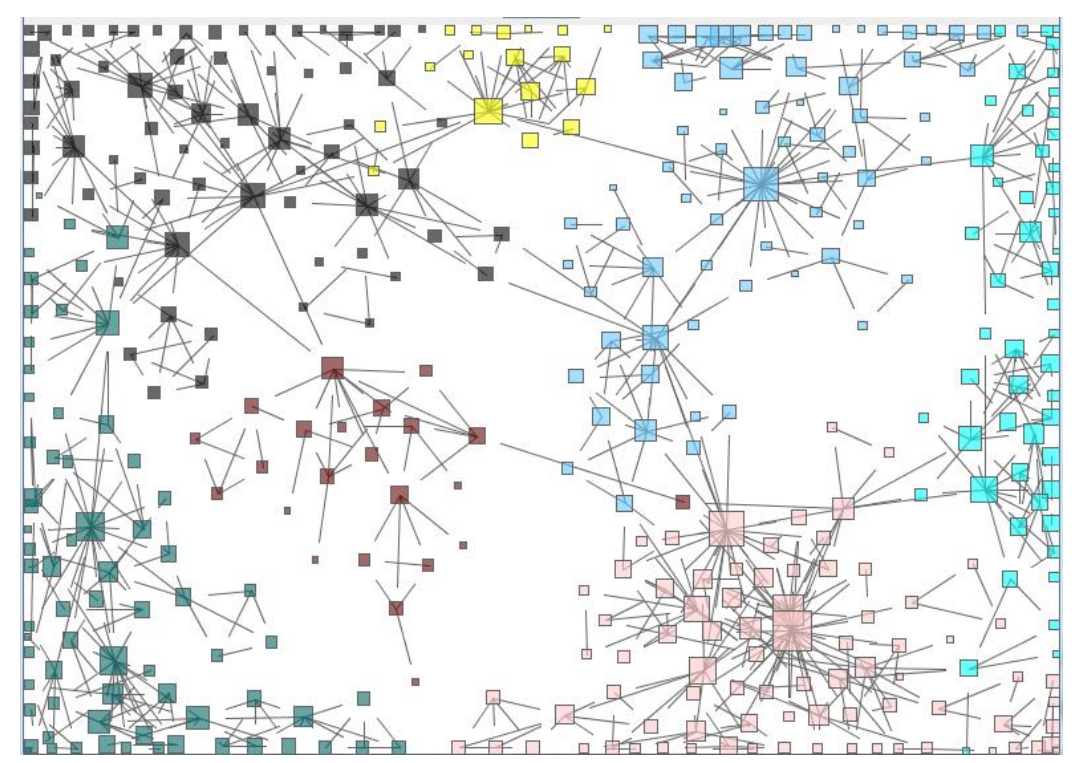

(a) Netscience

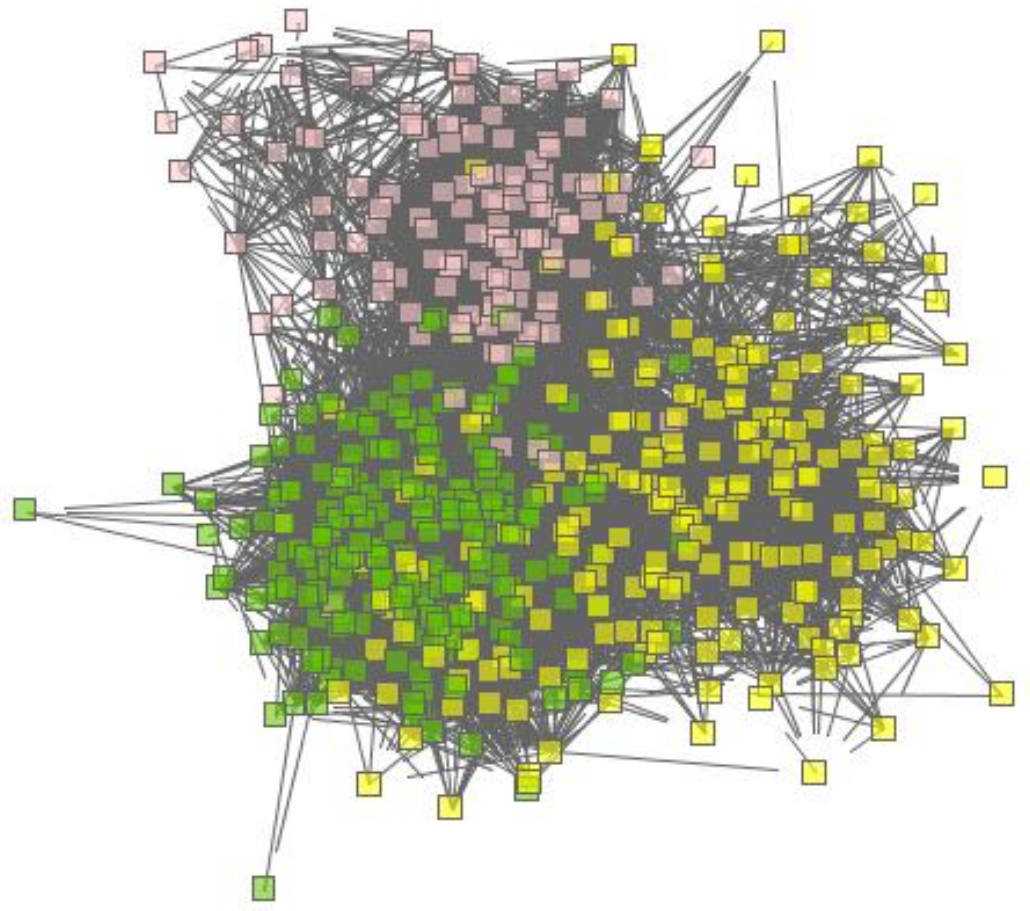

(b) Cbr-ilp-ir

Figura 5.7: Visualização das comunidades geradas pelo AMOM para as redes netscience e $c b r-i l p-i r$.

rede. A comparação também inclui o resultados obtidos pelo Metis Karypis e Kumar (1998) com a configuração padrão.

Para todas as redes analisadas, exceto a finan512, o melhor resultado de corte foi obtido pelo algoritmo Jostle Walshaw e Cross (2007) ou por sua versão comercial Jostle*. Na rede finan512 o menor valor de corte foi obtido pelo Chaco Hendrickson e Leland (1994). Na rede add32 o menor valor de corte para o particionamento em 64 grupos foi obtido pelo Metis.

Embora os resultados de corte obtidos pelo AMOM para todas as redes, exceto a finan512, tenham sido inferiores aos outros dois algoritmos não se pode realizar uma 
Tabela 5.5: Tabela comparativa entre os valores de corte obtido pelos algoritmos no particionamento dos grafos em 16, 32 e 64 grupos.

\begin{tabular}{c|c|c|c|c}
\hline \multirow{2}{*}{ grafos } & \multirow{2}{*}{ Algoritmo } & \multicolumn{3}{|c}{ Corte } \\
\cline { 3 - 5 } & & $k=16$ & $k=32$ & $k=64$ \\
\hline \hline \multirow{3}{*}{ add20 } & Jostle* $^{*}$ & 2095 & 2493 & 3152 \\
\cline { 2 - 5 } & Metis & 2428 & 3780 & 4134 \\
& AMOM & 1398 & 2282 & 2620 \\
\hline \multirow{4}{*}{ add32 } & Jostle* $^{*}$ & 117 & 212 & - \\
\cline { 2 - 5 } & Metis & 195 & 352 & 597 \\
& AMOM & 179 & 273 & 777 \\
\hline \multirow{4}{*}{ crack } & Jostle* & 1092 & 1686 & 2535 \\
\cline { 2 - 5 } & Metis & 1254 & 1879 & 2783 \\
& AMOM & 1263 & 1897 & 3152 \\
\hline \multirow{3}{*}{ t60k } & Jostle & 916 & 1537 & 2581 \\
\cline { 2 - 5 } & Metis & 1160 & 1755 & 2840 \\
& AMOM & 909 & 1335 & 2023 \\
\hline \multirow{3}{*}{ finan512 } & Jostle* & 822 & 1391 & 2198 \\
\cline { 2 - 5 } & Metis & 1001 & 1643 & 2513 \\
& AMOM & 704 & 1301 & 2130 \\
\hline & Chaco & 1296 & 2592 & 10560 \\
\hline & Metis & 1296 & 2592 & 12263 \\
& AMOM & 1970 & 2800 & 3152 \\
\hline \multirow{4}{*}{144} & Jostle & 38478 & 57354 & 80767 \\
\cline { 2 - 5 } & Metis & 42546 & 62395 & 86863 \\
& AMOM & 40543 & 64876 & 97612 \\
\hline & & & &
\end{tabular}

comparação direta. Conforme explicado anteriormente, os resultados gerados pelo Metis, Jostle e Chaco possuem uma margem definida de balanceamento em 5\%. Entretanto, essa restrição não é considerada pelo AMOM, já que o objetivo do algoritmo é otimizar a medida de modularidade sem que necessariamente haja o balanceamento entre elas.

Na Figura 5.8 é ilustrada a diferença no balanceamento obtida pelo AMOM e pelo Metis para a rede $t 60 k$. Como pode ser visto, os grupos formados pelo Metis possuem praticamente o mesmo tamanho, enquanto que o AMOM gera grupos de tamanhos variados.

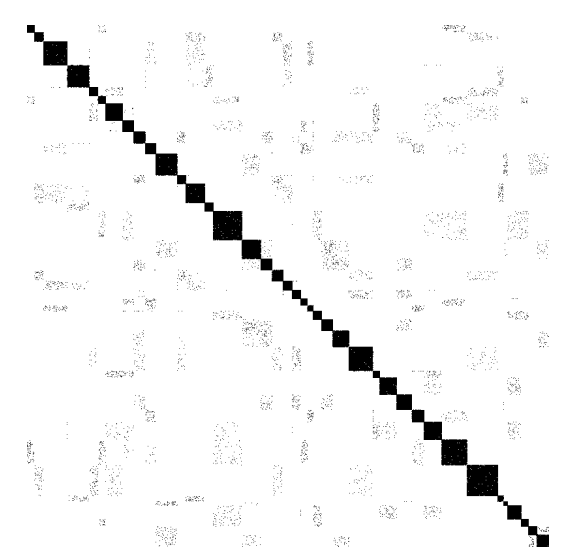

(a) AMOM

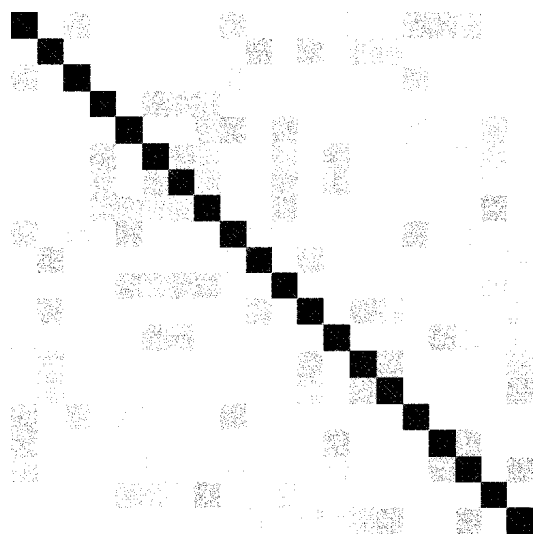

(b) Metis 3\% desbalanceamento

Figura 5.8: Comparativo entre as matrizes de adjacências do grafo t60k 


\subsection{Avaliação em conjunto de dados de imagens}

A fim de avaliar os resultados do algoritmo em conjunto de dados com variação de tamanho, forma e densidade nos agrupamentos foi realizado o experimento de separação de grupos em imagens bi-dimensionais. A visualização da imagens do conjunto utilizado neste experimento é apresentada na Figura 5.9. As imagens 1, 2, 3 e 4 possuem respectivamente 14284, 13590, 21327 e 16640 pontos, que foram obtidos a partir da aplicação de um filtro de cores nas figuras a fim de capturar preferencialmente os pontos na cor vermelha.

Intuitivamente, a Imagem 1 da Figura 5.9 apresenta 5 agrupamentos distintos: 2 elipses na parte superior e 3 círculos na inferior. Já Imagem 2 apresenta dois agrupamentos com forma homogênea. As Imagens 3 e 4 apresentam agrupamentos de formas, tamanhos e densidades variadas.

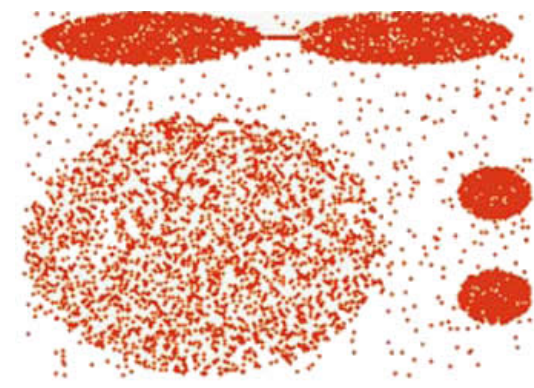

(a) Imagem 1 - 14284 pontos

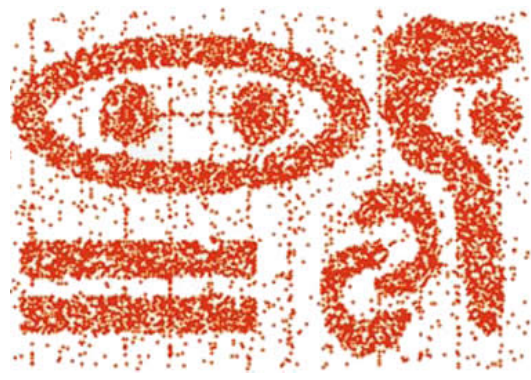

(c) Imagem 3 - 21327 pontos

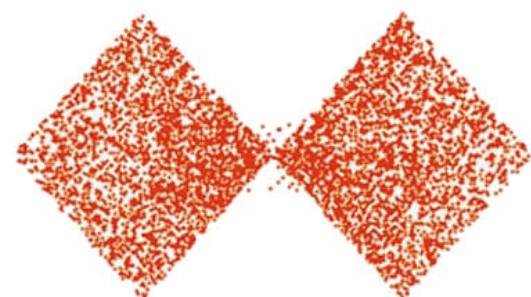

(b) Imagem 2 - 13590 pontos

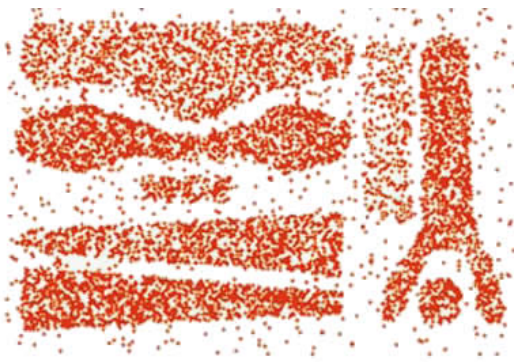

(d) Imagem 4 - 16640 pontos

Figura 5.9: Conjunto de dados de imagens bi-dimensionais Karypis et al. (1999)

Tendo disponível o conjunto de pontos em cada figura, foi utilizado o critério de ligação entre os $k$ vizinhos mais próximos para formar as redes que representassem as imagens. A rede de $k$ vizinhos mais próximos ( $k$-nearest neighbors $)^{3}$ é amplamente utilizada em AM, principalmente em problemas de aprendizado supervisionado. Neste experimento, as redes foram construídas conectando os 7 vizinhos mais próximos a cada ponto, e para medir a proximidade entre os pontos foi utilizada a medida de distância euclidiana. A definição da quantidade de vizinhos influi diretamente nos resultados do experimento. Utilizar apenas 1 ou 2 vizinhos mais próximos, implica em reduzir a dimensionalidade, mas também em perda de qualidade. Entretanto, valores muito elevados impactam na performance. Foi decidido utilizar 7 vizinhos a partir da análise dos resultados preliminares com a variação da quantidade de vizinhos. Na Tabela 5.6 são listadas as quantidades de vértices e arestas

\footnotetext{
${ }^{3}$ A letra $k$, embora tenha sido utilizada anteriormente na representação da quantidade de agrupamentos, foi repetida nesta seção por também ser amplamente conhecida para representar redes de vizinhos mais próximos.
} 
Tabela 5.6: Tabela descritiva das redes 7-nn geradas para o conjunto de dados de imagens

\begin{tabular}{c|c|c}
\hline rede & $n$ & $m$ \\
\hline \hline Imagem 1 & 14284 & 99959 \\
Imagem 2 & 13590 & 92302 \\
Imagem 3 & 21327 & 149260 \\
Imagem 4 & 16640 & 116451 \\
\hline
\end{tabular}

dos grafos construídos para cada imagem.

A partir da representação das imagens como redes de vizinhos mais próximos, foi realizado um comparativo entre o AMOM e o AOM na tarefa de agrupar os pontos mais próximos em cada uma das imagens. As separações obtidas pelo Chameleon Karypis et al. (1999) foram acrescentadas às comparações visuais dos agrupamentos das imagens. Os algoritmos AOM e AMOM foram ajustados para que a quantidade de agrupamentos fosse definido com base no passo de aglomeração que apresentasse maior valor de modularidade. Além disso, o AMOM foi configurado para utilizar o método LEM na fase de coarsening com $\mathrm{CPC}=1000$, e o refinamento foi feito utilizando o ROM.

A escolha do método LEM se deve a característica de construção das redes, na qual as arestas possuem peso relativo a distância entre dois pontos. Sendo assim, quanto maior o peso de uma aresta $e$, maior a distância entre dois vértices $u$ e $v$ ligados por ela. Como descrito na Seção 3.2.1, a estratégia utilizada no LEM é de selecionar para matching as arestas com menor peso, o que representa na rede arestas ligando vértices mais próximos.

Os resultados desse conjunto de experimentos são apresentados a seguir de duas maneiras. Inicialmente são apresentadas visualizações, Figuras 5.10, 5.11, 5.12 e 5.13, dos particionamentos gerados pelos algoritmos a fim de possibilitar uma avaliação qualitativa dos resultados. Posteriormente, na Tabela 5.7 é feita a comparação dos resultados considerando as medidas de corte e modularidade.

Na Figura 5.10 são apresentadas as visualizações dos particionamentos encontrados pelos algoritmos para a Imagem 1. O AOM particionou a rede da Imagem 1 em 4 grupos diferentes conforme visualizado em 5.10 (a), contudo os agrupamentos não se aproximam do resultado intuitivo esperado. Em (b) é apresentado o resultado obtido pelo AMOM. Embora tenha separado corretamente as formas, o algoritmo colocou os círculos no mesmo grupo. Em (c) o resultado obtido pelo Chameleon que identifica os 5 grupos na Imagem 1.

A Imagem 2 possui apenas dois grupos, ambos com a mesma forma e densidade. Para a rede representante da imagem, o AOM e AMOM encontraram 4 grupos distintos, conforme visualizado na Figura 5.11 (a) e (b). Em (c) é o particionamento obtido pelo AMOM configurado para encontrar 2 partições. Assim como o Chameleon, Figura 5.11 (d), os grupos foram identificados corretamente.

Os grupos contidos na Imagem 3 possuem diferentes formas e densidades, o que dificulta o particionamento. O AOM, Figura 5.12 (a) conseguiu identificar corretamente apenas os retângulos inferiores, mesmo assim não os separou em grupos distintos. Já AMOM, Figura 5.12 (b), identificou 5 agrupamentos distintos, mas assim como o AOM, uniu formas similares no mesmo grupo, tais como os pares de círculos, retângulos e as 


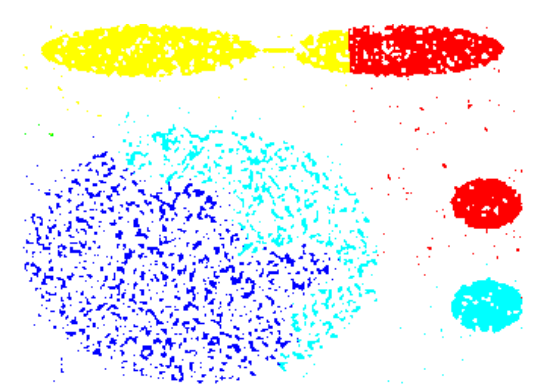

(a) $\mathrm{AOM}$

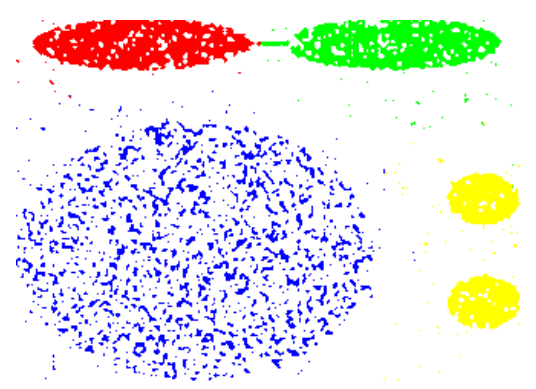

(b) AMOM (LEM + ROM)

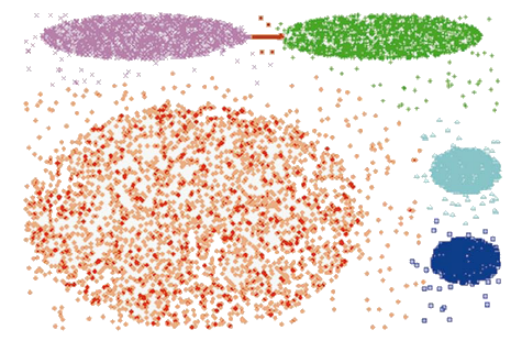

(c) Chameleon

Figura 5.10: Comparativo entre as separações de pontos na Imagem 1 geradas pelos algoritmos AOM, AMOM e Chameleon.

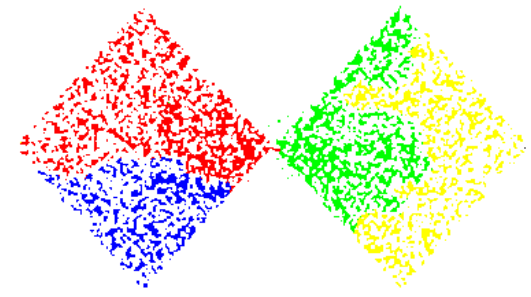

(a) AOM

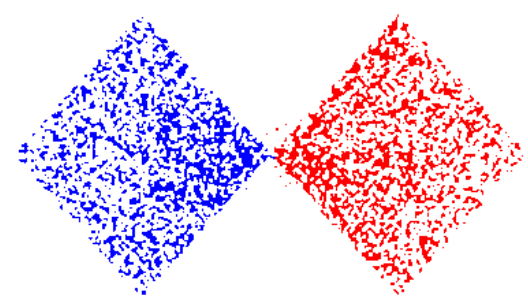

(c) $\mathrm{AMOM}^{*}(\mathrm{LEM}+\mathrm{ROM})$

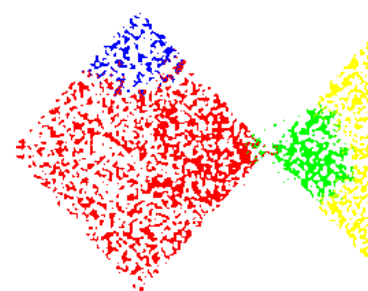

(b) $\mathrm{AMOM}(\mathrm{LEM}+\mathrm{ROM})$

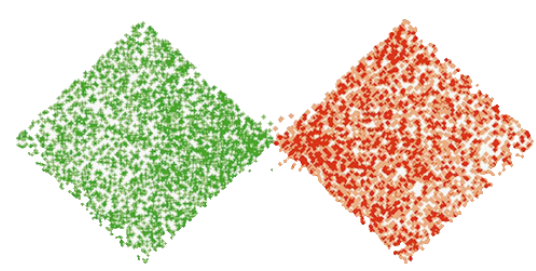

(d) Chameleon

Figura 5.11: Comparativo entre as separações de pontos na Imagem 2 geradas pelos algoritmos AOM, AMOM, AMOM* e Chameleon.

semi-coroas circulares. Na Figura 5.13 é apresentado o resultado obtido pelo Chameleon, que identificou 9 agrupamentos distintos na Imagem 3.

A Imagem 4 possui grupos maiores, mas de formas diferenciadas. O AOM conseguiu identificar corretamente somente a forma em cor vermelha, 5.13 (a). O AMOM, por sua vez, identificou totalmente 4 formas distintas nas cores vermelha, verde, azul escuro e amarela, e parcialmente 2 formas nas cores cinza e azul claro. O Chameleon identificou 8 formas distintas.

Na Tabela 5.7 são apresentados os valores de modularidade e de corte obtidos pelo AOM e AMOM nos experimentos utilizando as redes representativas das imagens. Para as redes das imagens 1, 2 e 3, o AOM obteve particionamentos com maior valor de 


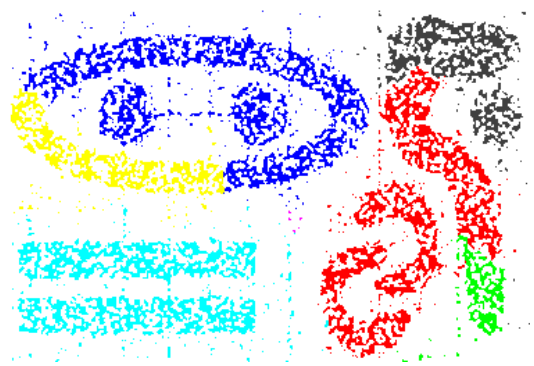

(a) $\mathrm{AOM}$

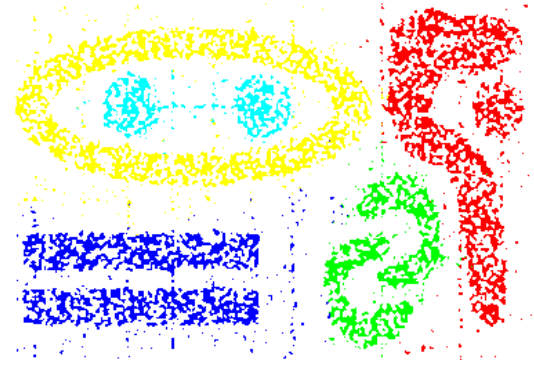

(b) AMOM ( LEM+ROM)

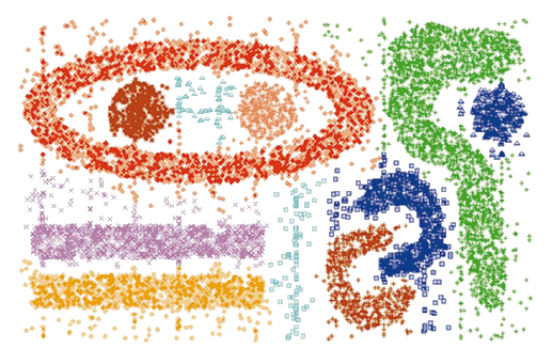

(c) Chameleon

Figura 5.12: Comparativo entre as separações de pontos na Imagem 3 geradas pelos algoritmos AOM, AMOM e Chameleon.

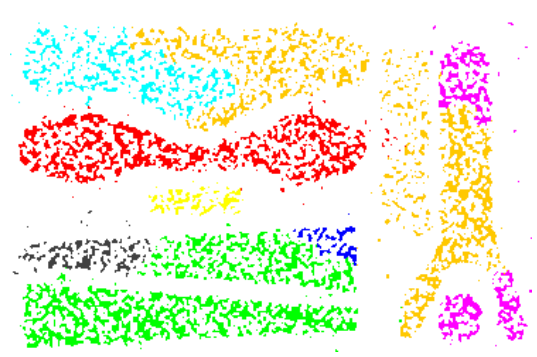

(a) $\mathrm{AOM}$

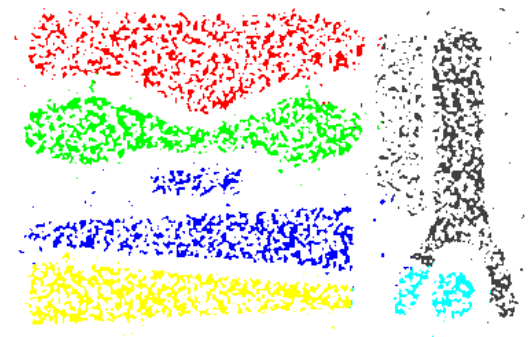

(b) AMOM ( LEM+ROM)

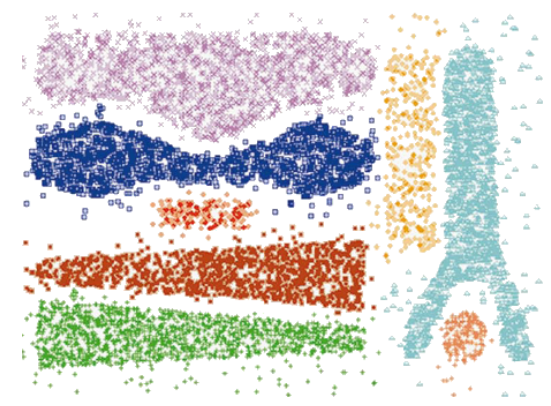

(c) Chameleon

Figura 5.13: Comparativo entre as separações de pontos na Imagem 4 geradas pelos algoritmos AOM, AMOM e Chameleon.

modularidade, e nesse critério, foi superado apenas na rede da imagem 4. Considerando os valores de corte, o AOM também superou o AMOM em todos as quatro redes, exceto quando o AMOM foi configurado para encontrar uma quantidade determinada de grupos, como ocorrido para a rede da imagem 2 .

Segundo as medidas objetivas, o AOM apresenta melhores resultados que o AMOM, entretanto uma análise visual dos particionamentos gerados pelos métodos sugerem o contrário. Os particionamentos encontrados AMOM aproximam-se mais do que é intuitivamente esperado, e também dos resultados obtidos pelo Chameleon. 
Tabela 5.7: Tabela comparativa entre os valores de corte e modularidade para o particionamento das redes $7-\mathrm{nn}$

\begin{tabular}{c|c|c|c} 
Imagem & Algoritmo & Corte & Q \\
\hline \hline \multirow{2}{*}{1} & AOM & $\mathbf{7 7 3}$ & $\mathbf{0 , 7 4 5}$ \\
& AMOM - LEM & 2864 & 0,673 \\
\hline \multirow{3}{*}{2} & AOM & 1152 & $\mathbf{0 , 7 4 6}$ \\
& AMOM (LEM + ROM) & 3261 & 0,731 \\
& AMOM* (LEM + ROM) & $\mathbf{1 2 0}$ & 0,500 \\
\hline \multirow{2}{*}{3} & AOM & $\mathbf{9 3 9}$ & $\mathbf{0 , 7 8 4}$ \\
& AMOM (LEM + ROM) & 4870 & 0,720 \\
\hline \multirow{2}{*}{4} & AOM & $\mathbf{1 0 3 0}$ & 0,784 \\
& AMOM (LEM + ROM) & 3174 & $\mathbf{0 , 8 0 6}$ \\
\hline \multicolumn{2}{|c}{}
\end{tabular}

A diferença nos resultados gerados está na rede considerada por cada algoritmo para o particionamento. No experimentos com as imagens, o AMOM particiona uma rede formada por super-vértices enquanto que o AOM considera cada vértice individualmente. Isso significa que ao colocar dois ou mais super-vértices em um mesmo grupo, o AMOM está na verdade agrupando dois ou mais blocos de vértices similares, o que favorece a descoberta de agrupamentos com tamanho maior do que os obtidos pelo AOM.

\subsection{Considerações Finais}

Neste capítulo foram descritos os experimentos realizados para avaliar a performance do Algoritmo Multinível de Otimização de Modularidade (AMOM) na detecção de comunidades. Os resultados obtidos foram avaliados de acordo com a performance e a qualidade do particionamentos encontrados.

Inicialmente foram feitas as análises de escalabilidade do AMOM utilizando redes com tamanhos diferentes, que mostraram um ganho significativo de performance comparado com ao AOM. A análise de escalabilidade contemplou também o estudo do impacto do Critério de Parada da fase de Coarsening (CPC) no tempo total de execução e no valor da medida de modularidade do particionamento gerado. Com base nos experimentos realizado, percebeu-se que a variação da modularidade em função do CPC é muito pequena, de maneira que mesmo tendo sido configurado para utilizar o CPC relativo a $30 \%$ do tamanho da rede inicial em alguns dos experimentos, esse valor poderia ter sido menor.

No comparativo entre os métodos RM, HEM e MHEM a diferença foi pequena, tanto na análise de performance quanto na de qualidade. De forma semelhante, a análise de qualidade dos métodos de refinamento mostrou pequenas diferenças entre o ROM e o ROCA, embora ambos tenham conseguido incrementar a modularidade dos particionamentos.

Na comparação dos valores de corte para os grafos benchmark de Walshaw há diferença entre os tipos de particionamento obtido pelo método proposto e algoritmos convencionais de particionamento multinível. Para estes algoritmos, entretanto, a necessidade de gerar resultados balanceados é um requisito fundamental.

Por fim foi apresentado a análise de resultados para o conjunto de dados de imagens. Nesse conjunto, embora não tenha alcançado a mesma qualidade obtida pelo Chameleon, 
o AMOM mostrou superior ao AOM na análise visual.

No próximo capítulo são feitos os comentários sobre o algoritmo proposto e os resultados obtidos nas redes utilizadas nos experimentos. Além disso, são sugeridos algumas possíveis continuações ou investigações a partir deste trabalho. 


\section{Conclusão}

O principal objetivo deste trabalho foi o realizar o estudo de escalabilidade do AOM Newman (2004c). Para isso foi desenvolvido o AMOM que é fruto da integração do AOM com a estratégia de particionamento multinível de grafos. A meta do trabalho era reduzir a complexidade de tempo do AOM preservando a qualidade das soluções geradas pelo AOM, e assim contribuir com um opção eficiente para detecção de comunidades em redes com elevada quantidade de vértices e arestas.

O trabalho realizou uma revisão bibliográfica em redes complexas e particionamento em grafos com o intuito de avaliar a possibilidade de combinação de técnicas desenvolvidas por ambas as áreas no problema de encontrar agrupamentos em redes. O AOM é um algoritmo de otimização que utiliza a medida de modularidade, proposta como critério de avaliação de qualidade em detecção de comunidade, e que tem se mostrado adequada para tal. Em particionamento de grafos, a estratégia multinível tem sido bastante utilizada sobretudo no tratamento de grafos de alta dimensionalidade.

A fim de proporcionar uma integração eficiente, alguns ajustes no AOM e nos métodos mais conhecidos da estratégia multinível foram necessários, tais como:

- avaliar e definir o impactor do Critério de Parada da fase de Coarsening (CPC) no tempo de execução e na qualidade do particionamento;

- adaptar o AOM de modo a considerar redes com pesos nas arestas que é uma das características do grafo reduzido utilizado na fase de particionamento;

- desenvolver métodos de refinamento apropriados às características de modularidade de redes complexas.

A verificação e validação da eficiência do algoritmo desenvolvido foi analisada por meio da realização de experimentos empíricos com redes conhecidas na literatura e consideradas como benchmark em detecção de comunidade e particionamento de grafos. Os experimentos foram compostos de análise de escalabilidade e qualitativa do algoritmo proposto. Os 
resultados dos experimentos, apresentados no Capítulo 5, demonstraram que o algoritmo alcançou o objetivo inicial de escalabilidade e efetividade na detecção de comunidades em redes com grande quantidade de vértices e arestas.

$\mathrm{Na}$ avaliação de escalabilidade pode-se observar o incremento de performance obtido quando a estratégia multinível é utilizada. De fato, à medida que a dimensionalidade da rede cresce, a curva de crescimento do tempo de execução do AMOM mostrou-se bem menos acentuada do que a do AOM. Pode-se avaliar também que os métodos RM, HEM e MHEM têm as curvas de crescimento do tempo de execução muito próximas uns dos outros.

A análise do impacto do CPC nos resultados contribuiu para a descoberta do intervalo de valores relativos para o critério em que há um equilíbrio entre a performance e a qualidade. Para os experimentos realizados, observou-se que um bom intervalo do CPC que mantém um pequeno tempo de execução e boa modularidade estaria entre $30 \%$ à $50 \%$ do tamanho da rede inicial. Contudo, a variação da medida de modularidade em função do $\mathrm{CPC}$ foi pequena, o que permite utilizar uma rede mais compactada sem que se haja grande redução na medida de modularidade.

Os experimentos qualitativos mostraram que o algoritmo proposto mantém a capacidade de encontrar comunidades com qualidade em redes com diferentes características e topologias. Na comparação com os algoritmos convencionais de particionamento multinível, o AMOM apresentou valores de corte inferiores aos demais, porém os grupos geradas não atenderam ao requisito de balanceamento comum em alguns domínios.

O algoritmo não apresentou resultados tão bons comparados ao Chameleon nos experimentos envolvendo imagens. Embora tenha sido capaz de encontrar agrupamentos com diferentes formas e densidade.

\subsection{Contribuições}

Ao encerramento, destacam-se as principais contribuições a seguir.

- Desenvolvimento do Algoritmo Multinível de Otimização de Modularidade (AMOM) para detecção de comunidades em redes complexas com elevada dimensionalidade;

- Análise da impacto dos métodos RM, HEM e MHEM na configuração do algoritmo AMOM em relação à performance e à qualidade dos resultados;

- Desenvolvimento de dois novos métodos para refinamento de particionamento na fase de uncoarsening, baseados na medida de modularidade e no coeficiente de agrupamento;

Outra contribuição do trabalho foram os artigos com os resultados obtidos durante o desenvolvimento do trabalho. Um publicado Mota et al. (2008) e um aceito para publicação Almeida e Lopes (2009). 


\subsection{Limitações}

O trabalho realizado possui algumas limitações que foram observadas. Na fase de coarsening os métodos utilizados, RM, HEM, MHEM e LEM restringem a compactação a pares de vértices em cada etapa. Em redes com distribuição livre de escala, selecionar hub limita que apenas um de seus vizinhos seja contraído, deixam os demais possivelmente sem alternativa para contração.

Outra limitação observada é a impossibilidade de separar comunidades durante o refinamento. No AMOM a quantidade inicial de partições é definida na fase de particionamento utilizando o valor de máxima modularidade, ou uma quantidade desejada fornecida como parâmetro. Em seguida, na fase de refinamento, podem ocorrer mudanças no particionamento, movendo os vértices entre as partições. As mudanças podem provocar a eliminação de uma comunidade, no caso de todos os vértices que faziam parte dela terem migrado para uma outra. Entretanto, não é possível adicionar novas comunidades a partir da divisão das existentes.

\subsection{Trabalhos Futuros}

Com base no estudo e avaliações realizados, é possível dar continuidade a este trabalho investigando alguns dos pontos a seguir.

- Investigar novos métodos de compactação da rede que contemplem características peculiares. As redes do tipo livre de escala possuem alguns vértices com muitas conexões (hubs) e esse critério poderia ser considerado em novo método;

- Investigar novos métodos de refinamento que possibilitem não somente movimentação de vértices entre partições, como também criação de novas ou exclusão delas;

- Investigar a aplicação do algoritmo em agrupamento de textos, já que o resultado obtido utilizando a rede cbr-ilp-ir encontrou comunidades condizentes com a estrutura da rede.

- Investigar o comportamento do AMOM, principalmente utilizando o ROCA, em redes sociais que tipicamente possuem uma média do coeficiente de agrupamento mais alta que as demais. 



\section{Referências Bibliográficas}

Albert, R. e Barabási, A.-L. (2002). Statistical mechanics of complex networks. Reviews of Modern Physics, 74:47-97.

Albert, R., Jeong, H., e Barabasi, A.-L. (1999). The diameter of the world wide web. Nature, 401:130.

Albert, R., Jeong, H., e Barabasi, A.-L. (2000). Error and attack tolerance of complex networks. Nature, 406(6794):378-382.

Almeida, L. J. e Lopes, A. A. (2009). An ultra-fast modularity-based graph clustering algorithm. Em Local Proceedings of Web and Network Intelligence Track of Fourteenth Portuguese Conference on Artificial Intelligence, páginas 1-9, Aveiro, Portugal.

Barabasi, A.-L. (2003). Linked: How Everything Is Connected to Everything Else and What It Means for Business, Science, and Everyday Life. Plume Books.

Barabási, A.-L. (2002). Linked: The New Science of Networks. Perseus Books Group.

Barabási, A. L. e Albert, R. (1999). Emergence of scaling in random networks. Science, 286:509-512.

Barabási, A. L., Albert, R., e Jeong, H. (1999). Mean-field theory for scale-free random networks. Physica A, 272:173-187.

Barabási, A. L., Albert, R., e Jeong., H. (2000). Scale-free characteristics of random networks: the topology of the world-wide web. Physica, 281(1):69-77.

Bollobas, B. (1998). Modern Graph Theory. Springer.

Bradley, P., Fayyad, U., e Reina, C. (1998). Scaling clustering algorithms to large databases. Em Knowledge Discovery and Data Mining, páginas 9-15. AAAI Press.

Brandes, U. (2001). A faster algorithm for betweenness centrality. Journal of Mathematical Sociology, 25 (2):163-177.

Bui, T. N. e Jones, C. (1993). A heuristic for reducing fill in sparse matrix factorization. Em 6th Conference of Parallel Processing for Scientific Computing of Society for Industrial and Applied Mathematics, páginas 445-452. SIAM. 
Chevalier, C. e Pellegrini, F. (2006). Improvement of the efficiency of genetic algorithms for scalable parallel graph partitioning in a multi-level framework. Em 12th International Euro-Par Conference on Parallel Processing, páginas 243-252.

Chung, F. R. K. (1997). Spectral Graph Theory. American Mathematics Society and CBMS Regional Conference Series in Mathematics.

Clauset, A. e Moore, C. (2005). Accuracy and scaling phenomena in internet mapping. Physical Review Letters, 94:018701.

Costa, L. F., Rodrigues, F. A., Travieso, G., e Boas, P. R. V. (2007). Characterization of complex networks: A survey of measurements. Advances In Physics, 56 (1):167 -242.

Dangalchev, C. (2006). Residual closeness in networks. Physica A: Statistical Mechanics and its Applications, 365(19):556-564.

De Raedt, L. (2008). Logical and Relational Learning. Springer.

de S. Price, D. J. (1965). Networks of scientific papers. Science, páginas 510-515.

Dhillon, I. S., Guan, Y., e Kulis, B. (2004). Kernel k-means: spectral clustering and normalized cuts. Em KDD '04: Proceedings of the tenth ACM SIGKDD international conference on Knowledge discovery and data mining, páginas 551-556, New York, NY, USA. ACM.

Dhillon, I. S., Guan, Y., e Kulis, B. (2007). Weighted graph cuts without eigenvectors: A multilevel approach. IEEE Transactions on Pattern Analysis and Machine Intelligence, 29(11):1944-1957.

Diestel, R. (2005). Graph Theory (Graduate Texts in Mathematics). Springer.

Dorogovtsev, S. N. e Mendes, J. F. F. (2003). Evolution of Networks. Oxford University Press.

Dubes, R. C. (1993). Cluster analysis and related issues. páginas 3-32.

Džeroski, S. (2003). Multi-relational data mining: an introduction. SIGKDD Explor. Newsl., 5(1):1-16.

Eisen, M. B., Spellman, P. T., Brown, P. O., e Botstein, D. (1998). Cluster analysis and display of genome-wide expression patterns. Proceedings of the National Academy of Sciences of the United States of America, 95(25):14863-14868.

Erdös, P. e Rényi, A. (1959). On random graphs. Publicationes Mathematicae, 6:290-297.

Erdös, P. e Rényi., A. (1960). On evolution of random graphs. Publications of the Mathematical Institute of the Hungarian Academy of Sciences, 5:17-61.

Erdös, P. e Rényi, A. (1961). On the strength of connectedness of a random graph. Acta Mathematica Scientia Hungary, 12:261-267. 
Fiduccia, C. M. e Mattheyses, R. M. (1988). A linear-time heuristic for improving network partitions. Em 25 years of DAC: Papers on Twenty-five years of electronic design automation, páginas 241-247, New York, NY, USA. ACM.

Filippone, M., Camastra, F., Masulli, F., e Rovetta, S. (2008). A survey of kernel and spectral methods for clustering. Pattern Recognition, 41(1):176-190.

Ford, L. R. e Fulkerson, D. R. (1956). Maximal flow through a network. Canadian Journal of Mathematics, 8:399-404.

Freeman, L. C. (1977). A set of measures of centrality based on betweenness. Sociometry, 40(1):35-41.

Freeman, L. C. (1978). Centrality in social networks: conceptual clarification. Social Networks, 1(3):215-239.

Garey, M., Johnson, D., e Stockmeyer, L. (1976). Some simplified NP-complete graph problems. Theoretical Computer Science, 1:237-267.

Garey, M. R. e Johnson, D. S. (1990). Computers and Intractability; A Guide to the Theory of NP-Completeness. W. H. Freeman \& Co., New York, NY, USA.

Girvan, M. e Newman, M. E. J. (2002). Community structure in social and biological networks. Proceedings of the National Academy of Sciences of the United States of America, 99:7821-7826.

Hagen, L. e Kahng, C. B. (1992). New spectral methods for ratio cut partitioning and clustering. IEEE Transactions on Computer-Aided Design of Integrated Circuits and Systems, 11(9):1074-1085.

Halkidi, M., Batistakis, Y., e Vazirgiannis, M. (2001). On clustering validation techniques. Journal of Intelligent Information Systems, 17:107-145.

Hartuv, E. e Shamir, R. (2000). A clustering algorithm based on graph connectivity. Information Processing Letters, 76(4-6):175-181.

Heer, J., Card, S. K., e Landay, J. A. (2005). prefuse: a toolkit for interactive information visualization. Em CHI '05: Proceedings of the SIGCHI conference on Human factors in computing systems, páginas 421-430, New York, NY, USA. ACM.

Hendrickson, B. e Leland, R. (1993). A multilevel algorithm for partitioning graphs. Relatório Técnico SAND93-1301, Sandia National Laboratories.

Hendrickson, B. e Leland, R. (1994). The chaco user's guide — version 2.0. Relatório técnico.

Hubert, L. e Arabie, P. (1985). Comparing partitions. J. of Classification, 2(1):193-218.

Jaccard, P. (1912). The distribution of the flora of the alpine zone. Em New Phytologist, volume 11, páginas 37-50. 
Jain, A. K. e Dubes, R. C. (1988). Algorithms for Clustering Data. Prentice Hall.

Jain, A. K., Duin, R. P. W., e Mao, J. (2000). Statistical pattern recognition: A review. IEEE Transactions on Pattern Analysis and Machine Intelligence, 22(1):4-37.

Jain, A. K., Murty, M. N., e Flynn, P. J. (1999). Data clustering: a review. ACM Comput. Surv., 31(3):264-323.

Karypis, G., Han, E.-H., e Kumar, V. (1999). Chameleon: hierarchical clustering using dynamic modeling. Computer, 32(8):68-75.

Karypis, G. e Kumar, V. (1995a). Analysis of multilevel graph partitioning. Em Supercomputing '95: Proceedings of the 1995 ACM/IEEE conference on Supercomputing, New York, NY, USA. ACM Press.

Karypis, G. e Kumar, V. (1995b). A fast and high quality multilevel scheme for partitioning irregular graphs. Em International Conference on Parallel Processing, páginas $113-122$.

Karypis, G. e Kumar, V. (1998). Multilevel k-way partitioning scheme for irregular graphs. Journal of Parallel and Distributed Computing, página 10 pp.

Kernighan, B. W. e Lin, S. (1970). An efficient heuristic procedure for partitioning graphs. The Bell system technical journal, 49(1):291-307.

Latora, V. e Marchiori, M. (2001). Efficient behavior of small-world networks. Physical Review Letters, 87(19):198701.

Lyman, P. e Varian, H. R. (2003). How much information 2003? http://www2.sims . berkeley.edu/research/projects/how-much-info-2003/ acessado em 25 de janeiro de 2008 .

MacQueen, J. B. (1967). Some methods for classification and analysis of multivariate observations. Em Cam, L. M. L. e Neyman, J., editores, Proceedings of the Fifth Berkeley Symposium on Mathematical Statistics and Probability, volume 1, páginas 281-297, Berkeley, CA. University of California Press.

Milgram, S. (1967). The small-world problem. Psychology Today, 1:60-67.

Mirkin, B. (2005). Clustering For Data Mining: A Data Recovery Approach (Chapman $\&$ Hall/Crc Computer Science). Chapman \& Hall/CRC.

Mitchell, T. M. (1997). Machine Learning. McGraw-Hill Higher Education.

Mota, R. C., Almeida, L. J., e Lopes, A. A. (2008). Redes probabilísticas baseadas em similaridade na exploração de comunidades. Em Web and Text Intelligence (SBIA-WTI 2008), páginas 11-18, Salvador, BA, Brasil.

Newman, M. (2004a). Detecting community structure in networks. The European Physical Journal B - Condensed Matter, 38(2):321-330. 
Newman, M., Barabasi, A.-L., e Watts, D. J. (2006). The Structure and Dynamics of Networks: (Princeton Studies in Complexity). Princeton University Press.

Newman, M. E. J. (2001). The structure of scientific collaboration networks. Proceedings of the National Academy of Sciences of the United States of America, 98:404.

Newman, M. E. J. (2003). The structure and function of complex networks. Society for Industrial and Applied Mathematics Review, 45(2):167-256.

Newman, M. E. J. (2004b). Analysis of weighted networks. Physical Review E, 70:056131.

Newman, M. E. J. (2004c). Fast algorithm for detecting community structure in networks. Physical Review E, 69:066133.

Newman, M. E. J. (2006). Finding community structure in networks using the eigenvectors of matrices. Physical Review E, 74(3):036104.

Newman, M. E. J. (2008). The New Palgrave Encyclopedia of Economics, capítulo The mathematics of networks. Palgrave Macmillan, Basingstoke, 2nd edição. http://wwwpersonal.umich.edu/ mejn/papers/palgrave.pdf, acessado em 25 de janeiro de 2008.

Newman, M. E. J. e Girvan, M. (2004). Finding and evaluating community structure in networks. Physical Review E, 69:026113.

Ng, A. Y., Jordan, M. I., e Weiss, Y. (2001). On spectral clustering: Analysis and an algorithm. Em Advances in Neural Information Processing Systems 14, páginas 849856. MIT Press.

Paulovich, F. V., Oliveira, M. C. F., e Minghim, R. (2007). The projection explorer: A flexible tool for projection-based multidimensional visualization. Em SIBGRAPI '07: Proceedings of the XX Brazilian Symposium on Computer Graphics and Image Processing, páginas 27-34.

Pellegrini, F. e Roman, J. (1996). A software package for static mapping by dual recursive bipartitioning of process and architecture graphs. páginas 493-498. Springer.

Rand, W. M. (1971). Objective criteria for the evaluation of clustering methods. Em Journal of the American Statistical Association, volume 66, páginas 846-850.

Rezaee, M. R., Lelieveldt, B. B., e Reiber, J. H. (1998). A new cluster validity index for the fuzzy c-mean. Pattern Recogn. Lett., 19(3-4):237-246.

Schaeffer, S. E. (2007). Graph clustering. Computer Science Review, 1(1):27-64.

Shi, J. e Malik, J. (2000). Normalized cuts and image segmentation. IEEE Transactions on Pattern Analysis and Machine Intelligence, 22(8):888-905.

Soper, A. J., Walshaw, C., e Cross, M. (2004). A combined evolutionary search and multilevel optimisation approach to graph-partitioning. J. of Global Optimization, 29(2):225241. 
Stoer, M. e Wagner, F. (1997). A simple min-cut algorithm. Journal of the ACM, 44(4):585-591.

Theodoridis, S. e Koutroumbas, K. (1999). Pattern Recognition. Academic Press.

Verma, D. e Meila, M. (2005). A comparison of spectral clustering algorithms. Relatório técnico, Department of CSE University of Washington Seattle.

Wagner, D. e Wagner, F. (1993). Between min cut and graph bisection. Em Proceedings of the 18th International Symposium on Mathematical Foundations of Computer Science, páginas 744-750. Springer.

Walshaw, C. e Cross, M. (2007). JOSTLE: Parallel Multilevel Graph-Partitioning Software - An Overview. Em Magoules, F., editor, Mesh Partitioning Techniques and Domain Decomposition Techniques, páginas 27-58. Civil-Comp Ltd.

Watts, D. J. (1999a). Networks, dynamics, and the small world phenomenon. American Journal of Sociology, 105(2):493-527.

Watts, D. J. (1999b). Small Worlds. Princeton University Press, Princeton.

$\mathrm{Xu}, \mathrm{R}$. e Wunsch, I. (2005). Survey of clustering algorithms. IEEE Transactions on Neural Networks, 16(3):645-678. 